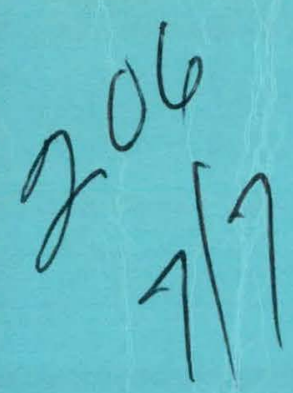

FINAL REPORT

RADIATION CHEMISTRY OF CHROMOSOMES

JULY 1, 1969 TO JUNE 27, 1970

AEC Research and Development Report

Atomics International

North American Rockwell

P.O. Box 309

Canoga Park, California 91304 


\section{DISCLAIMER}

This report was prepared as an account of work sponsored by an agency of the United States Government. Neither the United States Government nor any agency Thereof, nor any of their employees, makes any warranty, express or implied, or assumes any legal liability or responsibility for the accuracy, completeness, or usefulness of any information, apparatus, product, or process disclosed, or represents that its use would not infringe privately owned rights. Reference herein to any specific commercial product, process, or service by trade name, trademark, manufacturer, or otherwise does not necessarily constitute or imply its endorsement, recommendation, or favoring by the United States Government or any agency thereof. The views and opinions of authors expressed herein do not necessarily state or reflect those of the United States Government or any agency thereof. 


\section{DISCLAIMER}

Portions of this document may be illegible in electronic image products. Images are produced from the best available original document. 
This report was prepared as an account of Government sponsored work. Noither the United States, nor the Commission, nor any person acting on behalf of the Commission:

A. Makes any warranty or representation, express or implied, with respect to the accuracy, completeness, or usefulness of the information contained in this report, or that the use of any information, apparatus, method, or process disclosed in this report may not infringe privately owned rights; or

B. Assumes any liabilities with respect to the use of, or for damages resulting from the use of information, apparatus, mothod, or process disclosed in this report.

As used in the above, "person acting on behalf of the Commission" includes any employoo or eontractor of the Commission, or employe of such enntrnetor, th the extent that such employee or contractor of the Commission, or employee of such contrector prepares, disseminates, or provides access to, any information pursuant to his omployment or contract with the Commission, or his employment with such contractor.

Printed in the United States of America Available from

Clearinghouse for Federal Scientific and Technical Information National Bureau of Standards, U.S. Department of Commerce Springfield, Virginia 22151

Price: Printed Copy $\$ 3.00$; Microfiche $\$ 0.65$ 
FINAL REPORT

RADIATION CHEMISTRY OF CHROMOSOMES

JULY 1, 1969 TO JUNE 27, 1970

BY

M. D. SEVILLA

Contract No. AT(04-3)-701

AEC Task 22 General Order 7724

Subaccount-1 17001

LEGAL NOTICE

This report was prepared as an account of work sponsored by the United States Government. Neither the United States nor the United States Atomic Energy Commission, nor any of their employees, nor any of their contractors, subcontractors, or their employees, makes any warranty, express or implied, or assumes any legal liability or responsibility for the accuracy, completeness or usefulness of any information, apparatus, product or process disclosed, or represents that its use would not infringe privately owned rights.

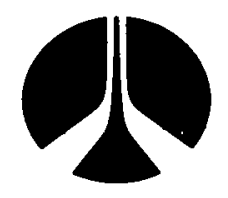

\section{Atomics International} North American Rockwell

P.O. Box 309

Canoga Park, California 91304 


\section{DISTRIBUTION}

This report has been distributed according to the category "Biology and Medicine" as given in the Standard Distribution for Unclassified Scientific and Technical Reports. 
Abstract ..................... 1

I. Introduction .................. 3

II. Positive Ions and Reactions . . . . . . . . . . . . 5

A. The Thymine Positive Ion. . . . . . . . . 5

B. Reaction of the Thymine Positive Ion. . . . . . . 22

C. The Thymidine Positive Ion and Its Reaction . . . . 25

III. Electron Studies . . . . . . . . . . . . 30

A. Reactions of Electrons with Peptides. . . . . . 30

B. Anions of Pyrimidines and Nucleosides. . . . ; 30

C. Electron Reactions at $\mathrm{pH} 7$. . . . . . . . 34

IV. Radiolysis of Frozen Aqueous Solutions of DNA . . . . . 36

V. References. . . . . . . . . . . . . . 39

VI. List of Publications and Presentations (Dec. 1966 to

June 27, 1970). . . . . . . . . . . 42

APPENDICES

Publications July 1, 1969 to June 27, 1970

APPENDIX A: "The Reaction of Hydrogen Atoms with DNA"

APP ENDIX B: "An Electron Spin Resonance Study of Several Purine and Pyrimidine Radical Anions"

APPENDIX C: $\quad$ "An Electron Spin Resonance Study of Acetate Dianion and Acetamide Anion"

APPENDIX D: "Radicals Formed by the Reaction of Electrons with Amino Acids in an Alkaline Glass"

APPENDIX E: "Radicals Formed by Electron Attachment to Peptides" (in press)

APPENDIX F: $\quad$ "Radicals Formed in Proteins by Reaction with Hydrogen Atoms" (in press) 


\section{LIST OF FIGURES}

Page

Figure 1. Structures of thymine in acid and alkaline glasses. . 6

Figure 2. ESR spectra of the thymine cation radical in an alkaline glass . . . . . . . . . . . . 9

Figure 3. ESR spectra of the thymine cation radical in an acid glass... . . . . . . . . . . . . 11

Figure 4. ESR spectra of the thymine cation decomposition product . . . . . . . . . . . . . 23

Figure 5. ESR spectra of photoionized thymidine in an alkaline glass . . . . . . . . . . . 26

Figure 6. ESR spectra of the thymidine cation decomposition product . . . . . . . . . . . . . . 27

Figure 7. ESR spectra of the anions of pyrimidines and nucleosides . . . . . . . . . . . . 32

Figure 8. ESR spectra of 6 -methyluracil anion . . . . . . . 33

Figure 9. ESR spectra of the radiolysis of a frozen aqueous solution of DNA . . . . . . . . . . . . . .

\section{LIST OF TABLES}

Table I. Theoretical spin densities and hyperfine splittings for thymine cation and anion radicals... . . . . 17

Table II. Pyrimidine and nucleoside anion proton hyperfine splittings at $90^{\circ} \mathrm{K}$ 


\section{A RSTRACT}

In this study the effects of ionizing radiation on chromosomes and chromosome constituents have been investigated. This work has concentrated on the reactions of radical intermediates produced by ionizing radiation with chromosome constituents. The reactions of hydrogen atoms and electrons with these constituents have been investigated in past work.

In this work the study of the reactions of electrons with chromosome constituents was continued with an investigation of peptides, pyrimidines and nucleosides. The electrons were photolytically generated in an alkaline $\mathrm{D}_{2} \mathrm{O}$ glass and allowed to react with the peptide solute. The radicals produced were identified by means of ESR spectroscopy. The reaction sequence for peptides is found to be similar to the amino acids in our previous investigation. At $77^{\circ} \mathrm{K}$ electron attachment to dipeptides and tripeptides composed of glycine and amino acids with alkyl side groups produce the dianion radical. Upon warming, the dianion undergoes $\mathrm{N}$-terminal deamination. The radical formed in this step subsequently abstracts from the parent compound to form an $\alpha$ carbon radical. The results for $\mathrm{N}$-acetylamino acids and $\mathrm{N}$-acetylpeptides show that the electron is localized in the peptide bond in dipeptides and in the $\mathrm{N}$-terminal peptide bond in tripeptides. The localization at the $\mathrm{N}$-terminal 
bond is suggested to be a result of a deeper potential energy well at that bond. The anion radicals of the pyrimidines and nucleosides were produced by electron attachment. The use of a deuterated glass yielded resolved ESR spectra which were not observed in our previous work with these compounds. The spectra consist of a large doublet splitting. It is shown that this splitting is due to a large unpaired electron density at the $\mathrm{C}_{6}$ position. Significant differences in this splitting are found for the pyrimidine and nucleoside anions.

The study of positive ions of chromosome constituents was initiated with an investigation of the positive ions of thymine and thymidine. The positive ion of thymine was produced at $77^{\circ} \mathrm{K}$ by photoionization in both acid and alkaline glasses. The ESR spectrum found for this species is in excellent agreement with that predicted by theory. Upon warming the sample to $130^{\circ} \mathrm{K}$ the positive ion decays by loss of a methyl proton to form a $\mathrm{R}-\mathrm{CH}_{2}$. radical. Tho thymidine positive inn is not found to be stable at $77^{\circ} \mathrm{K}$. For thymidine the ESR spectra indicate that the $\mathrm{R}-\mathrm{CH}_{2}$. radical is formed at $77^{\circ} \mathrm{K}$. This work suggests that in the chromosome positive ions or holes formed in the DNA during radiolysis would localize unpaired spins on thymidine by production of $\mathrm{R}-\mathrm{CH}_{2} \cdot$ radicals.

A study of the radiolysis of frozen aqueous solutions of DNA suggests that the thymidine anions formed by electron attachment protonate at the $\dot{C}_{6}$ position for form the usual "thymyl" radical. 


\section{INTRODUCTION}

The most important effects of radiation on mammalian tissue are the genetic effects, that is the changes induced in the chromosomes. An understanding of such effects in terms of molecular alterations in the chromosomes is being sought in this study. Effects of radiation on bacteria, such as cell death and mutation, have been linked to molecular changes such as chain breaks, crosslinking and base alteration in DNA. Mammalian chromosomes, which consist of histones and RNA as well as DNA, may be affected by these changes as well as changes involving other parts of the chromosome. Crosslinking of histone to DNA may be visualized to occur, for example; the biological consequence of such an alteration is unknown. The focus of this study is to understand molecular alterations to chromosomes occurring during radiolysis in terms of elementary reactions of intermediates generated by the radiation. It is hoped that the information gained in this study will eventually be useful in devising treatment for radiation exposure.

The overall approach taken in this study is to expose chromosomes and chromosome constituents to intermediates expected to be produced by ionizing radiation. Direct interaction of radiation with chromosomes in cells is expected a priori to produce electrons, positive ions and excited molecules. Subsequently these species may form secondary free radicals which will react further. In addition, chromosomes are subject to indirect attack by the hydrogen atoms, solvated electrons and hydroxyl radicals which are formed 
in the aqueous media of cells during radiolysis. This project has been concerned primarily with the reactions of hydrogen atoms and electrons with DNA, histones and their constituents. In recent work the project has been extended to include the study of positive ions and their reactions. The reactions of these intermediates are followed by detecting radicals formed through electron spin resonance (ESR) spectroscopy.

A detailed accounting of this program from December 1966 to June 1969 is given in the three year report (AI-AEC-MEMO-12861). This report describes work performed principally during the past year.

In this work electron reaction studies were continued with an investigation of the reaction of peptides, pyrimidines and nucleosides. The peptide study has led to a better understanding of the role of the electron in radical production in peptides. The study of electron reactions with pyrimidines and nucleosides have yielded information concerning the electronic structure of the anions.

The study of positive ions began with an investigation of the thymine and thymidine positive ions. The results for thymine and thymidine show that the positive ions are not stable and decay by loss of a methyl proton to form a neutral radical. Since positive ions of the various DNA bases should be formed as a result of the direct interaction of radiation, the reaction mechanism found in this work is considered to be significant to the under standing of the radiolysis of DNA. 


\section{POSITIVE IONS AND REACTIONS}

\section{A. The Thymine Positive Ion}

The cation radicals of several purines have been reported to be produced through photolysis in frozen aqueous solutions at low temperatures. ${ }^{1}$ The mechanism has been suggested to be photolysis of the metastable triplet state of these species. However, for the pyrimidine compounds, e.g. thymine and cytosine, cation radicals are not produced at $\mathrm{pH} 7 .^{1}$ In agreement with these results Shulman and co-workers have found through both optical and ESR methods that the neutral thymine and cytosine molecules do not show phosphorescence or appreciable population of the triplet state. 2,3 By increasing the $\mathrm{pH}$ to 12 where thymine has lost its $N_{3}$ proton, phosphorescence and ESR signals due to the triplet were observed by these workers with a decay time of 0.60 sec. $^{4}$ Evidence was also presented which suggested an ESR triplet resonance for thymine $(\mathrm{pH}=12)$ with both $\mathrm{N}_{1}$ and $\mathrm{N}_{3}$ protons removed. From this previous work it is reasonable to expect that under conditions of high $\mathrm{pH}$ and low temperature thymine should photoionize from its excited triplet state. This work reports an ESR study in which the thymine $\pi$-cation radical is shown to be a product of the photoionization of thymine in an alkaline ice glass. Perhaps unexpected from previous work the cation is produced by photolysis of thymine in an acid glass as well. The anion radical of thymine is also produced by electron attachment in the alkaline glass.

\section{AI-A EC- 12974}




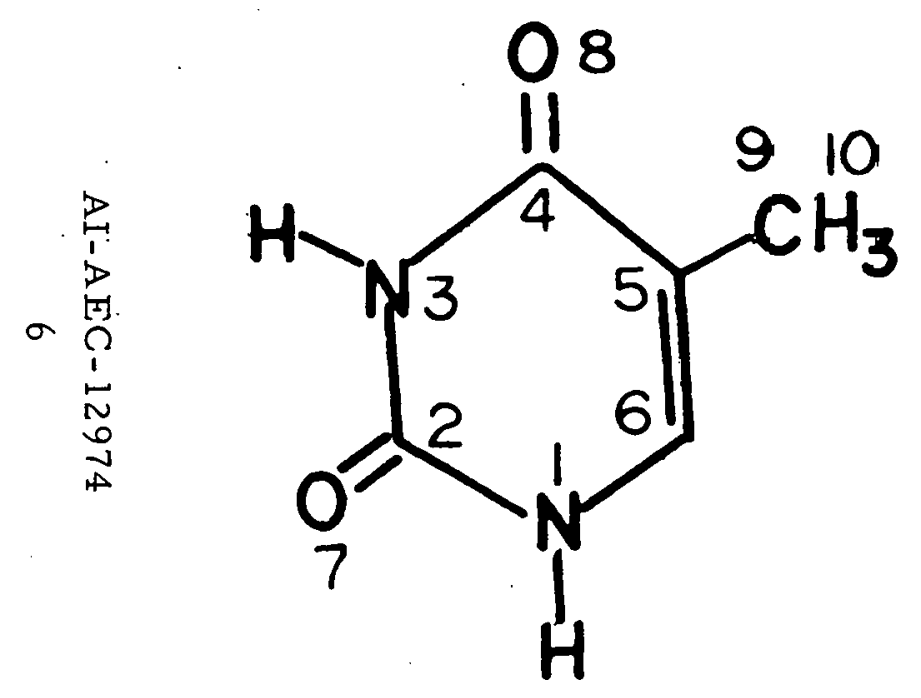

I
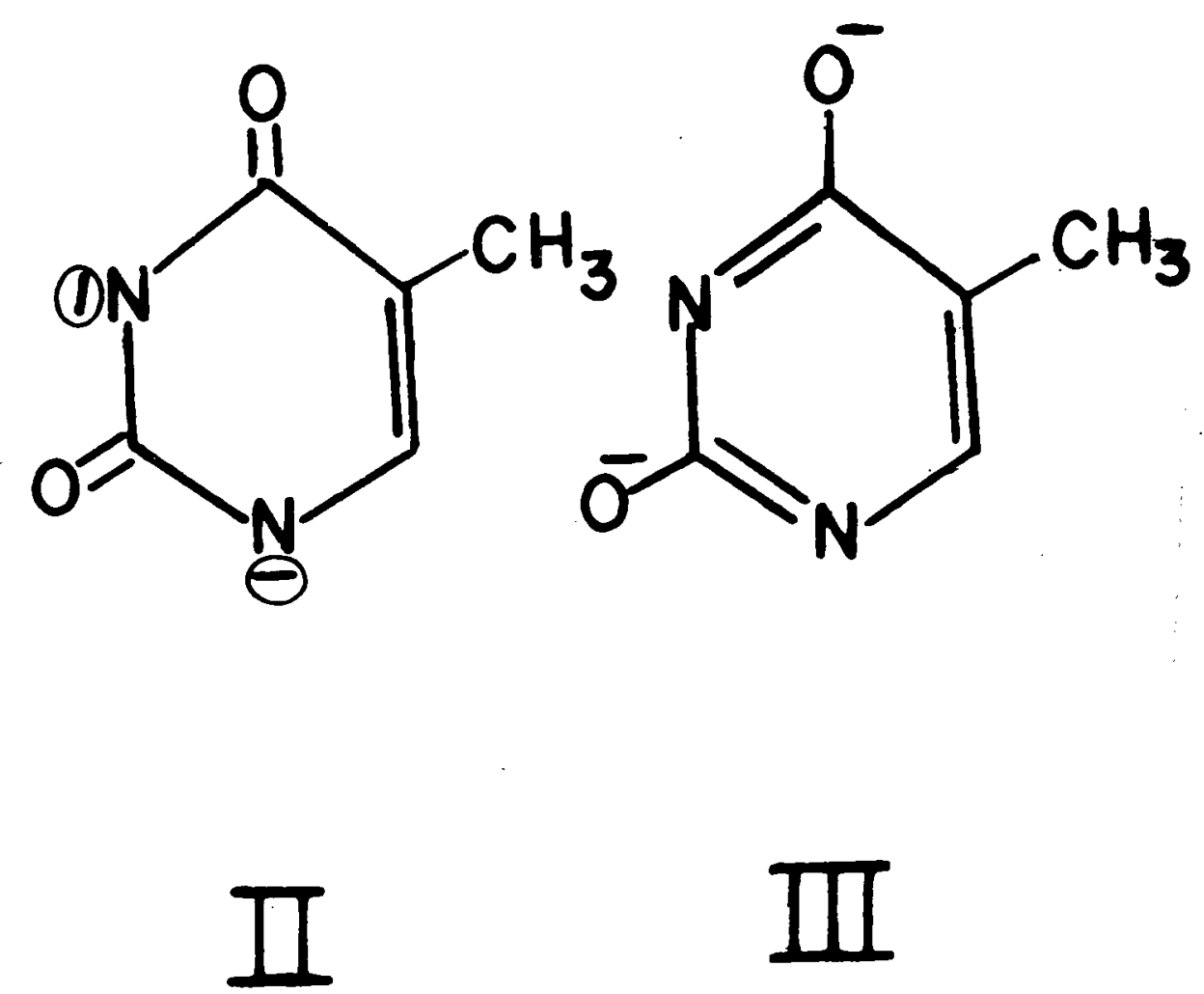

Figure 1. Structures of Thymine in acid (I) and alkaline (II, III) glasses. 
Ion radicals have been shown to be products of the radiolysis of a crystalline pyrimidine, cytosine. ${ }^{5}$ The results found here for thymine are used to propose a mechanism for product formation in the radiolysis of thymine single crystals.

\section{EXPERIMENTAL}

Both acid and alkaline glasses were employed in this work. The glasses are produced by cooling solutions of $8 \mathrm{~N} \mathrm{NaOH}$ or $6 \mathrm{M} \mathrm{H}_{3} \mathrm{PO}_{4}$ and the solute (thymine) in a $4 \mathrm{~mm}$ OD quartz tube to $77^{\circ} \mathrm{K}$. To improve resolution of the ESR signal deuterated glasses were usually employed. $6 a, b$ The photolysis was performed at $77^{\circ} \mathrm{K}$ outside the ESR cavity. A helical low pressure mercury lamp was employed for the photolysis.

The ESR speclrometer used in this study is a Varian V-4500-10A equipped with a Fieldial, low noise klystron, frequency meter and dual cavity. Measurements of the hyperfine splittings and $g$ values were made vs. peroxylamine disulfonate $\left(A_{N}=13.0 \mathrm{G}\right.$ and $\left.\mathrm{g}=2.0056\right)$. Thymine was obtained from Calbiochem (Grade A).

\section{RESULTS}

1. Thymine in an alkaline glass.

Photolysis of thymine $\left(77^{\circ} \mathrm{K}\right)$ in an $8 \mathrm{~N} \mathrm{NaOD}(92 \% \mathrm{D})$ glass at concentrations of $0.25 \mathrm{mg} / \mathrm{ml}^{7}$ for as little as 15 secs produces a dark blue color in the glass. The sample is found to phosphoresce in the visible 
region during photolysis and for a few seconds after the photolysis is terminated. The later results suggest a significant population of the triplet state during photolysis. ${ }^{3}$ The ESR spectrum observed immediately after photolysis is shown in Figure $2 \mathrm{~A}$. The large singlet at $\mathrm{g}=2.001^{8}$ and the blue color in the glass are characteristic of trapped electrons. 9 The remaining hyperfine structure is attributed to the species produced by photoionization. Since at $\mathrm{pH}>14$ thymine is most likely unprotonated at the 1 and 3 positions, the species produced by loss of an electron (see Figure 1) is a monoanion. However, for ease of discussion the species will be considered a $\pi$-cation radical. The $\pi$ electron system, as will be shown, has lost one electron.

Photobleaching the sample containing the electron and $\pi$-cation with light from an IR-visible lamp causes the electron to become mobile. The electron reacts with the $\pi$-cation to form thymine and with thymine to form the $\pi$-anion, 10 The result is a spectrum which is assumed to consist of approximately equal concentrations of the $\pi$-cation and $\pi$-anion (Figure $2 \mathrm{~B}$ ). Warming the sample to $-130^{\circ} \mathrm{C}$ results in the apparent loss of the $\pi$-cation signal; however, the signal due to the $\pi$-anion remains. Due to the fact that the spectrum found for $\pi$-anion is overlapped with a decay product of the $\pi$-cation, the anion was prepared by a separate method. This method involves the photolysis of $10^{-2} \mathrm{M} \mathrm{K}_{4} \mathrm{Fe}(\mathrm{CN})_{6}$ to produce electrons in the deuterated alkaline glass which upon photobleaching 


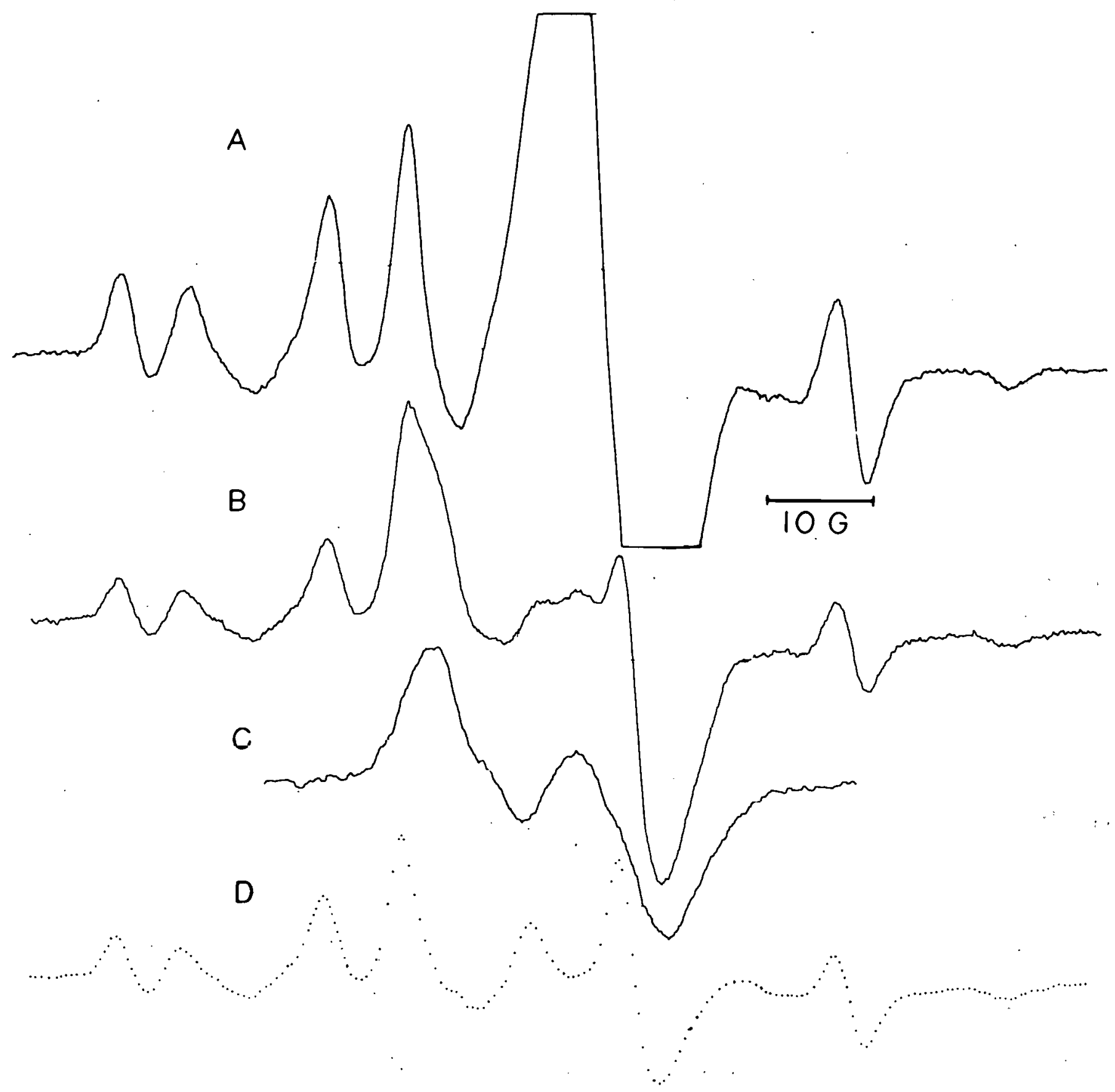

Figure 2. ESR spectra produced by the photoionization of thymine in an alkaline $\mathrm{D}_{2} \mathrm{O}$ glass. A. Cation spectrum taken immediately after photolysis at $77^{\circ} \mathrm{K}$. The large central component is due to the electron. B. Spectrum of the cation and anion radical produced by photobleaching the electron in A. C. Anion radical in an alkaline glass produced by electron attachment. D. Spectrum of cation resulting from the subtraction of $C$ from $B$. 
react with thymine $\left(5 \times 10^{-4} \mathrm{M}\right)$. This technique has beeri described in detail by other workers. ${ }^{11}$ The spectrum due to the thymine $\pi$-anion produced in this manner at $77^{\circ} \mathrm{K}$ is shown in Figure $2 \mathrm{C}$. This spectrum consists of two hyperfine components separated by $16 \mathrm{G}$ with $\Delta \mathrm{H}_{\mathrm{II}_{\circ} \mathrm{s} .} \cong 12 \mathrm{G}$. Molecular orbital calculations (see below) suggest this splitting arises from the $C_{6}$ proton. 'L'his is vetified by the production of the $\pi$-anion of 6-methyluracil by the method described above. The 6-methyluracil anion shows a quartet spectrum with a $15.4 \mathrm{G}$ hyperfine splitting. The intensity ratios are near $1: 3: 3: 1$ and leave no doubt that this is the methyl proton splitting. This shows the origin of the hyperfine interaction in the thymine (5-methyluracil) anion to be the $C_{6}$ proton.

A simple subtraction of the spectrum in Figure $2 \mathrm{C}$ from $2 \mathrm{~B}$ gives the dotted curve (Figure 2D) which is solely due to the cation. The two components obscured in Figure $2 \mathrm{~A}$ by the electron signal are now clearly resolved. However, the uncertainty in the subtraction technique is such that these components should be considered semi-quantitative.

Upon warming of the sample containing the anion and cation decay product to $-90^{\circ} \mathrm{C}$ a further reaction occurs. The anion protonates $\left(\mathrm{H}_{2} \mathrm{O}\right.$ glass) to form the 5-methyl-5, 6-dihydrouracil-5-yl or "thymyl" radical which shows a characteristic 8 line spectrum extending over 135 G. This reaction has been investigated previously by other workers. 11 The decay product of the $\pi$-cation radical has been identified as the radical produced by loss of a proton from the methyl group ${ }^{12}$, i. e., AI-AEC- 12974 


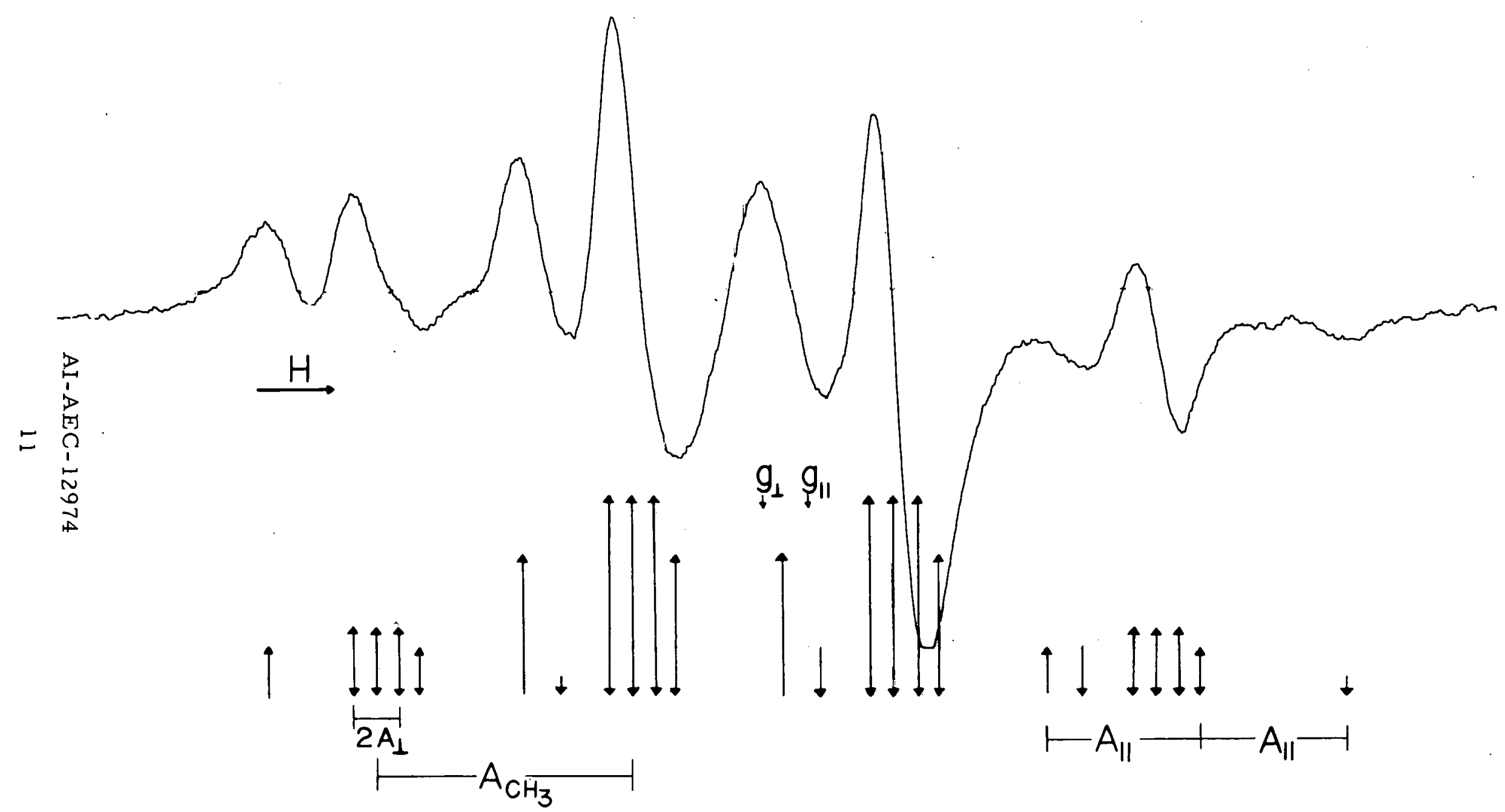

Figure 3. ESR spectrum of the thymine cation radical in an acid glass produced by photoionization of thymine at $77^{\circ} \mathrm{K}$. The stick reconstruction is based on theoretical parameters described in text. 


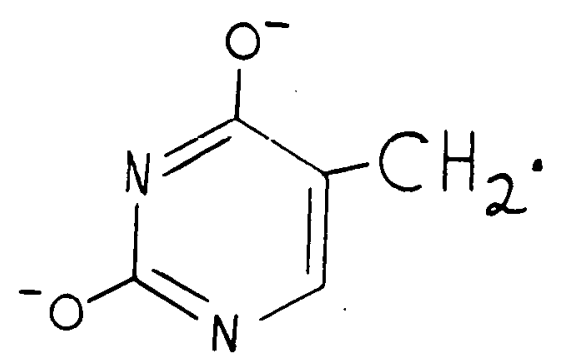

2. Thymine in an acid glass.

Photolysis of $0.5 \mathrm{mg} / \mathrm{ml}$ thymine in $6 \mathrm{M} \mathrm{H}_{3} \mathrm{PO}_{4}$ at $77^{\circ} \mathrm{K}$ produces a spectrum attributed to the cation radical. In the absence of electron scavengers the cation spectrum is overlapped by a spectrum of the "thymyl" radical: Hydrogen atoms are also present in the spectrum most likely due to the reaction of electrons and $\mathrm{H}_{3} \mathrm{O}^{+} \cdot{ }^{9}$ Again the sample phosphoresces visibly during and immediately after photolysis, although the intensity is less than was found in the alkaline glass. In order to observe a spectrum of the positive ion relatively free from another signal, thymine solutions of $\mathrm{D}_{3} \mathrm{PO}_{4}(95 \% \mathrm{D})$ were saturated with $\mathrm{N}_{2} \mathrm{O}$ at ca. $-50^{\circ} \mathrm{C}$. Photolysis of this solution at $77^{\circ} \mathrm{K}$ produces a spectrum due to the positive ion (Figure 3). 'The electron reacls lu form $\mathrm{N}_{2} \mathrm{O}^{-}$which further decays to $\mathrm{OD}^{9}$ In the acid glass the spectrum of $\cdot O D$ is broad and unresolved and does not significantly interfere with that of the positive ion. 13 A comparison of Figures $2 D$ and 3 shows that the spectra of the $\pi$-cation and cation radicals are remarkably similar.

\section{DISCUSSION}

Spectrum Analysis

Several properties of the spectrum of the thymine positive ion in the acid glass suggest a large splitting due to the methyl protons. First is 
the large total width of $85 \mathrm{G}$. For organic radicals such widths usually occur when there are large $\beta$-proton splittings. Second, the ratio of peak heights of $0.8: 2.6: 3.2: 1.0$ for the major components in Figure 3 suggest a freely rotating methyl group (theoretical $1: 3: 3: 1$ ). Third, the linewidths of ca. $4 \mathrm{G}$ are quite narrow for a glassy ("polycrystalline") spectrum. This property suggests some motional averaging such as a rotating methyl group. The spectrum also shows other hyperfine components which are anisotropic in nature (note ends of spectrum). Such lineshapes would be expected for a single anisotropic nitrogen hyperfine coupling. 6,14 Similar arguments hold for the $\pi$-cation radical in the alkaline glass.

Molecular orbital calculations discussed below also suggest a large methyl splitting and a single nitrogen splitting (position 1)。Other magnetic nuclei at positions $3(N)$ and $6(H)$ are predicted to have small splittings 。

If it is assumed that the nitrogen at position 1 has axial symmetry (generally a good approximation) the spectrum can be readily interpreted. The spin Hamiltonian for a molecule containing a single anisotropic hyperfine splitting under the assumption of axial symmetry has been solved. The transitions for such a system with the addition of an isotropic methyl group coupling are given by the relation: 15,16

$$
h \nu=\left(1 / 3 g_{\|}+2 / 3 g_{\perp}\right) \beta H+A_{C H_{3}}^{H} M_{C H_{3}}+A_{N^{M}}+\left[1 / 3\left(g_{\|}-g_{\perp}\right) \beta H+B_{N} M_{N}\right]
$$


where $\mathrm{A}_{\mathrm{CH}_{3}}^{\mathrm{H}}, \mathrm{A}_{\mathrm{N}}$ and $\mathrm{B}_{\mathrm{N}}$ are in units of $\mathrm{Mc} / \mathrm{sec}$ and are the isotropic methyl, isotropic nitrogen and anisotropic nitrogen hyperfine splitting, respectively.

In glassy or polycrystalline substances values of $\theta$ equal to 0 and $\pi / 2$ produce various maxima and minima in the spectrum. ${ }^{17}$ Positions in magnetic field of these extrema are given by:

$$
\begin{aligned}
& \mathrm{H}(\theta=0)=\frac{\mathrm{h} \nu}{\mathrm{g}_{\|} \beta}-\frac{\mathrm{g}_{\mathrm{e}}}{\mathrm{g}_{\|}} A_{\|} M_{N}-\frac{\mathrm{g}}{\mathrm{g}_{\|}} Q_{\mathrm{CH}_{3}} \mathrm{M}_{\mathrm{H}} \\
& \mathrm{H}(\theta=\pi / 2)=\frac{\mathrm{h} \nu}{\mathrm{g}_{\perp} \beta}-\frac{\mathrm{g}_{\mathrm{e}}}{\mathrm{g}_{\perp}} A_{\perp} M_{\mathrm{N}}-\frac{\mathrm{g}_{\mathrm{e}}}{\mathrm{g}_{\perp}} Q_{\mathrm{CH}_{3}} \mathrm{M}_{\mathrm{H}}
\end{aligned}
$$

where $A_{11}=a_{N}+2 b_{N}, a_{\perp}=a_{N}-b_{N}$, and $a_{C_{3}}, a_{N}, b_{N}$ correspond to $\mathrm{A}_{\mathrm{CH}_{3}}, \mathrm{~A}_{\mathrm{N}}, \mathrm{B}_{\mathrm{N}}$ converted into units of gauss.

Analysis of the spectrum of the positive ion (Figure 3 ) in terms of the parameters in equations 2 and 3 yields $a_{.} \mathrm{CH}_{3}=2.0 .4 \pm 0.1 \mathrm{G}$, $A_{\|}^{N}=11.8 \pm 0.2 \mathrm{G}, A_{\perp}^{N} \leq 2 \mathrm{G},{ }^{18} g_{\|}=2.0026 \pm 0.0002$, and $g_{\perp}=2.0046$ \pm 0.0006 . A similar analysis for the $\pi$-cation radical in the alkaline glass gives $a_{\mathrm{CH}_{3}}^{\mathrm{H}}=20.5 \pm 0.2 \mathrm{G}, \mathrm{A}_{\| 1}^{\mathrm{N}}=12.0 \pm 0.3 \mathrm{G}, \mathrm{A}_{\perp}^{\mathrm{N}} \leq 2 \mathrm{G}$, $g_{\|}=2.0023 \pm 0.0002$ and $g_{\perp}=2.0042 \pm 0.0006$

The large uncertainty in $g_{\perp}$ is due to the fact that the components used to measure $g_{\perp}$ are overlapped. Consequently only an approximate value could be determined from an analysis of the lineshape of these components. The values of $g_{\|}$are less uncertain since the end components of the spectrum which determine $g_{\|}$are free from overlap. A 
stick reconstruction based on the parameters for the cation in the acid glass is shown in Figure 3. The agreement between theory and experiment is excellent and indicates that the analysis is correct. The diagram also compares favorably with the results found in the alkaline medium:

The hyperfine parameters found for the cation and the $\pi$-cation are nearly identical. Only the $g$ values and lineshapes of the various components distinguish the two radicals. These results suggest a very small or negligible effect due to the differences in protonation. This is a somewhat surprising result.

For later comparison to theoretical calculations it is of interest to determine $a_{\mathrm{N}}$ and $\mathrm{b}_{\mathrm{N}}$. Solution of simultaneous equations employing the experimental values of $A_{1}{ }^{N}$ and $A_{\perp} N^{\prime}$ yields $4<a_{N}<5.3$ and $4>b_{N}<3.3$ for both radicals.

\section{Spin Density Calculations}

McLachlan SCF-MO calculations of the spin density have been performed for comparison to the experimental results. Such M.O. calculations have been shown to give good agreement with the hyperfine splittings found for the purine and pyrimidine anions ${ }^{19}$ and should provide an adequate description of the spin density in these molecules.

Spin density calculations are performed for both the protonated (cation) and unprotonated ( $\pi$-cation and $\pi$-anion) radicals. The calculation for the protonated case employs $M . O$. parameters suitable for structure I 
in Figure 1, 20 while the calculations for the unprotonated case employs parameters suitable for structures II and III. 20,21 These M. O. parameters are given in Table $I$ and have been employed in similar molecules with good results. 19,20

The table lists the hyperfine splittings calculated from the spin density distribution. Values of $Q$ employed for the cations are $Q_{\mathrm{N}}^{\mathrm{N}}=+27,20 \mathrm{~b}, 21 \mathrm{Q}_{\mathrm{CH}_{3}}^{\mathrm{H}} \cong+40,{ }^{20 \mathrm{~b}}$ and $\mathrm{Q}_{\mathrm{CH}}^{\mathrm{H}}=-30 .^{20 \mathrm{~b}}$ The values $Q_{C H}^{\mathrm{H}}=-24, Q_{\mathrm{N}}^{\mathrm{N}}=+27$ and $Q_{\mathrm{CH}_{3}}^{\mathrm{H}} \cong 20$ are employed for the anion radical. $20 \mathrm{~b}$ For the cation radicals a comparison of the theoretical splittings with the experimental results for each calculation shows that the major features are generally correctly predicted, i. e. a large methyl splitting of ca. $20 \mathrm{G}$, only one nitrogen with a significant splitting, and a small splitting for the proton at position 6. Only the calculation for the proton at position 6 in case $I$ is not in good agreement. A more detailed comparison for the unprotonated thymine $m$-cation showe the calculation. based on structure III is in better agreement with the nitrogen hyperfine splitting than that based on structure $I$.

One aspect of the experimental results for the cation radicals is intriguing. It is the fact that the hyperfine splittings for the two cation radicals show. no apparent effect of protonation. The theoretical calculations predict little effect on the methyl splitting but a significant effect on the $a_{\mathrm{H}(6)}$ and $a_{\mathrm{N}(1)}$ splittings. Identical theoretical nitrogen hyperfine 
TABLE 1. THEORETICAL SPIN DENSITIES AND HYPERFINE SPLITTINGS

Cation

Structure

I

II

III
Anion

III

McLachlan Spin Densities ${ }^{a}$

Position

1

2

3

4

5

6

7

8

9

10
0.150

$-0.008$

$-0.004$

$-0.019$

0.457

0.194

0.035

0.112

0.003

0.081
0.335

$-0.013$

$-0.006$

$-0.011$

0.441

0.024

0.064

0.098

$-0.002$

0.071
0.115

0.083

$-0.011$

0.078

0.465

0.064

0.056

0.058

0.006

0.087
0.165

$-0.037$

0.140

0.304

$-0.050$

0.457

$-0.006$

0.033

0.000

$-0.005$

\section{M.O. Parameters}

$\begin{array}{lllll}\mathrm{h}_{\mathrm{N}} & 1.5 & 0.8 & 0.8 & 0.8 \\ \mathrm{k}_{\mathrm{C}-\mathrm{N}} & 0.8 & 0.8 & 1.08 & 1.08 \\ \mathrm{~h}_{\mathrm{O}} & 1.2 & 1.2 & 2.0 & 2.0 \\ \mathrm{k}_{\mathrm{C}-\mathrm{O}} & 1.5 & 1.5 & 1.0 & 1.0\end{array}$

Theoretical Splittings (G)

\begin{tabular}{|c|c|c|c|c|c|c|c|}
\hline & & $(\operatorname{Exp})$ & & & $(\operatorname{Exp})$ & & $(\operatorname{Exp})$ \\
\hline $1(\mathrm{~N})$ & 4.1 & $4-5.3$ & 9.1 & 3.1 & $4-5.3$ & 4.5 & $\mathrm{~b}$ \\
\hline $3(N)$ & 0.1 & $<2$ & 0.2 & 0.3 & $<2$ & 3.8 & $\mathrm{~b}$ \\
\hline $5\left(\mathrm{CH}_{3}\right)$ & 18.3 & 20.4 & 17.6 & 18.6 & 20.5 & 1.0 & $\mathrm{~b}$ \\
\hline $6(\mathrm{H})$ & 5.8 & $<4$ & 0.7 & 1.9 & $<4$ & 11.0 & 16 \\
\hline
\end{tabular}

a. $\lambda=1.0$

b. No other splittings are found for the thymine anion; however, the linewidth of $12 \mathrm{G}$ sets an upper limit for these values. The lack of resolution and the large splitting for the $\mathrm{C}_{6}$ proton suggests values considerably smaller than $12 \mathrm{G}$ for these splittings.

\section{AI-A EC- 12974}


splittings for the protonated and unprotonated cases are found by varying the nitrogen and oxygen coulomb and resonance integrals so that they lie between those used in case II and III. This agreement is found for a weighted average of the parameters for II and III consisting of . 85II and $0.15 \mathrm{III}$. In terms of valence theory this would suggest an admixture of the two valence states with state III predominating.

It should be noted that calculations for one of the other tautomeric forms of the protonated molecule, i.e. where the oxygens are protonated rather than the nitrogens, would employ similar MO parameters as used for calculation III. Since this would result in similar hyperfine splittings, there is no way to distinguish between these tautomers by means of their methyl proton and nitrogen hyperfine splittings alone. Only a complete resolution of the ESR spectra in single crystals or in solution would settle this question.

The theoretical and experimental results for the single anion splitting are not in goud agreement. The fact that the anion of 6-methyluracil gave a similar methyl proton splitting $(15.4 \mathrm{G})$ is further evidence that a high spin density is found at position 6. For anions the $Q$ for a methyl is approximately $20 \mathrm{vs} .24$ for an $\alpha$ proton. $20 \mathrm{~b}$ The spin density indicated by experiment is then between 0.67 and 0.77 . It is found that calculations employing other recommended heteroatom parameters do not significantly improve the agreement with experiment. $20 a$ 
In a study of irradiated single crystals of cytosine monohydrate at $77^{\circ} \mathrm{K}$ the cytosine cation and anion radicals were identified. ${ }^{5}$ It was found that the spin density calculations for the cystosine cation were not in good agreement with experiment. The hyperfine splitting for the $\mathrm{C}_{5}$ proton was predicted to be lower than experiment. In this work this condition is found for the thymine cation as well. Results found for the cytosine anion suggest the spin density predicted by theory for the C-6 proton is again low as is the case for the thymine anion.

These deviations may be a result of some nonplanarity in the pyrimidine ion ring; however, the degree of nonplanarity would have to be significant to affect the results even moderately. It is considered more likely that the theoretical predictions are in error for these molecules.

\section{SUMMARY AND CONCLUSIONS}

The evidence for the production of the thymine cation radical in the acid glass and a thymine "$\pi$-cation" in an alkaline glass is considered strong. Phosphorescence is observed in both alkaline and acid glasses. This suggests an appreciable population of the triplet state which is necessary for photoionization. The electron is found after photolysis of thymine in the alkaline glass and products of electron reactions ( $\mathrm{H}$ etc.) are found in the acid glass. Finally the hyperfine couplings found from the analysis of the ESR spectra for these radicals are in reasonable agreement with theoretical splittings.

$$
\text { AI-AEC- } 12974
$$


The identification of the cation and anion radicals in this work are of significance to radiolysis studies of thymine single crystals. These species should be the prime radical species formed upon radiolysis at low temperatures. At present radiolysis studies of thymine $22,23,24$ at $77^{\circ} \mathrm{K}$ do not give evidence of ionic species. However, these species Inay be stabilized at lower temperatures than have been thus far employed.

In the radiolysis of thymine monohydrate at $77^{\circ} \mathrm{K}$ two radical species have been identified. 24 These radicals are:<smiles>CC1CNC(=O)NC1=O</smiles><smiles>O=c1[nH]cc(Cc2ccco2)c(=O)[nH]1</smiles>

The radicals are formed in approximately equal concentrations. The productinn of the first species has been attributed to hydrogen atom attack. In this mechanism the $\mathrm{H}$-atoms originate by loss of a hydrogen from the $\mathrm{CH}_{3}$ group of thymine. This produces the second radiral.

In view of the results found in thio work and by Holroyd and Glass ${ }^{11}$ an alternant hypothesis must be considered for radical production in the radiolysis of thymine. In this mechanism the radiation ionizes thymine to form the positive ion and by electron attachment the negative ion. The negative ion then reacts with the water in the crystal (protonates) to form the "thymyl" radical whereas the positive ion reacts by loss of a proton to form the second radical species. 
Several experimental observations add some weight to the latter hypothesis:

1. The two radical species found in the radiolysis of thymine are found to be products of the positive and negative ions of thymine. 11,12

2. Radiolysis of cytosine is found to product the positive and negative ions at $77^{\circ} \mathrm{K}$. This shows ionic species are produced in the radiolysis of crystalline pyrimidines.

3. Radiolysis of anhydrous single crystals of thymine at room: temperature does not produce the "thymyl" radical. ${ }^{25}$ However, the second radical is produced. This suggests that water is necessary for production of the thymyl radical. This agrees with a protonation mechanism but not with an $\mathrm{H}$-atom addition mechanism. 
B. Reaction of the Thymine Positive Ion

Positive ions are important intermediates in the radiolysis of biological systems (direct effect). This work was performed to elucidate the role of positive ions in the radiolysis of DNA. In recent work we have shown that the thymine positive ion is a product of the photoionization of thymine in acid and in alkaline glasses at $77^{\circ} \mathrm{K}$ (see Part II, Section A of this report). The spectrum of the cation was interpreted and found to be in excellent agreement with that expected from the thymine structure. During the photoionization process electrons are produced as well as the positive ion. Reaction of the electron with the parent compound by photobleaching produces an. ESR spectrum of both the cation and anion radicals (Figure $2 \mathrm{~B}$ ). Warming the solution containing the cation and anion to $190^{\circ} \mathrm{K}$ results in protonation $\left(\mathrm{H}_{2} \mathrm{O}\right.$ glass) of the anion $\left(190^{\circ} \mathrm{K}\right)$ and decomposition of the cation $\left(135^{\circ} \mathrm{K}\right)$. The overlapped spectrum of the protonated thymine anion ("thymy1" radical) and the decomposition product of thymine is shown in Figure 4A. The dotted curve is the spectrum of the "thymyl" radical alone. This species is produced by electron attachment techniques described previously (see Section A of Part II). Subtraction of the thymyl radical spectrum from the overlapped curve results in the spectrum in Figure $4 B$. The spectrum extends $53 \mathrm{G}$ and consists of 8 components. The spectrum is anisotropic in nature and cannot be interpreted directly. However, the spectrum appears as an overall $15 \mathrm{G}$ triplet further split. The two likely mechanisms for reaction are given below in reactions 1 and 2: AI-AEC- 12974 


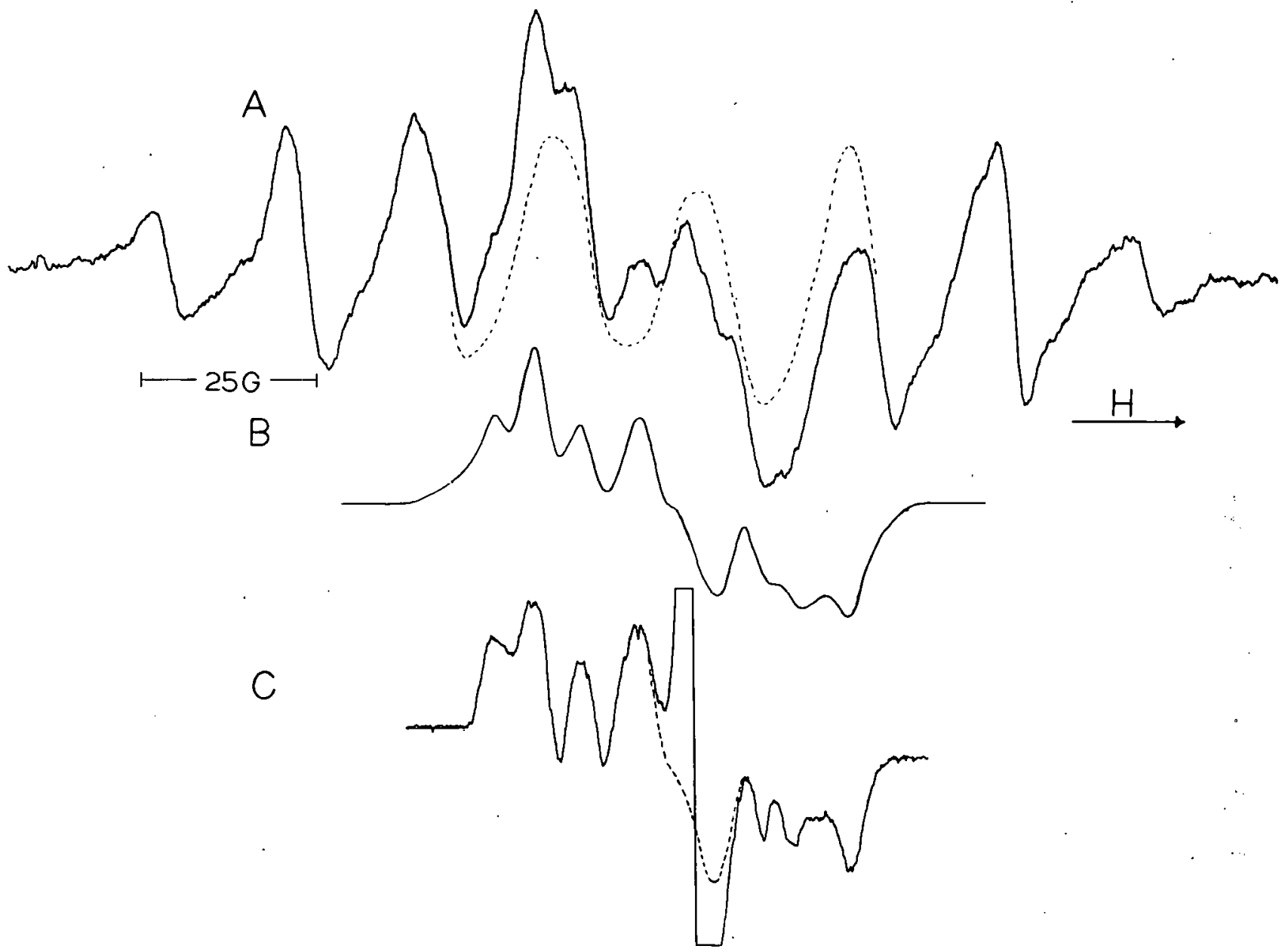

Figure 4. A. ESR spectrum of the protonated thymine anion and cation decomposition product at $190^{\circ} \mathrm{K}$ in an alkaline $\mathrm{H}_{2} \mathrm{O}$ glass. The dotted curve is the spectrum due to the protonated species alone. B. Spectrum of the cation decomposition product resulting from a subtraction of the two curves in $A$. C. Spectrum of the $\mathrm{T}-\mathrm{CH}_{2} \cdot$ radical at $190^{\circ} \mathrm{K}$ produced by $\cdot \mathrm{O}^{-}$attack on thymine in $\mathrm{D}_{2} \mathrm{O}$. The central peak is a background signal. The nearly identical spectra in B and C confirm the identity of the cation decomposition product. 
<smiles></smiles><smiles>C[C@@H]1C(=O)N2O[C@]1(C)CNC2=O</smiles>

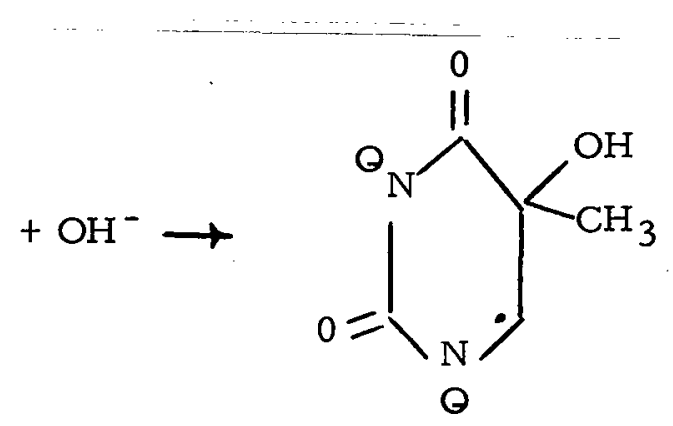<smiles>CC1C(=O)N(O)C(=O)NC1O</smiles>

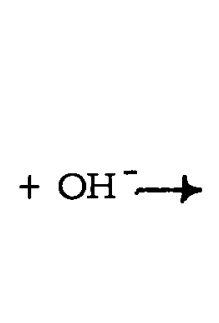<smiles></smiles>

Reaction 2 is considered most likely since the radical formed has been produced previously in $\gamma$-irradiated thymine single crystals. 24 The spectral parameters found for this species are in good agreement with those found in this work.

In order to verify that a $\mathrm{T}-\mathrm{CH}_{2}$ type radical is the decomposition product of the cation radical, the same radical was produced by an independent means. It is well known that at high $\mathrm{pH}$ hydroxyl radicals $\left(\cdot \mathrm{O}^{-}\right)$attack the methyl group of thymine to produce the $\mathrm{T}-\mathrm{CH}_{2}$ radical. 26,27 In order to produce this radical species only, an alkaline $\mathrm{D}_{2} \mathrm{O}$ glass containing $10^{-3} \mathrm{M}$ thymine and saturated with $\mathrm{N}_{2} \mathrm{O}$ at low temperature was irradiated by Co $60 \gamma$-rays (Dose $\left.2.4 \times 10^{18} \mathrm{ev} / \mathrm{gram}\right)$. This produces $\cdot \mathrm{O}^{-}$and electrons. Upon warming the electrons react predominately with $\mathrm{N}_{2} \mathrm{O}$ to produce $\cdot \mathrm{O}^{-}$and $\mathrm{N}_{2}$. The primary attacking species in then $\cdot \mathrm{O}^{-}$. Figure $4 \mathrm{C}$ 
shows the spectrum of the irradiated sample at $190^{\circ} \mathrm{K}$ after $\cdot \mathrm{O}^{-}$attack. The large central peak is a background signal resulting from the irradiated. quartz sample tube. Except for increased resolution of the hyperfine components and the background signal in Figure $4 \mathrm{C}$, the spectra in Figures $4 \mathrm{~B}$ and $4 \mathrm{C}$ are identical. The increased resolution is due to the fact that the irradiated sample was prepared in $\mathrm{D}_{2} \mathrm{O}$ while that which yielded spectrum $4 \mathrm{~B}$ was prepared in $\mathrm{H}_{2} \mathrm{O}$. These results confirm that the radical produced by decomposition of the positive ion is that formed in reaction 2 . C. The Thymidine Positive Ion and Its Reaction

Ultraviolet irradiation of $10^{-3} \mathrm{M}$ thymidine in an alkaline $\mathrm{D}_{2} \mathrm{O}$ glass at $77^{\circ} \mathrm{K}$ results in a strong ESR signal due to the electron. However, a spectrum due to the cation radical produced in the photoionization process is not observed. It is therefore considered likely that the thymidine cation radical is unstable even at $77^{\circ} \mathrm{K}$. Photobleaching the trapped electron produces a spectrum of the thymidine anion which is overlapped with the protonated species and the decay product of the thymidine cation. These spectra are shown in Figure $5 \mathrm{~A}$ for an $\mathrm{H}_{2} \mathrm{O}$ glass and Figure $5 \mathrm{~B}$ for a $\mathrm{D}_{2} \mathrm{O}$ glass. The spectrum of the thymidine anion consists of a $13,7 \mathrm{G}$ doublet. This is shown clearly in Figure $5 \mathrm{~B}$. In $\mathrm{D}_{2} \mathrm{O}$ the deuteration of the anion does not occur readily at $77^{\circ} \mathrm{K}$. Protonation apparently occurs more readily than deuteration. This effect has been noted previously in a study of electron reactions with thymidine by Holroyd and Glass. Il Warming of the sample to $195^{\circ} \mathrm{K}$ allows the protonation reaction to go to completion. 


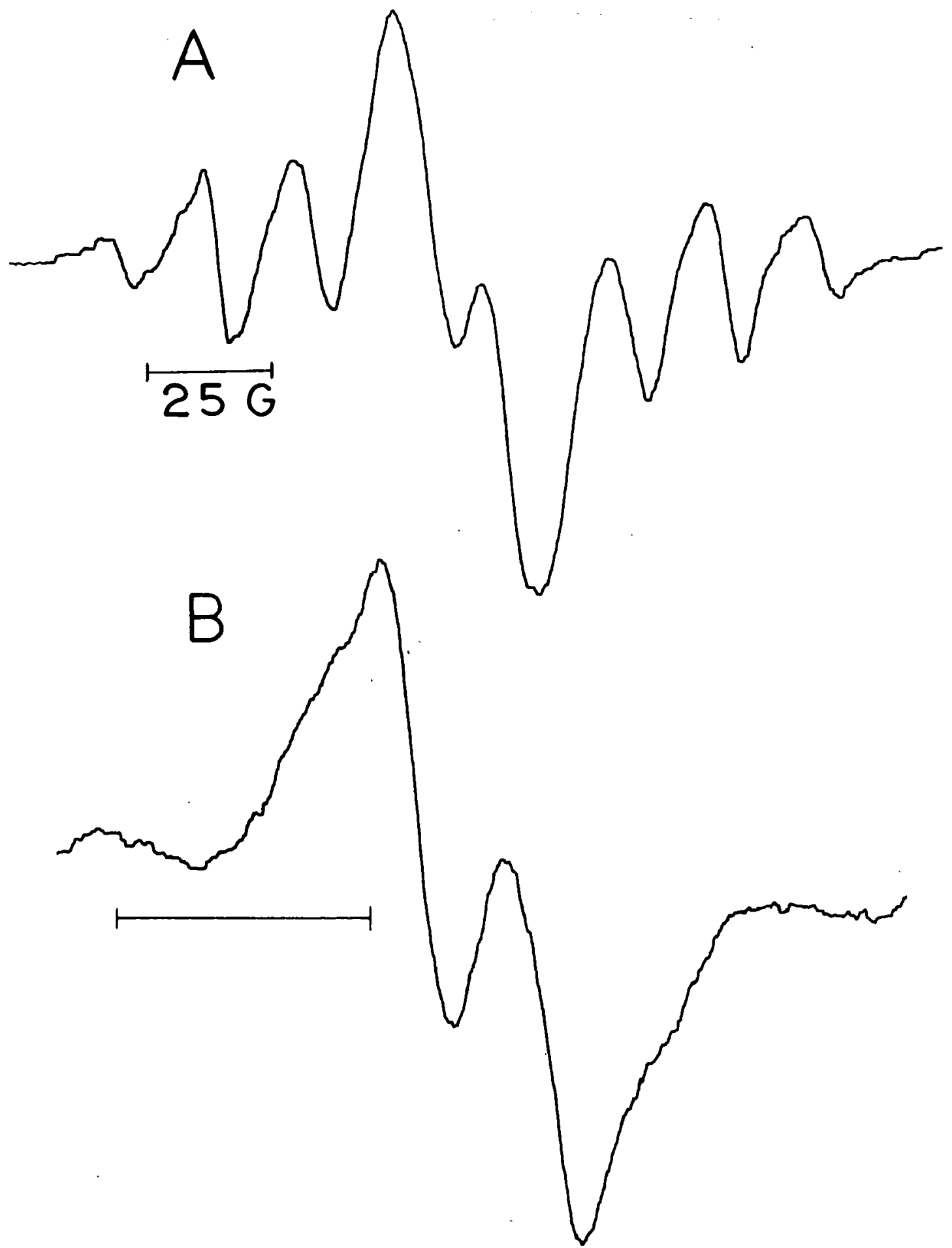

Figure 5. A. ESR spectrum of thymidine photoionized and photobleached at $77^{\circ} \mathrm{K}$ in an alkaline $\mathrm{H}_{2} \mathrm{O}$ glass. Three radical species are present: the protonated anion, the anion, and the cation decomposition product. B. ESR spectrum of thymidine photoionized and photobleached at $77^{\circ} \mathrm{K}$ in an alkaline $\mathrm{D}_{2} \mathrm{O}$ glass. The anion and the cation decomposition product predominate. 


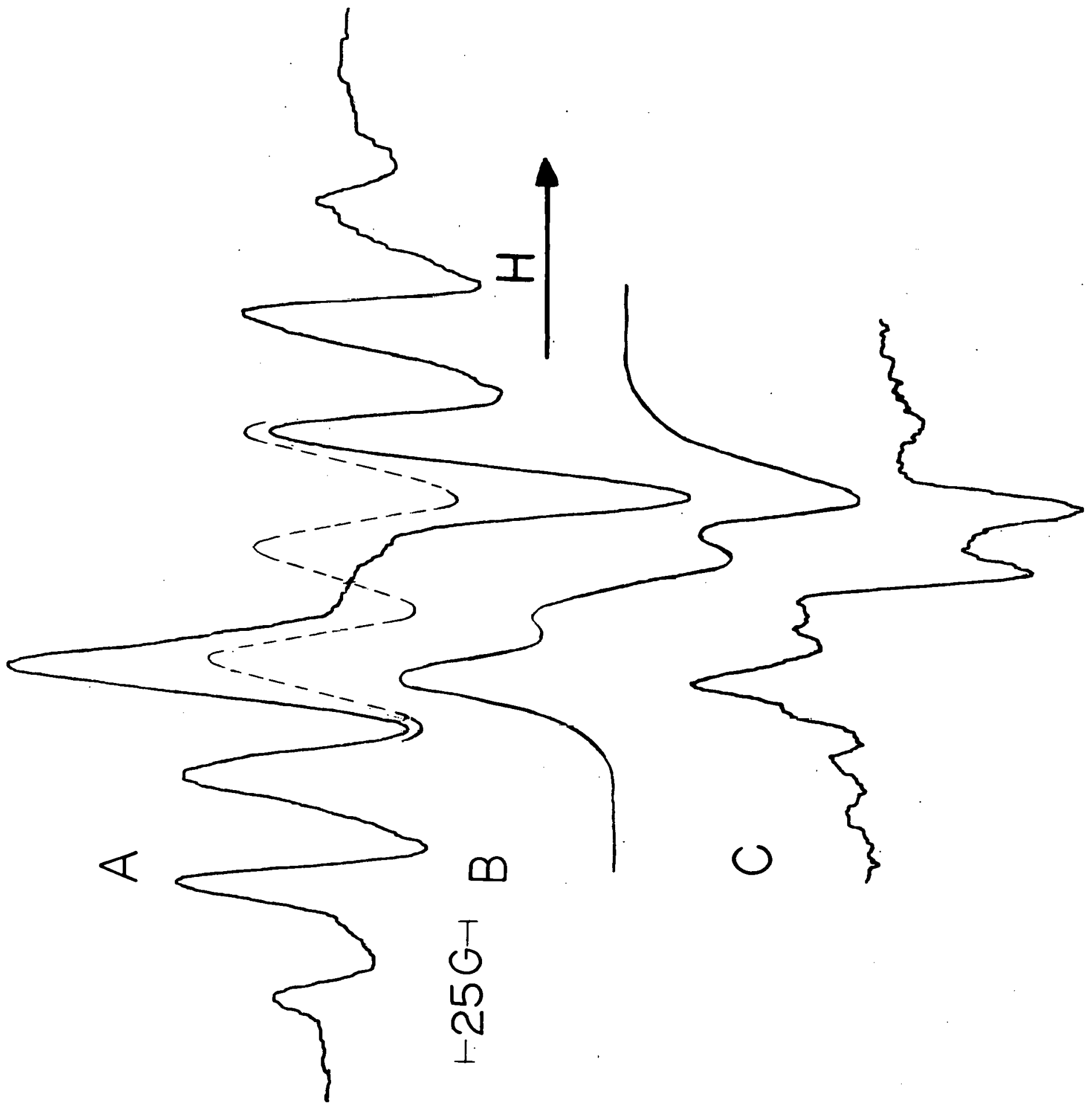

Figure 6. A. ESR spectrum of the protonated thymidine anion and the cation decomposition product at $190^{\circ} \mathrm{K}$. The dotted curve is the spectrum due to the protonated species alone. B. Spectrum of the cation decomposition product resulting from a subtraction of the two curves in A. C. Spectrum obtained by saturating solution used in $A$ with $\mathrm{N}_{2} \mathrm{O}$ before photolysis. 
This results in the spectrum shown in Figure 6A. The dotted curve is that found for the protonated thymidine anion alone. The difference between the two curves is then considered to be the cation decomposition product. This difference is shown in Figure 6B. The spectrum consists of a triplet with a $13.5 \mathrm{G}$ separation between the componcnts. Arguing by analogy to thymine this radical would be expected to have the structure.<smiles>[R][n+]1cc([12CH2])c([O-])nc1OC</smiles>

However, the spectra for the two radicals are significantly different. The thymine radical is known to have a $15 \mathrm{G}$ major isotropic splitting $\left(\mathrm{CH}_{2}\right.$ protons) further split by an $11 \mathrm{G}$ splitting (C-6 proton). The $13.5 \mathrm{G}$ splitting found here shows no evidence of a further splitting. This indicatoe the serond expected hyperfine splitting must be less than the linewidth in magnitide or ca. $7 \mathrm{G}$. If these radicals are structurally similar, the substitution of the ribose group must affect the dictributinn of unpaired spin greatly. There is some evidencc that the ribose group can affect the spin density distribution on the thymine ring. (Sce Part III, Section B).

In order to further verify the identity of the final radical species, experiments were performed with alkaline $\mathrm{D}_{2} \mathrm{O}$ samples containing $10^{-3} \mathrm{M}$ thymine which were saturated with $\cdot \mathrm{N}_{2} \mathrm{O}$ at low temperature. Photolysis of these samples results in an ESR signal due to the electron which

$$
\text { AI-AEC- } 12974
$$


obscures the cation decomposition product. Warming to $195^{\circ} \mathrm{K}$ should result in the reaction of the electrons and $\mathrm{N}_{2} \mathrm{O}$ to produce $\cdot \mathrm{O}^{-}$. This radical species can then attack the parent compound. It is known that the 5-methyl group is the site of $\cdot \mathrm{O}^{-}$attack in thymidine. ${ }^{27}$ Thus the $\mathrm{T}-\mathrm{CH}_{2}$ radical should be produced. The ESR spectrum in Figure $6 \mathrm{C}$ is nearly identical to that found for the cation decomposition product. It should be noted that these results are not unambiguous since the cation decomposition product is produced in this experiment. Experiments similar to those performed for thymine (using radiolysis) will be necessary for an unambiguous determination. The results thus far suggest that the thymidine cation decomposes by the same mechanism as the thymine cation. In addition the results suggest a significant difference in the spin density distribution of the two radical species.

The results found here for thymine and thymidine suggest a mechanism for radiation damage in DNA. The direct effect of radiation on DNA will produce electrons and positive ions. Our previous work has shown that electrons attach to the DNA bases to form anions; however, only the thymine and thymidine anions protonate to form the characteristic "thymyl" spectrum. In DNA we suggest that the electrons migrate from base to base until finding a thymine base where protonation occurs. Likewise for the cations formed in DNA the positive pole would migrate through the chain until encountering a thymine base where it would localize by production of $\mathrm{R}-\mathrm{CH}_{2}$ radicals. This hypothesis is supported by the fact that irradiated wet DNA shows an ESR spectrum nearly identical to those found in Figures 4 and 6 for thymine and thymidine. ${ }^{32}$ Further work is planned to verify this hypothesis. 


\section{ELECTRON STUDIES}

\section{A. Reactions of Electrons with Peptides}

The study of the reactions of electrons with chromosome constituents was continued with an investigation of peptides. The electrons were photolytically generated in an alkaline $\mathrm{D}_{2} \mathrm{O}$ glass and allowed to react with the peptide solute. The reaction sequence for peptides is found to be similar to the amino acids (Appendix D). Upon warming the first species, the dianion, undergoes $\mathrm{N}$-terminal deamination and the resultant radical. subsequently abstracts from the parent compound to form an $\alpha$ carbon radical. The results for $\mathrm{N}$-acetylamino acids and peptides show that the electron is localized in the peptide bond in dipeptides and in the $\mathrm{N}$-terminal peptide bond in tripeptides. The localization at the $\mathrm{N}$-terminal bond is suggested to be a result of a deeper potential energy well at that bond. A paper describing this work has been accepted for publication and a preprint is incluted here as Appendix E.

B. Anions of Pyrimidines and Nucleosides

In previous work in these laboratories it was found that electron attachment to various pyrimidines produced the anions. However, the ESR spectra of these species were generally found to be unresolved singlets. Since these anions are formed in the radiolysis of. DNA, electron attachment in a deuterated alkaline glass was attempted. Use of a deuterated glass has improved resolution of hyperfine components in previous work with amino acid radicals and would be expected to do so here as well. $6 a, b$ Electrons AI-AEC- 12974 
are generated by the photolysis of $\mathrm{K}_{4} \mathrm{Fe}(\mathrm{CN})_{6}$ technique 6,11 and then reacted with the pyrimidine or nucleoside. It is found that all the ESR spectra for the pyrimidines and nucleosides are resolved. The pyrimidines thymine, cytosine and uracil show ca. $16 \mathrm{G}$ doublets at $90^{\circ} \mathrm{K}$ (see Figures $5 \mathrm{~B}, 7 \mathrm{~A}$ and $7 \mathrm{~B})$. ESR spectra of the nucleoside anions for thymidine, deoxyuridine and deoxycytosine also show doublet splittings (see Figures 7C and 7D); however, less in magnitude than those found for the pyrimidines. Table If reports the hyperfine splittings for the various pyrimidine and nucleoside anions.

\section{TABLE II}

PYRIMIDINE AND NUCLEOSIDE ANION PROTON HYPERFINE SPLITTINGS AT $90^{\circ} \mathrm{K}$

\begin{tabular}{lcllc} 
Pyrimidine & Splitting (G) & & Nucleoside & Splitting (G) \\
\cline { 2 - 3 } Uracil & 16.5 & & Deoxyuridine & 14.2 \\
Thymine & 16.0 & Deoxythymidine & 13.7 \\
Cytosine & 15.6 & Deoxycytosine & 13.0
\end{tabular}

Theoretical calculations of the spin density show that the large doublet splittings in these anions originates from an interaction with the $C_{6}$ proton. This is confirmed by a study of the anion of 6-methyluracil. In this molecule the methyl group has replaced the $C_{6}$ proton thus the spectrum of the anion should show a large quartet splitting due to the methyl group. The spectrum of this radical at $90^{\circ} \mathrm{K}$ is shown in Figure $8 \mathrm{~A}$. The $15.4 \mathrm{G}$ quartet in the spectrum confirms that the $\mathrm{C}-6$ position is that of high spin density for the pyrimidine anions. Warming the sample containing the anion to $180^{\circ} \mathrm{K}$ 

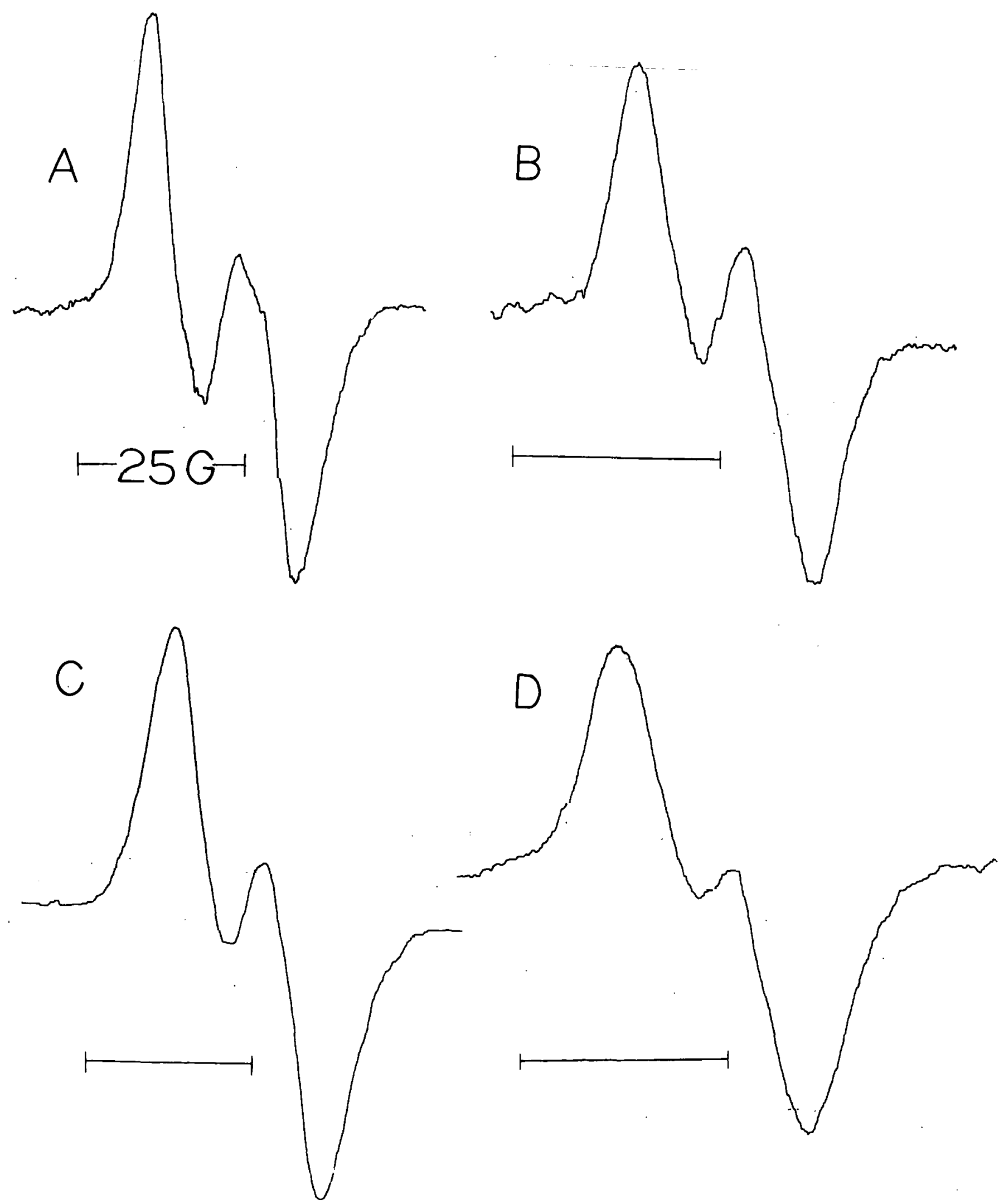

Figure 7. ESR spectra of anions of pyrimidines and nucleosides produced by electron attachment at $77^{\circ} \mathrm{K}$. A. Cytosine anion. B. Deoxycytidine anion. C. Uracil anion. D. Deoxyuridine anion. 


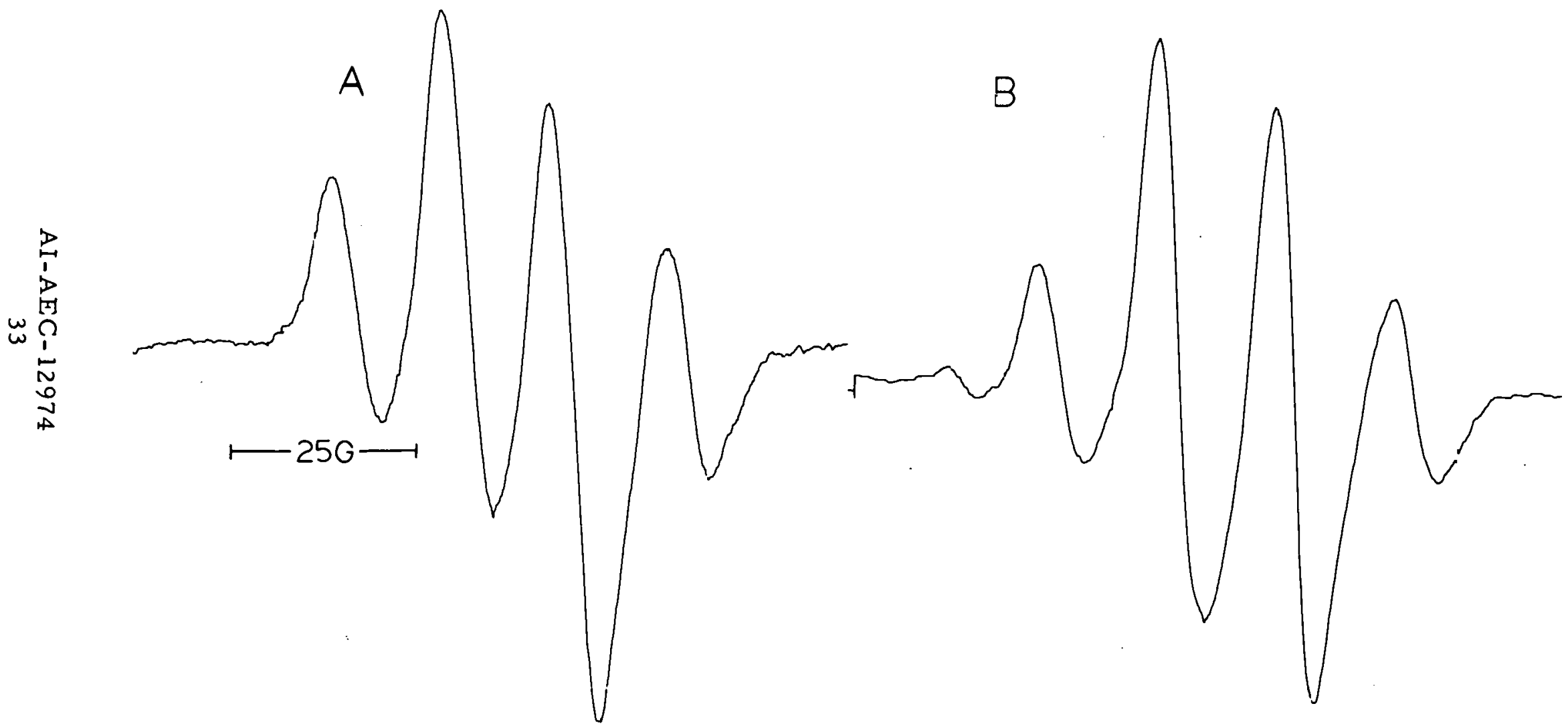

Figure 8. A. ESR spectrum of the anion of 6-methyl uracil produced by electron attachment in an alkaline $\mathrm{D}_{2} \mathrm{O}$ glass at $77^{\circ} \mathrm{K}$. B. Anion spectrum after warming to $190^{\circ} \mathrm{K}$ and cooling to $100^{\circ} \mathrm{K}$. 
and recooling results in an increase in the methyl proton splitting to 16. $2 \mathrm{G}$ and a change in the lineshape (Figure $8 \mathrm{~B}$ ). This increase in the hyperfine splitting upon warming and recooling was also found for all the pyrimidine and nucleoside anions. It suggests either a change in the conformation of the pyrimidine ring or protonation of the nitrogen at position 3 due to the increased bascity induced by the extra electron.

The difference in hyperfine splitting between the pyrimidines and nucleotisides is also of interest. The splittings for the nucleotides are approximately $15 \%$ lower than those of the corresponding pyrimidine. This shows that the ribose group has a moderately large effect upon the spin density distribution in the pyrimidine ring.

These results are considered to be of significance since they may aid the identification of anions of the pyrimidines and nucleosides which are produced via radiolysis.

\section{Electron Reactions at $\mathrm{pH} 7$}

Recent work by several workers has suggested that deamination should proceed more slowly in alkaline solutions than at $\mathrm{pH} 7 .^{28}$ Since our work on amino acids and peptides was performed in an alkaline ice glass, it is of interest to investigate the reactions of electrons with these compounds at $\mathrm{pH}$ 7. Another reason for this work is that reactions of the anions of acetylamino acids are reported to be different at $\mathrm{pH} 7$ than in an alkaline glass. The study employs the photooxidation of $\mathrm{K}_{4} \mathrm{Fe}(\mathrm{CN})_{6}$ in $\mathrm{D}_{2} \mathrm{O}$ as the source of electrons. Electron attachment to glycine and alanine in frozen aqueous solutions ( $\mathrm{pH}$ 7) results in ESR spectra of the deaminated species AI-AEC- 12974 
of glycine and alanine. Spectra of the anions of the amino acids are not observed. This confirms the fact that the anions are less stable at $\mathrm{pH} 7$. Recent work with acetyl amino acids in frozen aqueous solutions have produced the spectra of the anions; however, the spectra are not readily interpretable. It is hoped that production of these anions in neutral glasses will lead to improved resolution. 


\section{RADIOLYSIS OF FROZEN AQUEOUS SOLUTIONS OF DNA}

Previous studies of the radiolysis of DNA have dealt primarily with dry or damp DNA. ${ }^{29-32}$ These experiments therefore have bearing primarily on the direct effect of radiation with DNA. A study of the attack of the radiolytic intermediates produced in the radiolysis of water $(e ; \cdot O H)$ is therefore of interest. For this rcason irradiation experiments were performed with frozen aqueous solutions of DNA.

Radicals produced in solutions of $1-5 \%$ salmon sperm DNA in $\mathrm{H}_{2} \mathrm{O}$ and $\mathrm{D}_{2} \mathrm{O}$ at $77^{\circ} \mathrm{K}$ were studicd as a function of dose (Co60 $\gamma$-irradiation). It was found that the signal due to all radicals produced increased linearly with dose up to a dose of $6.1 \times 10^{18} \mathrm{ev}\left(5 \times 10^{4} \mathrm{R}\right)$. In a $2 \%$ sample $\left(\mathrm{H}_{2} \mathrm{O}\right)$ the $G$ value for all radicals was $G=0.035$. This includes the $\bullet O H$ trapped in the ice lattice. The ESR spectrum of the irradiated sample is shown in Figure 9A. It consists of the hydroxyl radical spectrum dill tlat produced by electron attachment to the DNA. No hydrogen atoms are observed in the sample. Warming the sample to where the $\cdot \mathrm{OH}$ becomes mobile $\left(130^{\circ} \mathrm{K}\right)$ and reacts with the DNA results in a decrease in radical concentration to $1 / 5$ the original concentration (see Figure 9B). Further warming to $180^{\circ} \mathrm{K}$ results in protonation of the thymidine anions to produce the "thymyl" radical spectrum (Figure 9C). The thymyl radical represents ca. $3 \%$ of the total radical concentration at this point. Further warming $\left(200^{\circ} \mathrm{K}\right)$ results in a decrease in the signal of other radical species; however, the thymyl radical remains constant (Figure 9D). The concentration

$$
\text { AI-AEC- } 12974
$$




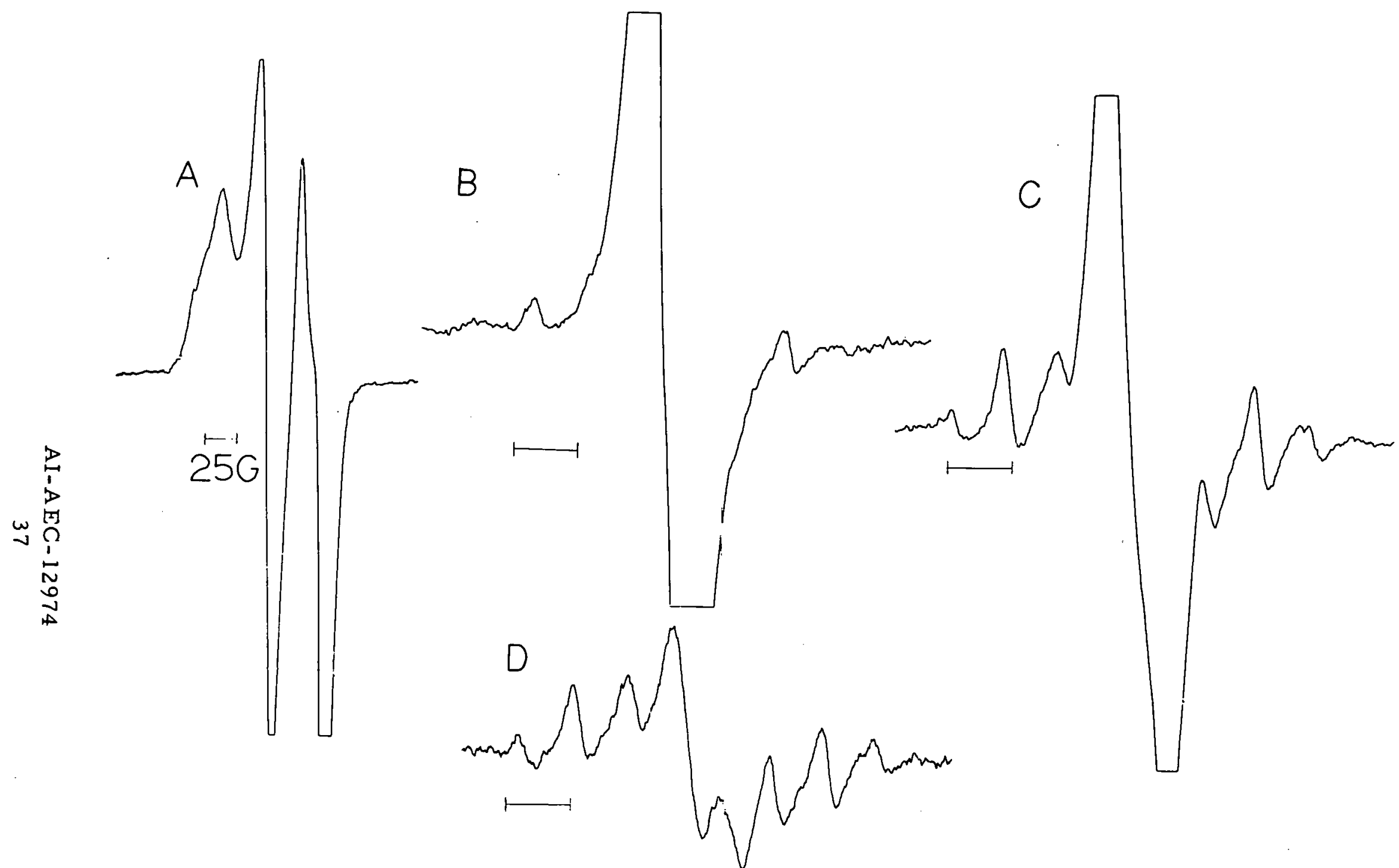

Figure 9. ESR spectra of the radiolysis of a frozen aqueous solution of DNA at $77^{\circ} \mathrm{K}$. A. Spectrum immediately after radiolys is showing the predominant hydroxyl radical signal. B. Spectrum after warming to $130^{\circ} \mathrm{K}$ where the hydroxyl radical attacks the DNA. C. Spectrum after warming to $180^{\circ} \mathrm{K}$ where the thymidine anions protonate. D. Spectrum after warming to $200^{\circ} \mathrm{K}$. 
of thymyl radical at this point is $25 \%$ of the total radical concentration.

The results show that the $\cdot \mathrm{OH}$ attack produces radicals which are largely "annealed" as the temperature increases. The fact that no $\mathrm{H}$-atoms were present after radiolysis shows that the subsequent appearance of the "thymyl" radical spectrum is due to protonation of the thymidine anion not $\mathrm{H}$-atom attack. These experiments therefore give good evidence that it is the electron produced in the radiolysis which results in the "thymyl" radical spectrum. 


\section{REFERENCES}

1. C. Helene, R. Santus, P. Douzou, Photochem. Photobiology 5, 127 (1966)

2. R. G. Shulman and R. O. Rahn, J. Chem. Phys. 45, 2940 (1966)

3. J. W. Longworth, R. O. Rahn and R. G. Shulman, J. Chem. Phys. 45, $2930(1966)$

4. Phosphorescence due to single ionized thymine is reported at lower $\mathrm{pH}^{\prime} \mathrm{s}$ in much lower intensity (ref. 2,3 )

5. J. N. Herak and V. Galogaza, J. Chem. Phys. 50, 3101 (1969)

6a. M. D. Sevilla, J. Phys. Chem. 74, 669 (1970)

b. M. D. Sevilla, J. Phys. Chem. 74, 2096 (1970)

7. This luw concentration should prevent appreciable aggregation.

8. M. J. Blandemer, L. Shields and M. C. R. Symons, Nature, 199, $902(1963)$

9. P. B. Ayscough, R. G. Collins and F. S. Dainton, Nature, 205, $965(1965)$

10. This species is a trianion. It is probably stabilized by the large number of available counter ions and the low temperature.

11. R. A. Holroyd and J. W. Glass, Int. J. Rad. Biol. 14, 445 (1968)

12. M. D. Sevilla, results in preparation for publication.

13. There is an interfering signal which increases the amplitude of the component at $g_{\perp}$. 
14. N. Edelstein, A. Kwok and A. H. Maki, J. Chem. Phys. 41, 179 (1964)

15. F. J. Adrian, J. Chem. Phys. 36, 1692 (1962)

16. This relation is exact only at $\theta=0$ and $\pi / 2$. An exact solution for all angles $\theta$ has been found (R. Nieman and D. Kivelson, J. Chem. Phys. 35, 156 (1961)). This solution, of course, results in the same relations at $\theta=0$ and $\pi / 2$.

17. P. W. Atkins and M. C. R. Symons, "The Structure of Inorganic Radicals," Elsevier Publishing Co., New York, 1967, pp 268-271.

18. The magnitude of $A_{\perp}$ is assumed to be less than one-half the linewidth.

19. M. D. Sevilla, J. Phys. Chem. 74, 805 (1970)

20a. A. Streitwieser, "Molecular Orbital Theory for Organic Chemists," John Wiley and Sons, Inc., New York, N. Y., 1962

b. G. Vincow in "Radical Tons," E. T. Kaiser and L. Kevañ, Ed. Interscience, New York, N. Y., 1968

21. C. L. Talcott and R. J. Meyers, Mol. Phys., 12, 549 (1967)

22. H. C. Heller and T. Cole, Proc. Natl.Acad. Sci. 54, 1486 (1965)

23. M. G. Ormerod, Int. J. Rad. Biol. 9, 291 (1965)

24. J. Hütterman, Int. J. Rad. Biol. 17, 249 (1970)

25. J. Hütterman, Private Communication 
26. L. S. Myers, J. F. Ward, W. T. Tsukamoto, D. E. Holmes and J. R. Julca, Science, 148, 1234 (1965).

27. L. S. Myers, J. F. Ward, W. T. Tsukamoto and D. E. Holmes, Nature, 208, 1086 (1965).

28. R. W. Fessenden, J. Phys. Chem., in press and private communication.

29. J. P. Elliot, Proc. Roy. Soc. A302, 361 (1968).

30. P. S. Pershan, R. C. Shulman, B. J. Wyluda and J. Eisinger, Physics 1, 163 (1964).

31. W. Gordy, B. Pruden and W. Snipes, Proc. Nat. Acad. Sciences, 53, $917(1965)$.

32. A. Ehrenberg, A. Rupprecht and G. Strom, Science 157, 1317 (1967). 


\section{PUBLICATIONS AND PRESENTATIONS}

(Dec. 1966 to June 1970)

A. The following papers have been published

1. D. E. Holmes, R. B. Ingalls and L. S. Myers, Jr., "An ESR

Study of Free Radicals Formed by Reaction of Nucleotides and

Their Constituents with Hydrogen Atoms", International J. Rad. Biol., 12, 415 (1967).

2. D.E.Holmes, R. B. Ingalls and L. S. Myers, Jr., "ESR Spectra of Free Radicals Induced in Pyrimidines, Purines and Related Analogs by Exposure to Hydrogen Atoms", International J. Rad. Biol., 13, 225 (1968).

3. R. A. Holroyd and J. W. Glass, "Radicals Formed by Electron Transfer to Pyrimidine Derivatives", International J. Rad. Biol., 14, 445 (1968).

4. R. A. Holroyd and J. W. Glass, "The Reaction of Hydrogen Atoms with DNA", Radiation Research, 39, 758 (1969).

5. M. D. Sevilla, "An Electron Spin Resonance Study of Several Purine and Pyrimidine Radical Anions", J. Phys. Chem., 74, 805 (1970).

6. M. D. Sevilla, "An Electrun Spin Resonance Study of Acetatc Dianion and Acetamide Anion", J. Phys. Chem., 74, 669 (1970).

7. M. D. Sevilla, "Radicals Formed by Reaction of Electrons with Amino Acids in an Alkaline Glass", J. Phys. Chem., 74, 2096, (1970). 
B. The following papers have been accepted for publication

1. R. A. Holroyd, J. W. Glass and P. Riesz, "Radicals Formed

in Proteins by Reaction with Hydrogen Atoms", Radiation

Research.

2. M. D. Sevilla, "Radicals Formed by Electron Attachment to Peptides", Journal of Physical Chemistry.

C. The following paper is to be submitted for publication

1. M. D. Sevilla, "An ESR Study of the Photoionization of Thymine:

The Thymine Cation and Anion Radicals".

D. The following presentations were made

1. R. B. Ingalls, L. S. Myers, Jr., D. E. Holmes and J. W. Glass, "An ESR Study of Reactions of 1,3-dideutero-uracil and 1.3- . dideutero-5-bromouracil with Hydrogen Atoms", at 15 th Annual Meeting of Radiation Research Society, San Juan, Puerto Rico.

2. R. A. Holroyd and J. W. Glass, "Reaction of Hydrogen Atoms... with DNA and Nucleoproteins", at the 16th Annual Meeting of Radiation Research Society, Houston, Texas, April (1968).

3. R. A. Holroyd, "Radiation Chemistry of Chromosomes", at Univ. of Calif. at Los Angeles, Feb. 25, 1969.

4. R. A. Holroyd, "Radiation Chemistry of Chromosomes", at University of Oklahoma, April 11, 1969.

5. M. D. Sevilla, "The Reactions of Electrons with Amino Acids and Dipeptides", at 158th Meeting of ACS, Sept. 1969.

6. M. D. Sevilla, "Electron Reactions with Peptides", at the Laboratory of Nuclear Medicine and Radiation Biology, U. C. L. A. Nov. 1969. 
7. M. D. Sevilla, "Radicals Formed by Electron Attachment to Amino Acids", at the Department of Chemistry, San Diego State College, March 1970.

8. M. D. Sevilla, "Radicals Formed by Electron Attachment to Amino Acids and Peptides", at the Department of Chemistry, Oakland University, May (1970). 
Repriated from Radiation Research, Volume 39, No. 3, September 1969 Copyright (C) 1969 by Academic Press, Inc. Printed in U.S.A.

RADIATION RESEARCH 39, 758-769 (1969)

\title{
The Reaction of Hydrogen Atoms with DNA'
}

\author{
RICHARD A. HOLROYD AND JOSEPH W. GLASS \\ Atomics International, Division of North American Rockwell Corporation, \\ Canoga Park, California
}

\begin{abstract}
Holroyd, R. A., and Glass, J. W. The Reaction of Hydrogen Atoms with DNA. Radiation Res. 39, 758-769 (1969).

The reactions of hydrogen atoms with samples of calf and salmon deoxyribonucleic acid (DNA) have been investigated by an electron spin resonance technique. The reactions with component DNA nucleotides and deoxyribose were also investigated to aid in the interpretation of the DNA results. Analysis of the resultant ESR spectra was facilitated by use of a computer spectrum simulation technique. The results showed that hydrogen atoms react mainly by addition to purine (49\%) and thymine (23\%) base groups in DNA. The extent of attack on each base is roughly in proportion to the percentage of the base present in DNA. This result is in contrast to radiolysis where preferential attack on the thymine base occurs. Approximately $20 \%$ of the hydrogen atoms react with the deoxyribose groups in the backbone of the DNA molecule. The presence of histones in the samples is shown to inhibit hydrogen atom addition. It is expected that the presence of histones in vivo will protect DNA from hydrogen atom attack during radiolysis.
\end{abstract}

\section{INTRODUCTION}

This study of the reactions of hydrogen atoms with DNA was done for the purpose of evaluating the role of hydrogen atoms in the radiolysis of DNA. In vivo, DNA molecules in chromosomes of cells are subject to attack during radiolysis by radicals formed both from water molecules and from other parts of the chromosomes. There is a small but significant yield of hydrogen atoms from the radiolysis of water $(G \sim 0.6)(1)$. In addition, hydrogen atoms may result from direct interaction of the radiation with the chromosomes. Hydrogen atoms have been detected by ESR techniques in samples of gamma irradiated DNA $(2,3)$.

1 This work was supported by the Division of Biology and Medicine of the U.S. Atomic Energy Commission. 
Previous ESR investigations of the reactions of hydrogen atoms with DNA have not identified the site or sites of attack. An ESR study of the reaction of hydrogen atoms with calf-thymus DNA yielded a spectrum devoid of hyperfine structure, in particular, there was no evidence of formation of a radical on thymine (4). In another study, ESR spectra were obtained which showed about five, wide hyperfine lines spread over 76 gauss for salmon sperm DNA and a broad singlet for $E^{\prime}$. coli DNA (5). The reaction of hydrogen atoms with the closely related acid IRNA has been studied at $77^{\circ} \mathrm{K}(6)$. An ESR spectrum was obtained which was interpreted as indicating that hydrogen atoms add to purine and pyrimidine rings. Investigations of DNA nucleotides have shown that hydrogen atoms add primarily to the purine and pyrimidine rings $(7,8)$ but some reaction with the deoxyribose constituent has been suggested.

In this study, dry samples of DNA were bombarded with hydrogen atomis at $300^{\circ} \mathrm{K}$. Stable radicals were thereby formed and the ESIR spectra showed considerable hyperfine structure. These spectra were interpreted in terms of the various radicals formed in DNA. This requircd first investigating the reactions of hydrogen atoms with the four DNA nucleotides (TMP, DGMP, DAMP, and DCMP) and deoxyribose. The radical sites formed in each DNA nucleotide were characterized as well as possible on the basis of the ESIR spectra. The composite spectrum obtained with DNA was assumed to be the envelope of the spectra obtained for the various nucleotides. By means of a computer spectra simulation techniciue (9), it was possible to determine the relative amount of each type of radical present in the bombarded DNA sample.

\section{EXPEIRIMENTAL}

Samples of DNA, DNA nucleotides and deoxyribose were obtained commercially from Calbiochem and Worthington. Analysis of the samples by the liolin phenol method (10) showed that all samples of salmon sperm DNA contained less than $.5 \%$ protein whereas the calf thymus samples contained about $2 \%$ protein.

For the reaction with hydrogen atoms, the biological samples were placed in short pieces of quartz tubing $(\mathrm{OD}=4 \mathrm{~mm})$ and quartz wool was used to hold the samples in place. These tubes were then placed in a larger quartz tube passing through the ESR cavity. This tube was evacuated and then filled with flowing hydrogen gas. Hydrogen atoms were produced in the flowing hydrogen stream by a microwave discharge. The pressure in the discharge region was about 0.1 Torr. Ions were screened out magnetically and direct photolysis of the sumples by the light from the discharge did not occur.

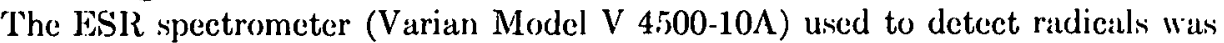
equipped with $100 \mathrm{kc} / \mathrm{sec}$ ficld modulation unit. $\Lambda$ TE $\mathrm{E}_{102}$ mode cavity was employed which permitted placing the samples in the cavity.

To facilitate the interpretation of ESIR spectra, and to verify assignments of 
radical species, a computer spectra simulation technique was employed (9). Frequently, an observed spectrum consisted of a superposition of those of several radical species. To identify all the radicals and to determine the percentage of each radical present, the spectra of the individual radicals were first calculated based on assumed hyperfine splittings and a particular line shape. Then the spectra of the radicals were combined in various proportions. A "best fit" to the experimental spectrum was selected and differences between calculated and experimental curves were used to improve on the initial combination. Continued repetition of this procedure often led to a determination of the number and nature of all radical species present.

\section{RESULTS AND DISCUSSION}

Deoxyribose. Deoxyribose was investigated since the backbone of the DNA polymer is made up of alternating deoxyribose and phosphate groups. Further, it had been suggested in a recent study $(8)$ that hydrogen atoms attack the deoxyribose group in DNA nucleolides as well as the purine and pyrimidine rings. A more detailed study of this reaction was made in hopes that the ESR spectra would provide some information about the nature of the radicals formed.

The reaction of hydrogen atoms with deoxyribose was found to give a five-lined ESR spectrum (Fig. 1). The same spectrum was obtained when deuterium atoms were used in place of hydrogen atoms, which suggests that the radical is formed by hydrogen atoin abstraction. A similar spectrum has been observed in the gamma-

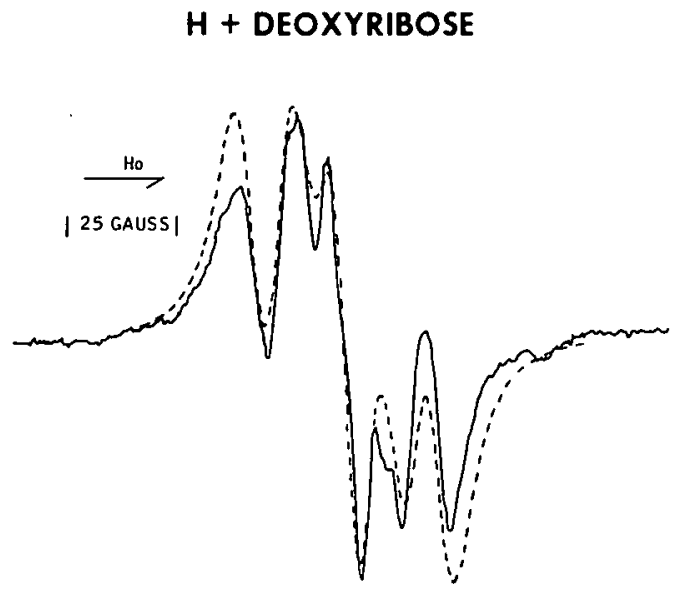

Fua. 1. Spectrum obyained on reastion of hydrogen aloms with deoxyribose. Solid line is experimental spectrum, recorded with a modulation of 1.5 gauss. Dotted curve is computed spect rum eomsisting $60 \%$ of radical I and $40 \%$ of a 19 -ganss donble1; lines are assumed to be Jorentzian and $\mathrm{X}$-ganss wide. 
radiolysis of deoxyribose (11). From changes in the intensities of various lines upon standing after bombardment, it was concluded that the spectrum was due to at least two radicals. One of the radicals (Type I) gave a 21 -gauss triplet and the other (Type IIa) was responsible for the two lines separated by 19 gauss. A computer generated spectrum, consisting $60 \%$ of Type I and $40 \%$ of Type IIa was (dotted curve in Fig. 1) consistent with the experimental spectrum.

Since deoxyribose in the crystalline state is in the pyranose (six-membered ring) structure (12), the reaction of hydrogen atoms with deoxyribose-5-phosphate which has the furanose (five-membered ring) structure was also invesligated. This would be expected to be more representative of DN $\Lambda$ since the deoxyribose in nucleotides is also a five-membered ring. The ESR spectrum (Fig. 2) which resulted in this case showed very little fine structure and positive identification of the radicals was not possible. However, as in the case of deoxyribose, the spectrum is not very wide and no large splittings are present (see following paragraph). It was found that the spectrum could be simulated (Fig. 2) by assuming that it consisted of $15 \%$ of a 21-gauss triplet (Type I), $70 \%$ of a 14-gauss doublet (Type IIb), and $15 \%$ of a singlet in the center of the spectrum. Thus, most of the radicals formed in this case are similar to those formed in deoxyribose but there is much less of the Type I radicals which lead to the 21 -gauss triplet spectrum.

The spectra observed for deoxyribose and deoxyribose-5-phosphate are attributed

\section{H + DEOXYRIBOSE PHOSPHATE}

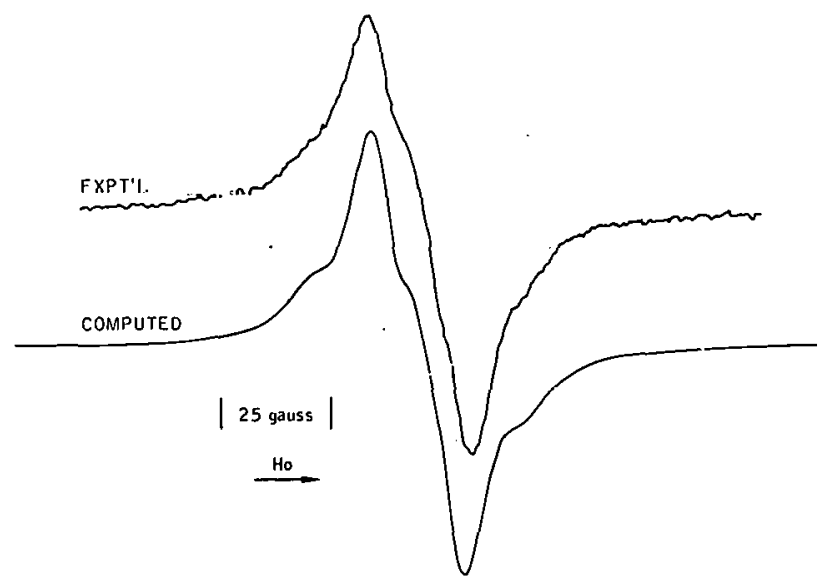

FIg. 2. Spectrum obtained on reaction of hydrogen atoms with deoxyribose-5-phosphate. Upper curve is experimental recorded with a modulation of 1.0 gauss. Lower curve is simulated spectrum consisting $15 \%$ of Type I, $70 \%$ of Type IIb, and $15 \%$ of a central line displaced 1 gauss upfield; lines for the three types are assumed to be 9,10 , and 9 gauss wide, respectively. 
to radicals resulting from ring rupture. The basis of this conclusion is as follows: Abstraction of a hydrogen atom from any position would lead to a radical with $\beta$ hydrogens. It is known that $\beta$-hydrogens in five and six-membered rings can give large splittings for example 35 and 41 gauss in cyclopentyl (13) and cyclohexyl (13) and 39 gauss in glucose (14). Such large splittings are not observed here and it is suggested that ring opening occurs following $\mathrm{H}$-atom abstraction. Such carboncarbon bond cleavage has been suggested to occur in straight-chain sugars following radical attack (14). The triplet spectra observed for deoxyribose may be due to a terminal radical of structure $\mathrm{CH}_{2} \mathrm{OR}$. Such a radical could be formed, for example, by cleavage of the $\mathrm{C}_{4}-\mathrm{C}_{5}$ bond following abstraction of a hydrogen atom from the $\dot{\mathrm{C}}_{4}$ position. Plausible structures of the radicals which result in the doublet ESR spectra are not obvious but ring opening may be involved here too.

DNA Nucleotides. The reaction of hydrogen atoms with thymidine- $5^{\prime}$-phosphate (TMP) at $25^{\circ} \mathrm{C}$ leads to an eight-lined spectrum of 131 -gauss total width (Fig. 3). The major lines in this spectrum are attributed to a substituted thymyl radical (Type III) formed by $\mathrm{H}$-atom addition to $\mathrm{C}_{6}(7)$. In addition to this radical, other radicals must be present since there are additional lines in the center of the spectrum

$$
H+T M P
$$

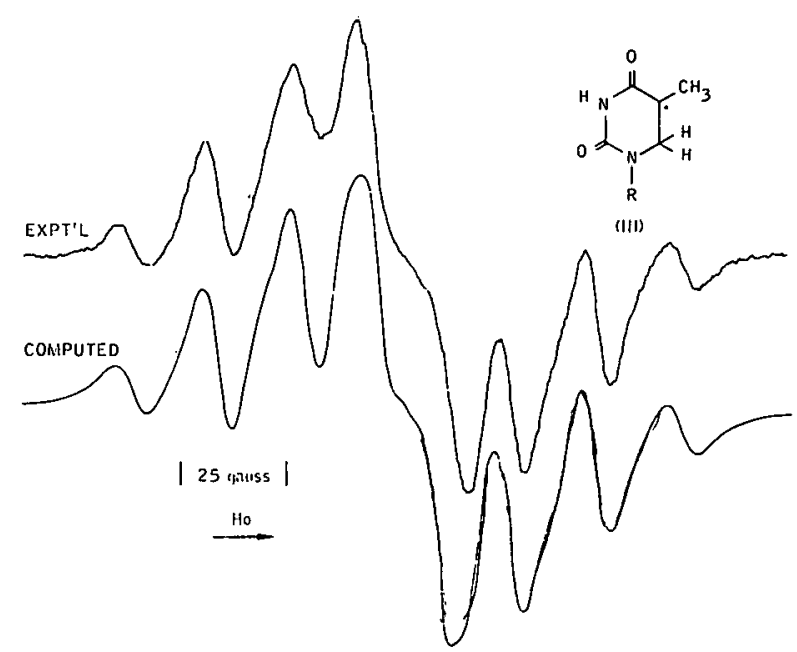

FIG. 3. Spectrum obtained on reaction of hydrogen atoms with TMP at $25^{\circ} \mathrm{C}$. Upper curve is experimental recorded with a modulation of 3 gauss. Lower curve is computer simulated spectrum for $22 \%$ of sugar radical I, $22 \%$ of sugar radical $\mathrm{IIb}$, and $56 \%$ of the thymine radical III. Lines are Lorentzian and 9,10 , and 8 gauss wide, respectively. 
$(7,8)$. It has been suggested that these central lines are due to deoxyribose radicals $(8)$.

To analyze the spectrum shown in Fig. 3, it was assumed that thymyl radicals (Type III) as well as deoxyribose radicals (Type I and IIb) were present. In the thymyl radical, the unpaired spin interacts with the hydrogens in the methyl group at $\mathrm{C}_{5}$ and with the two protons at $\mathrm{C}_{6}$. The best match to the positions of the lines was obtained for splittings of $a_{\mathrm{CH}_{2}}{ }^{\mathrm{H}}=20.3$ gauss and $a_{6}{ }^{\mathrm{H}}=32$ and 38 gauss. A previous study $(7)$ indicated that $a_{\mathrm{OH}}{ }^{\mathrm{H}}=20.5$ and $a_{6}{ }^{\mathrm{H}}=38$ for this radical at $77^{\circ} \mathrm{K}$. The spectrum of this thymyl radical (Type III) was mixed with varying proportions of the spectra of the dcoxyribose radicals (Types 1 and IIb) by the computer simuation program until a match of the experimental spectrum for TMP was obtained. The best fit (Fig. 3) contained $56 \%$ of the Type III thymyl radical, $22 \%$ of Type I, and $22 \%$ of Type $\mathrm{IIb}$ deoxyribose radicals. The large percentage of deoxyribose radicals is somewhat surprising since in a one-to-one mixture of thymine and deoxyribuse, only thymine radicals were formed. Further, the rate constant for hydrogen atom addition to thymine should be comparable to, or greater than, the rate constant for addition to uracil and the latter is reported to be 136 times greater than the rate constant for reaction with deoxyribose (15). Apparently the 5 -membered deoxyribose ring in TMP is more reactive than deoxyribose itself.

The ESR spectrum obtained when hydrogen atoms reacted with deoxyguanosine$5^{\prime}$-phosphate (DGMP) at $25^{\circ} \mathrm{C}$ is shown in Fig. 4 . This spectrum has been attributed to a radical ( $\mathrm{T} y$ pe IV) formed by hydrogen atom addition to the $\mathrm{C}_{8}$ position in the guanine ring $(\gamma, 8)$ and the free spin is located mainly at $\lambda_{7}$. The main lines in the spectrum constitute a $1: 2: 1$ triplet due to the two protons at the $\mathrm{C}_{8}$ position for which $a_{8}{ }^{\mathrm{H}}=36.5$ gauss. The shoulders which are most apparent on the central peak are attributed to nitrogen splittings. The nitrogen splitting is anisotropic and varies from 1.j to 21 gauss depending on the angle betwcen the magnetic field and the molecular plane (16). In a powdered sample, all orientations are possible and the resultant spectrā is an overlup of many spectra. Intcnoity ic found to he strongenit at magnetic field positions near $A_{\|}$and $A_{.1}$ and lines \pm 21.5 and \pm 1.5 gauss from the center would be expected. Because of the line width only the larger splitting is observed and accounts for the shoulders on each side of the main triplet lines in the observed spectrum (Fig. 4). The asymmetry in the spectrum is due to a difference in $\mathrm{g}_{\perp}$ and $a_{\|}$which amounts to $2 \times 10^{-3}$.

No effort was made to estimate the extent of attack on deoxyribose in this nucleotide because the sugar radicals have lines in the central portion of the spectrum and would thus be masked by the central lines of the spectrum of the guanine radical. The computer program GLAD was used to "curve fit" the experimental spectrum. The resulting computed spectrum (Fig. 4) simulated the experimental one reasonably well and therefore provided an analytical description of the DGMIP spectrum which could be used in the computer program to interpret the DNA results. 


$$
H+d G M P
$$

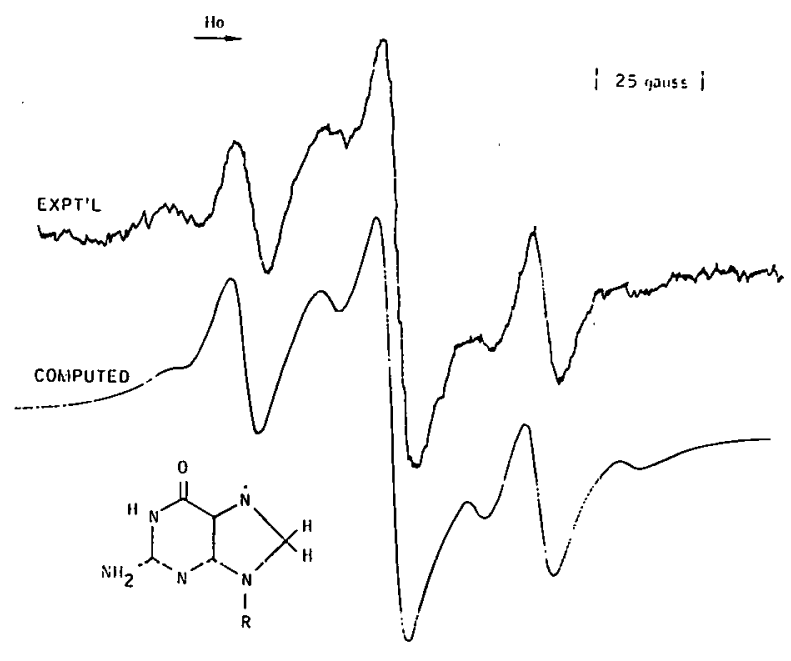

iv)

Fig. 4. Spectrum obtained on reaction of $\mathrm{H}$-atoms with DGMP. Lpper curve is experimental recorded at 3 -gauss modulation. Lower curve is a computer simulated spect rum consisting $36 \%$ of a 36 -gauss triplet, $3.7 \%$ of a sextet corresponding to the shoulders on the main lines and $80 \%$ of a singlec al $y=2.004$.

The reaction of hydrogen atoms with deoxyadenosine- $\bar{s}^{\prime}$-phosphate (DAMIP) at room temperature led to an ESR spectrum similar to that shown in Fig. 4 for DGMP. The three lines of the triplet were present as well as shoulders, which could be attributed to the nitrogen splittings. Since hydrogen atoms add to the fivemembered ring of the purine base in both nucleotides $(8)$ and since the structure of this ring is identical in both, similar spectra would be expected. In the analysis of the DNA spectra (see below), the DAMP and DGMIP spectra are taken to be identical.

The reaction of hydrogen atoms with deoxycytidine- $5^{\prime}$-phosphate (DCMP) resulted in an ESR spectrum consisting of six broad lines (Fig. 5). After termination of the hydrogen atom reaction, the spectrum changed; the outer four lines decayed relative to the central component (doublet). Thus, two radicals are formed in the reaction. The principal radical (Type $\mathrm{V}$ ) is one in which hydrogen atoms add to the 5,6 double bond in the cytosine ring $(7,8)$. In this radical, splittings are to be expected from the hydrogens at the $\mathrm{C}_{5}$ and $\mathrm{C}_{6}$ positions. Values of $a_{\mathrm{CH}}{ }^{\mathrm{H}}=21$ and $a_{\mathrm{CH}_{2}}{ }^{\mathrm{H}}=12.5$ and 50 gauss have been reported (7). In this work, it was found that values of $a_{\mathrm{CH}}{ }^{\mathrm{H}}=19$ and $a_{\mathrm{CH}_{2}}{ }^{\mathrm{H}}=19$ and 41 gauss gave a satisfactory fit to the line positions in the spectra. The nature of the radical responsible for the doublet spectrum is not known. Such doublets have been observed in hydrogen atom bom- 


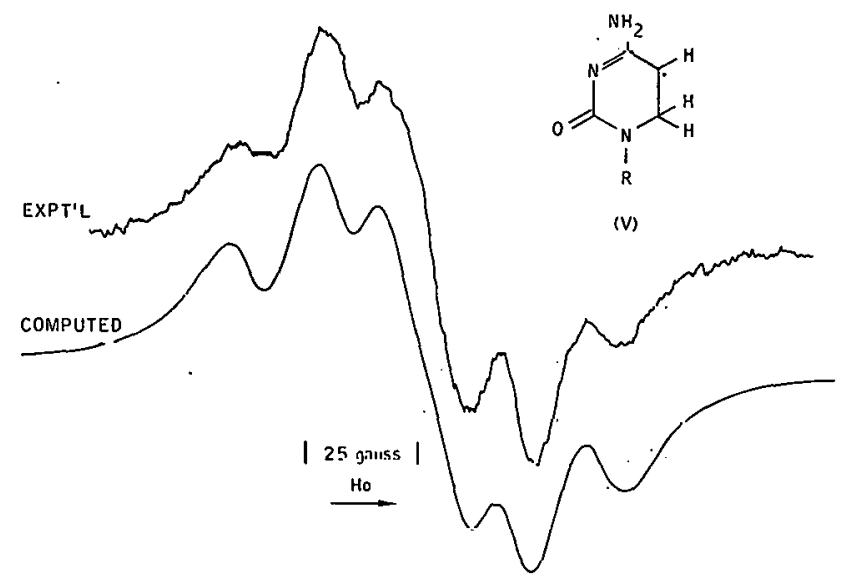

Fig. 5. Spectrum obtained for reaction of hydrogen atoms with DCMF. Upper curve is experimental recorded at 3.7-gauss modulation. Lower curve is a simulated spectrum in which radicals present are assumed to be $65 \%$ Type $\mathrm{V}$ and $35 \%$ of the radical giving the 15 -gauss doublet; lines are 14-gauss wide.

bardment $(7)$ as well as in the radiolysis $(17,18)$ of cytosine containing compounds. It was found possible to simulate the experimental spectrum by combining $65 \%$ of the spectrum of the Type $\mathrm{V}$ radicals with $35 \%$ of the 15 gauss doublet spectrum (Fig. 5).

$D N A$. The reaction of hydrogen atoms with salmon sperm DNA resulted in an ESR spectrum consisting of 11 hyperfine lines spread over 133 gauss (Fig. 6). During a 30-minute reaction, the number of radicals increased but there was no change in the ESR spectra. The same spectrum was obtained for samples of salmon sporm DNA nbtained from various commercial sources and for samples which had been subjected to prior vacuum drying at $60^{\circ} \mathrm{C}$. Samples of calf spleen and calf marrow DNA, when reacted with hydrogen atoms, gave ESR spectra essentially identical to that shown in Fig. 6. This is to be expected since the chemical composition and nucleic acid base ratio of calf DNA is comparable to that of salmon sperm. Samples of calf thymus DNA, on the other hand, gave an ESR spectrum in which the hyperfine lines were discernible only as shoulders on a broad signal. The poor resolution in this case was attributed in part to the presence of a small amount of protein (2\%) (see below) as well as to the physical nature of the sample. ${ }^{2}$

${ }^{2}$ It was generally found that the samples which reacted rapidly yielded better resolved spectra. Presumably the more reactive samples were of higher surface area which allowed more of the sample to be exposed to the hydrogen atom flux. In samples of lower surface area, the radicals are more likely to be formed closer together and line broadening can occur by spinspin interaction. 


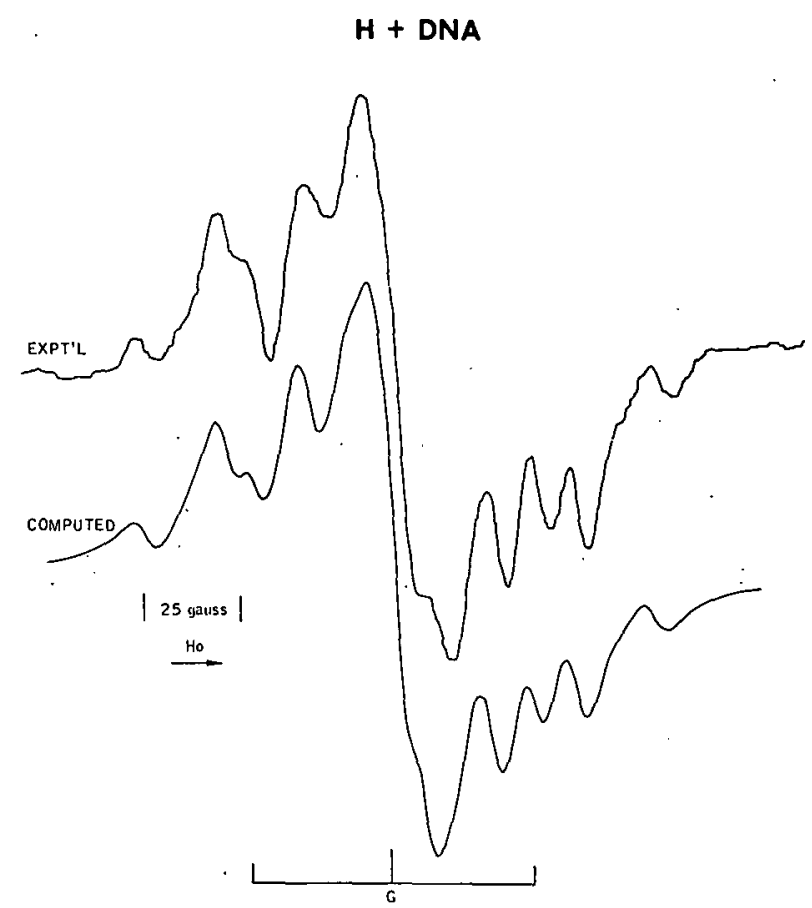

FIG. 6. Spectrum obtained by reaction of hydrogen atoms with salmon sperm DNA at $25^{\circ} \mathrm{C}$. Upper curve is experimental recorded at 3.7-gauss modulation. Lower curve is a computed spectrum for which radicals are $9 \%$ Type I, $9 \%$ Type IIb, $23 \%$ Typc III, 19\% Type IV, and $10 \%$ Type V.

The effect of histone impurities on the reaction of hydrogen atoms with DNA was investigated. Histones are intimately associated with DNA in vivo and thus are likely to be present as impurities in isolated DNA samples. For nucleohistone samples, which contain considerable histone (about $60 \%$ ), the ESR spectrum was similar to that obtained with pure histone indicating no attack on the DNA. The spectrum obtained on reaction of hydrogen atoms with histone is a 17-gauss doublet (19) very much like that obtained in the radiolysis of proteins (20, 21). To elucidate the effect of histones synthetic mixtures containing varying amounts of histone and DNA were prepared. These were prepared by lyophilization of solutions containing the appropriate amounts of salmon sperm DNA and nucleohistone. In the reaction of hydrogen atoms with a sample containing $30 \%$ protein, the characteristic hyperfine lines of the DNA spectrum were observed during the first few minutes of the reaction but continued bombardment resulted in a broad "singlet" with weak shoulders at the positions of the hyperfine lines in the DNA spectrum. The ESR spectrum obtained for a synthetic sample containing $3 \%$ histone showed the hyper- 
fine lines of the DNA spectrum but the lines were not as well resolved as in Fig. 6 . This effect of protein impurities in obscuring the resultant ESR spectrum is attributed to preferential reaction of hydrogen atoms with the protein component. It is suggested, on the basis of these results, that the histone which coats the DNA in cells in vivo will protect the DNA from hydrogen atom attack during radiolysis.

The percentage of radicals on each base and sugar group in the DNA sample after hydrogen atom bombardment was estimated from the ESR spectrum in Fig. 6 as follows. Radicals located on the individual nucleotides in DNA were assumed to give rise to the ESR spectra obtained for the nucleotides (Figs. 3, 4, and 5). These spectra were then added together in various proportions by means of the GLAD computer program. $\Lambda$ key to the analysis of the DN $\Lambda$ spcetrum is the intensity of thc outer lines relative to the total spectrum. Since these outer lines are due to a radical on a thymine ring, the contribution of this radical (Type III) to the tota] can be determined quite accurately. Another characteristic feature of the spectrum is the presence of the guanine triplet due to radicals of Type IV. (lines marked G in Fig. 6). The percentage of radicals on DGMP was adjusted to match the intensity of these lines. A trial synthetic spectrum generated by adding $46 \%$ of the spectrum obtained with TMP to $54 \%$ of the spectrum obtained for DGMP gave a satisfactory fit to the experimental spectrum. However, it is reasonable to expect some reaction to occur with DCMP as well. Therefore, varying amounts of the spectrum obtained for DCMP (Fig. 5) were added to the trial fit. The addition of $10 \%$ of this spectrum to the trial spectrum did not change it a great deal perhaps because of the nearly featureless spectrum observed for DCMP. Addition of more than $15 \%$ of the DCMP spectrum, however, began to markedly diminish the intensities of the outer lines of the TMP spectrum and those of DGMP. It is, therefore, estimated that no more than $10 \%$ of the radicals are cytosine radicals.

The final "best fit" synthetic spectrum (lower line, Fig. 6) consisted $41 \%$ of the spootrum obtained for TMP, $49 \%$ of the spectrum obtained for DGMP, and $10 \%$ of the spectrum obtained for DCMP. This simulation reproduces reasonably well the intensities of the TMP and DGMP lines, indicating that the percentages of radicals on thymine and guanine are correct. Particularly significant is the fact that the overall asymmetry of the spectrum is reproduced. This is due to a difference in $g$-values for the radicals involved. For the carbon radical in TMP, $g=2.0032$ (22), and for the nitrogen radical in DGMP, $g=2.0040$ (16). This difference amounts to a 1.3-gauss difference in centers of the two radicals and accounts for the asymmetry.

The final analysis indicated that $82 \%$ of the radicals formed are on base groups and $18 \%$ are on deoxyribose groups. Of the base radicals, $23 \%$ are on thymine and $49 \%$ are on purines. (Since the spectra obtained with DGMP and DAMP were not distinguishable, it was not possible to assess the relative amounts on each purine base.) Approximately $10 \%$ of the radicals were formed on cytosine bases. The attack 
on the purine and pyrimidine bases is nearly in proportion to their abundances in DNA, since in salmon and calf DNA the bases are $29 \%$ thymine, $21 \%$ cytosine, and $50 \%$ purines. Thus, although hydrogen atoms are selective in that reaction with the nucleic acid bases is more important than backbone attack, they add indiscriminately to the various bases.

The use of deuterium atoms in place of hydrogen atoms verified the fact that most of the radicals were formed by addition. The ESR spectrum obtained on reaction of $\mathrm{D}$ atoms with DNA was not as wide as the spectrum obtained with hydrogen atoms. This is expected if radicals are formed by addition as is the case for bases since a large hydrogen atom splitting is replaced by a smaller deuterium atom splitting. For deoxyribose, similar spectra are expected for deuterium and hydrogen atom reactions. A simulated spectrum obtained by assuming that the same percentages of radicals were present as determined for hydrogen atoms but with the appropriate proton splittings replaced by D-atom splittings was in reasonable agreement with the experimental curve. This provided further support to the validity of the analysis.

Conclusion. The importance of hydrogen atoms in the radiolysis of DNA can be evaluated by comparing the present results to ESR studies of the direct radiolysis of DNA. It has been shown by several workers that a principal radical formed in the radiolysis of DNA is the thymyl radical $(11,29-26)$ specifically no evidence of purine or cytosine radicals has been obtained. By contrast, this work shows that hydrogen atoms are unselective to the extent that they add nearly randomly to all the nucleic acid bases in DNA and only $23 \%$ of them alter thymine bases. The unique formation of the thymine radical observed in radiolysis must be attributed to some other reaction. A plausible mechanism of thymine radical formation in the radiolysis of DNA is suggester (27) to be localization of the electron on thymine bases followed by protonation of the thymine anion.

\section{ACKNOWLEDGMENTS}

We express our appreciation to R. B. Ingalls, D. E. Holmes, and L. S. Myers, Jr., whose interest and continued encouragement provided the stimulus for this study. Also, we would like to thank D. Kivelson and M. Sevilla for their aid in interpretation of the ESR spectra, and M. L. Hollis for carrying out the protein analysis.

Received: February 3, 1969

\section{REFERENCES}

1. M. Anbar, In "Fundamental Processes in Radiation Chemistry," (P. Ausloos, ed.), Wiley, N. Y. (1968).

2. A. Muller and H. Dentinger, The Formation of Hydrogen Atoms in the $\gamma$-irradiation of Bacteriophage and DNA. Z. Nalurforschung 23b, 83-89 (1968).

3. D. E. Holmes and J. J. Weiss, Formation and Reaction of Hydrogen $\Lambda$ toms in Gamuairradiated Deoxyribonucleic Acid Gels. Internatl. J. Radiat. Biol. 14, 187-191 (1968).

4. H. C. Heller and T. Cole, The Reaction of Hydrogen Atoms with Thymine and DNA. Proc. Natl. Acad. Sci. 54, 1486-1490 (1965). 
ש. D. E. Holmes, Rerctions of Hydrogen Atoms and Hydroxyl Free Radicals will Nuclcic Acids, Nucleic Acid Constituents and Constituent Analogs. UCLA thesis (1966).

6. J. N. Herak and W. Gordy, Hydrogen Addition Radicals on RNA and the Nucleic-Acid Bases at $77^{\circ} \mathrm{K}$. Proc. Nall. Acad. Sci. 55, 1373-1378 (1966).

7. J. N. HeraK and W. Gordy, ESR Study of Nucleosides and Nucleotides Bombarded with Hydrogen Atoms. Proc. Nall. Acud. Sci. 56, 7-11 (1966).

8. D.E. Holmes, R. B. Ingalls and L. S. MYers, JR., An ESR Study of Free Radicale Formed by Reaction of Nucleotides and their Constiluents with Hydrogen Atnms. Intern. $J$. Radiat. Biol. 12, 415-126 (1967).

9. K. W. Medeiros and W. A. Young, "GLAD," AEC report No. AMTD-177 (1962).

10. O. H. Lowry, N. J. Rosebnovail, A. L. Far.r and R. J. Randald, Protein Measurement With the Folin Phenol Reagent. J. Biol. Chem. 193, 265-275 (1951).

11. A. Muller, The Formation of Radicals in Nucleic Acids, Nucleoproteins, and their Constituents by Ionizing Radiation. Progress in Biophysics and Mol. Biol. 17, 101-147 (1967).

12. S. Furuera, The Structure of 2-Deoxyribose. Acta Chemica Scandinavica 14, 1357-1363 (1960).

13. R. W. Fessenden and R. H. Schuler, Electron Spin Resonance of Transient Alkyl Radicals. J. Chem. Phys. 39, 2147-2195 (1963).

14. P. J. Baugh, O. Hinojosa and J. C. Arthur, Jr., An Electron Spin Resonance Study of Intermediates Induced in Carbohydrates by Titanium Trichloride-Hydrogen Peroxide. J. Phys. Chem. 71, 1135-1137 (1968).

15. G. Scholes and M. Simic, Reactivity of Hydrogen Atoms Produced in the Radiolysis of Aqueous Systems. J. Phys. Chem. 68, 1738-1743 (1964).

16. C. Alexander, Jr, and W. Gordy, Electron Spin Resonance of an Irradiated Single Crystal of Guanine Hydrochloride Dihydrate. Proc. Nall. Acad. Sci. 58, 1279-1285 (1967)

17. H. Dertinger, Free Radicals in Irradiated Single-Crystals of Purine Nucleosides: Adenosine, Deoxyadenosine and Deoxyguanosine. Zeitschrift fur Naturforschung 22b, 1261$1266(1967)$.

18. J. B. Cook, J. P. Elliots and S. J. WYaRd, Electron Spin Resonance of an Irradiated Single Crystal of Cytosine. Mol. Phys. 13, 49-64 (1967).

19. R. A. Holroyd and J. W. Glass, to be published.

20. P. Riesz, F. H. WhITE, Jr. and H. Kon, Free Rudical Distribution in the ral Radinlysis of Dry Ribonuclease. .I. Am. Chem. Soc. 88, 872-877 (1966).

21. W. Gordy, W. B. Ard and H. Shizlds, Microwave Spectroscopy of Biolugical Substances. I. Paramagnetic Resonance in $\mathrm{x}$-irradiated Amino Acids and Proteins. Proc. Nall. Acad. Sci. 41, 983 (1955).

22. B. Pruden, W. Snipes and W. Gordy, Electron Spin Resonance of an Irradiated Single Crystal of Thymidine. Proc. Nall. Acad. Sci. 53, 917-923 (1965).

23. P. S. Pershan, R. G. Shulman, B. J. Wy luda and J. Eisinger, Electron Spin Resonance of Irradiated DNA. Physics 1, 163-182 (1964).

24. M. G. Ormerod, Free Radical Formation in Irradiated Deoxyribonucleic Acid. Intern. J. Radiat. Biol. 9, 291-306 (1965)

25. A. Ehrenuerg, A. Rupprecht and G. Strom, Electron Spin Resonance of Gamma-Irradiated Oriented DNA Prepared by Wet Spinning. Science 157, 1317-1319 (1967).

26. J. P. ElliotT, Electron Spin Resonance Spectroscopy of Irradiated DNA. Proc. Royal Soc. A302, 361-365 (1968).

27. R. A. Holroyd and J. W. Guass, Radicals Formed by Electron Transfer to Pyrimidine Derivatives. Intern. J. Radial. Biol. 14, 445-454 (1968). 


\title{
An Electron Spin Resonance Study of Several Purine and
}

\author{
Pyrimidine Radical Anions ${ }^{1}$
}

\author{
by Michael D. Sevilla \\ Atomica International Divioion of North American Rockwell Corp., Canoga Park, California 91504 \\ (Received Augut 14, 1989)
}

\begin{abstract}
Electron spin resonance spectra of purine, 6-cyanopurine, pyrimidine, and 5-methylpyrimidine anions were obtained during electrolysis in dimethylformamide solution at low temperature. These spectra were analyzed and reduced to hyperfine splitting constants. Analysis of the spectrum of the 5-methylpyrimidine anion aided in the complete assignment of splittings to positions on the pyrimidine structure. Interpretation of the spectrum of 6-cyanopurine enabled the assignment of the largest splitting to the 6 position on the purine structure. McLachlan SCF-MO calculations were performed for comparison to experiment and as an aid in the assignment of the remaining hyperfine splittings to molecular positions on the purines. For the purines the splittings and assignments are: purine $A_{z}^{\mathrm{N}}=4.4 \pm 0.3 \mathrm{G}, A_{6}^{\mathrm{B}}=10.4 \pm 0.2, \mathrm{~A}_{8}^{\mathrm{B}}=4.4 \pm 0.3, A_{2}^{\mathrm{B}}=1.8, A_{\mathrm{i}(0)^{\mathrm{N}}}=1.2$; 6-cyanopurine $A_{1}{ }^{\mathrm{N}}=2.43 \pm 0.03 \mathrm{G}, A_{2(2)} \mathrm{B}=0.18 \pm 0.02, A_{2}{ }^{\mathrm{N}}=3.81 \pm 0.05, A_{7(2)} \mathrm{N}=0.74 \pm 0.02, A_{8} \mathrm{~B}$ $=4.14 \pm 0.05, A_{9(7)^{\mathrm{N}}}=0.99 \pm 0.02, A_{11^{\mathrm{N}}}=1.55 \pm 0.02$. Good agreement between the magnitudes of the calculated and experimental hyperfine splittings is found for each anion. An aromatized dimer anion, 5,5'-dimethyl-2,2'-bipyrimidine -, is identified as a product of prolonged electrolysis of 5-methylpyrimidine.
\end{abstract}

The radical anions of nitrogen heterocycles have been the subject of numerous investigations by electron spin resonance (esr) spectroscopy. ${ }^{2 a, b, 0, d}$ These investigations have provided improved relations between spin density and the nitrogen hyperfine splittings as well as refined nitrogen coulomb and resonance parameters for use in molecular orbital calculations of the spin density. Past work has also shown that certain anions of nitmgen heterocycles dimerize when prepared by alkali metal reduction. ${ }^{8 \rightarrow}$ The dimerization is often followed by aromatization (loss of hydrogen to form an aromatic system). Dimerization has also been suggested to occur during electrolysis of both pyridine and pyrimidine. However, with this technique aromatization of the dimer has not been reported.
In this work the anions of pyrimidine, 5-methylpyrimidine, purine, and 6-cyanopurine (Figure 1) produced by low-temperature electrolysis in dimethylformamide have been investigated by esr spectroscopy. The anion of pyrimidine has been previously investigated in liquid

(1) This research was supported by the United States Atomic Encrey Commission under Contract No. AT (04-3)-701.

(2) See the following and references therein: (a) J. C. M. Henning J. Chem. Phys., 44, 2139 (1966); (b) C. L. Talcott and R. J. Myers, Mol. Phys, 12, 549 (1967); (c) D. H. Geske and G. R. Padmanabhan, Mol. Phys., 12, 549 (1967); (c) D. H. Geske and G. R. Padmanabhan,
$J$. Amer. Chem. Soc., 87, 1651 (1965); (d) T. Kubota, K. Niahikida, J. Amer. Chem. Soc., 87, 1651 (1965); (d) T. Kubota, K. N
H. Miyazaki, K. Iratani, and Y. Oishi, ibid., 90, 5080 (1968).

(3) J. Chaudhuri, B. Kume, J. Jagur-Grodzinski, and M. Bswarc, ibid., 90,6421 (1968).

(4) R. L. Ward, ibid., 83, 3623 (1961).

(5) A. Carrington and J. dos Santos Veiga, Mol. Phys., 5, 21 (1962). 
A<smiles>C#Cc1cncnc1</smiles>

B

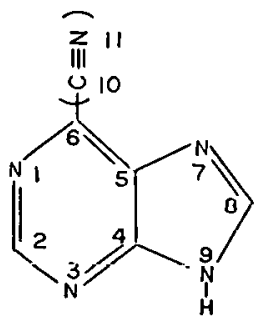

Figure 1. The structure and numbering scheme for the molecules in this study. A. Pyrimidine (5-methylpyrimidine). B. Purine (6-cyanopurine) shown as the $9 \mathrm{H}$ tautomer. The numbering scheme for $5,5^{\prime}$-dimethyl-2,2'-bipyrimidine is based on that of 5-methylpyrimidine.

ammonia; however, this paper reports results which provide for a more complete assignment of splittings. An esr study of the purine anion has not been reported previously. The results found here should aid in the description of the electronic structure of this biologically significant. molecule. Finally, strong evidence is found for dimerization and aromatization of the 5methylpyrimidine anion.

\section{Experimental Section}

Materials. Reagent grade dimethylformamide was dried and purified by shaking with potassium hydroxide, then with calcium hydride, and finally by vacuum distilling.

Compounds used for anion generation and their sources were: purine, Waldhof and Aldrich; 6-cyanopurine, Waldhof and Cyclo Chem. Co.; pyrimidine, Aldrich Chem. and Cyclo Chem. Co.; 5-methylpyrimidine, Schwarz Bioresearch. Pyrimidine was purified by gas chromatography: The other compounds were used without further purification.

Electrolytic Generation of Anions. Anions studied in this work were produced by electrolysis. The electrochemical cell used was similar to that used by previous workers. $^{2 \mathrm{~s}, 6}$ A tungsten electrode sealed in a 3-mm capillary acted as the cathode. A thin platinum plate acted as the anode. A fritted glass disk separated the cathode and anode. The cell was filled with a $0.1 \mathrm{M}$ solution of the supporting electrolyte, $n$-tetrabutylammonium iodide, in dimethylformamide. Typically the concentration of the substance to be reduced was from 1 to $5 \mathrm{mM}$. To purge oxygen from the cell the solution was "bubbled" with argon, evacuated, and filled with nitrogen.

The voltage used in electrogeneration of anions was varied for adequate signal with the lowest possible voltage. Voltages used varied from 3.5 to $10 \mathrm{~V}$. The temperature at which electrolysis took place was varied between -55 and $25^{\circ}$. At lower temperatures a drop in ion current took place. This was often more than compensated for by increased radical lifetime. Also at

lower temperatures the concentration of solute can often be increased while maintaining resolution.

A Varian V4510 esr spectrometer equipped with a Fieldial.magnetic field regulator, $100-\mathrm{kc}$ modulation, 6-in. ring shim magnet, and a dual cavity was utilized in this work. Measurements of hyperfine splittings werc made vs. Fremy's salt whose spacings were taken as 12.97 and 13.03 G. Esr spectra were reconstructed for comparison to experiment by use of the Gold program. ${ }^{7}$

The experimental hyperfine splitting $\left(A_{\text {exp }}\right)$ in $\mathrm{G}$ is related to the radical $g$ value $\left(g_{\mathrm{mol}}\right)$ by the relation $A_{\text {exp }}=g_{\mathrm{o}} / g_{\text {mol }} A_{\text {true. }}$. No attempt was made in this work to obtain accurate $g$ values. However, $g$ values for the moleculca rcported herein are within the range 2.002 to 2.005; thus the dcviation of the experimental hyperfine splitting from the true value is negligible.

\section{Results and Discussion}

Pyrimidine Anion. Electrolysis of a $3 \times 10^{-2} M$ solution of pyrimidine in dimethylformamide at $-55^{\circ}$ yielded a well-resolved spectrum of the pyrimidine anion (Figure 2). This spectrum differs slightly from that previously reported by Talcott and Myers. ${ }^{2 b}$ They. obtained the anion by electrolysis in liquid ammonia and found that the largest hydrogen splitting was a multiple of the nitrogen splitting. In dimethylformamide this condition was not found. We therefore have been able to make an unequivocal determination of these splittings which verifies the conclusions of Talcott and Myers. The results of the spectral analysis are reported in Table I along with those previously reported. The differences between the two results are small but beyond the limits of error and must therefore be attributable to a solvent effect.

Since the 9.54-G splitting arises from two equivalent protons and the 3.34-G splitting arises from two equivalent nitrogens they may be unequivocally assigned to the 4,6 and 1,3 positions, respectively. The smaller splittings have been assigned by analysis of the spectrum of 5-methylpyrimidine.

Continued electrolysis of $10^{-2} M$ solutions of pyrimidine in DMF at $-30^{\circ}$ resulted in a secondary spectrum. The spectrum consisted of 15 broad lines each separated by approximately $1.5 \mathrm{G}$. The same esr spectrum was found by reaction of a tetrahydrofuran solution of pyrimidine with a potassium mirror at room temperature. ${ }^{8}$ Due to the reported occurrence of aromatized dimer anions for similar molecules and the results found for 5-methylpyrimidine (see below), it is possible that this spectrum is due to a "dimer" anion or

(6) C. P. Poole Jr., "Electron Spin Resonance," Interscience Publisherg, New York, N. Y., 1967, p 620.

(7) W. A. Young, J. A ppl. Phy8., 35, 460 (1964).

(8) However, a more complex spectrum has been previously reported as the product of alkali metal reduction. See R. L. Ward, $J$. Amer. Chem. Soc., 84, 332 (1962). 
Table I: Experimental Hyperfine Splittings for the

Pyrimidine and Purine Anions

\begin{tabular}{|c|c|c|c|}
\hline Anion & Position" & Bplitting, $\mathrm{O}$ & $T,{ }^{\circ} \mathrm{C}$ \\
\hline \multirow[t]{4}{*}{ Pyrimidine } & $1(\mathrm{~N})$ & $3.34 \pm 0.01(3.26)^{b}$ & -55 \\
\hline & $2(\mathrm{H})$ & $0.72 \pm 0.01(0.72)^{b}$ & \\
\hline & $4(\mathrm{H})$ & $9.54 \pm 0.03(9.78)^{b}$ & \\
\hline & $5(\mathrm{H})$ & $1.24 \pm 0.01(1.31)^{\mathrm{b}}$ & \\
\hline \multirow[t]{4}{*}{ 5-Methylpyrimidine } & $1(\mathrm{~N})$ & $3.34 \pm 0.02$ & -58 \\
\hline & $2(\mathrm{H})$ & $0.67 \pm 0.02$ & \\
\hline & $4(\mathrm{H})$ & $9.26 \pm 0.03$ & \\
\hline & $5\left(\mathrm{CH}_{2}\right)$ & $1.56 \pm 0.02$ & \\
\hline \multirow{3}{*}{$\begin{array}{l}\text { 5,5'-Dimethyl-2,2'- } \\
\text { bipyrimidine }\end{array}$} & $1(\mathrm{~N})$ & $1.92 \pm 0.01$ & -24 \\
\hline & \multirow{2}{*}{$\begin{array}{l}4(\mathrm{H}) \\
5\left(\mathrm{CH}_{2}\right)\end{array}$} & $<0.14$ & \\
\hline & & $3.19 \pm 0.01$ & \\
\hline \multirow[t]{5}{*}{ Purine } & $3 \quad(\mathrm{~N})$ & $4.4 \pm 0.3$ & -55 \\
\hline & (H) & $10.4 \pm 0.2$ & \\
\hline & (H) & $4.4 \pm 0.3$ & \\
\hline & $2 \quad(\mathrm{H})$ & $(1.85)^{e}$ & \\
\hline & $1(9)(N)^{d}$ & $(1.25)^{c}$ & \\
\hline \multirow[t]{7}{*}{ 6-Cyanopurine } & $1 \quad(\mathrm{~N})$ & $2.43 \pm 0.03$ & 25 \\
\hline & $2(9)(H)^{d}$ & $0.18 \pm 0.02$ & \\
\hline & $3 \quad(\mathrm{~N})$ & $3.81 \pm 0.05$ & \\
\hline & $7(9)(N)^{d}$ & $0.74 \pm 0.02$ & \\
\hline & $8 \quad$ (H) & $4.14 \pm 0.05$ & \\
\hline & $9(7)(N)^{d}$ & $0.99 \pm 0.02$ & \\
\hline & $11 \quad(\mathrm{~N})$ & $1.55 \pm 0.02$ & \\
\hline
\end{tabular}

- For equivalent positions see Figure 1. ${ }^{6}$ Liquid ammonis solvent (ref $2 \mathrm{~b}$ ). ' $c$ Line components from these splittings are not completely resolved. The splittings were inferred from spectrum simulation. Numbers in parenthesis refer to possible sites for this splitting.

a mixture of "dimer" anions. A possible "dimer," $2,2^{\prime}$ bipyrimidine anion, has been previously reported;"2o however, this spectrum does not correspond to that found here.

5-Methylpyrimidine Anion. The anion of 5-methylpyrimidine was investigated to aid in the assignment of splittings to positions in the pyrimidine anion. The spectrum of 5-methylpyrimidine anion prepared by electrolysis of a $2 \times 10^{-3} \mathrm{M}$ solution at $-55^{\circ}$ is depicted in Figure 3. A straightforward analysis of the spectrum gave the hyperfine splittings reported in Table I.

From the results for the 5-methylpyrimidine anion it can be seen that the methyl group has replaced the proton of 1.24-G splitting in pyrimidine. The possibility that the proton of $0.7-\mathrm{G}$ splitting has been replaced and that the 1.24-G spliiting has been reduced to $0.67 \mathrm{G}$ is considered unlikely owing to the small effect of the methyl group on the larger splittings and the correspondence of the magnitude of the smaller splittings in 5-methylpyrimidine and pyrimidine. The smaller splittings in pyrimidine have therefore been assigned accordingly. The assignment of splittings to positions for 5methylpyrimidine is, of course, unequivocal.

Upon prolonged electrolysis of $10^{-2} M$. solutions of 5methylpyrimidine at temperatures greater than $-30^{\circ}$

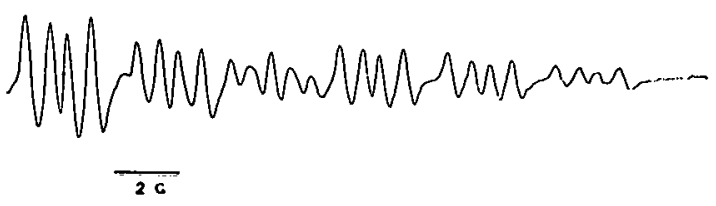

Figure 2. Approximately one-half the first derivative esr spectrum of pyrimidine anion in dimethylformamide at

$-55^{\circ}$. (Dot marks center.)

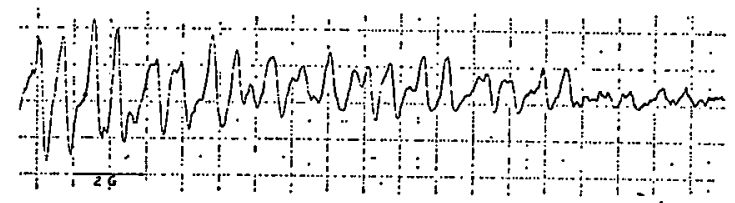

Figure 3. Approximately one-half the first derivative esr spectrum of 5-methylpyrimidine anion in dimethylformamide at $-58^{\circ}$.
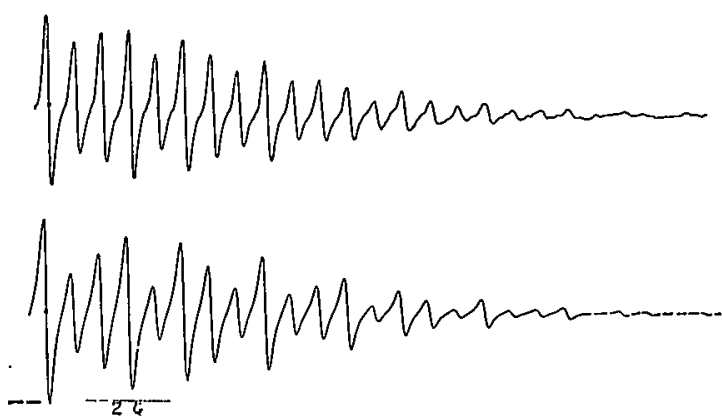

Figure 4. Upper curve, approximately one-half the first derivative esr spectrum of $5,5^{\prime}$-dimethyl-2,2'-bipyrimidine at $-24^{\circ}$; lower curve, calculated spectrum using a $3.19-\mathrm{G}$ splitting arising from 6 hydrogens and a 1.92-G splitting arising from 4 nitrogens. The line width for the computed spectrum is slightly larger than the experimental.

a secondary spectrum appeared (Figure 4). The spectrum extends over $30 \mathrm{G}$ and the intensity is sufficient to resolve all line components except for the end component (as interpreted). This always leads to some uncertainty in the interpretation, but several factors indicate that the spectrum is due to an aromatized anion. First, the spacing, regularity, and intensity ratios indicate a large number of equivalent protons such as would be found for two equivalent methyl groups. Second, the fact that this spectrum appeared at higher concentrations of 5-methylpyrimidine and only after prolonged electrolysis is consistent with "dimer" formation. Of the several possible aromatized dimers of 5-methylpyrimidine the only one that could yield such a regular spectrum is $5,5^{\prime}$-dimethyl $2,2^{\prime}$-bipyrimidine. Analysis of the spectrum on the basis of this structure yielded the splittings reported in Table I. The splitting due to the four meta protons is not resolved 
and is therefore less than the line width (ca. $0.14 \mathrm{G}$ ). A spectrum computed on the basis of this analysis is shown in Figure 4. The good fit between theory and experiment is considered strong evidence for a $2,2^{\prime}$ dimer.

The preferential observance of the $2,2^{\prime}$ aromatized dimer is most likely explained by the fact that dimerization at the 4 position to produce $2,4^{\prime}$ or $4,4^{\prime}$ dimers is less likely due to steric interactions. Also, even if such species are formed and subsequently aromatized they would have many more hyperfine components than the $2,2^{\prime}$ anion and therefore would be more difficult to observe.

Purine. Purine anion was formed by electrolysis of $0.001 M$ solutions of purine at temperatures between -34 and $-55^{\circ}$. The esr spectrum observed for this radical is only moderately resolved, $\Delta H_{\mathrm{ms}} \cong 0.9 \mathrm{G}$ (Figure 5). The large line width is most likely a result of unresolved hyperfine splittings. There is also evidence for a second radical species, present in lower concentrations, in the spectrum. It is possible that the second radical is associated with one of the two possible tautomeric forms of purine, i.e., the hydrogen can be at the 7 or 9 position. Analysis of the spectrum in Figure 5 yields 10.4 and $4.4-G$ splittings due to one proton each and a 4.4-G nitrogen splitting. Owing to the poor resolution the two 4.4-G splittings could differ by as much as $0.6 \mathrm{G}$ and still not be resolved. Two smaller splittings of approximately $1.8 \mathrm{G}$ (proton) and $1.2 \mathrm{G}$ (nitrogen) are inferred from analysis of the end portion of the spectrum. These splittings account for only 5 of the 8 possible. The remaining three splittings must be less in magnitude than the line width, $0.9 \mathrm{G}$. A computer reconstruction using the above splittings is shown in Figure 5. The excellent agreement between the experimental and theoretical spectra suggests that the analysis is correct. Assignment of the splittings to positions on the purine molecule is not possible from the experimental results, since all positions on the purine molecule are unequivalent. The splittings have therefore been assigned where possible by recourse to McLachlan SCF-MO theory (discussed below) as shown in Table I.

6-Cyanopurine. The anion of 6-cyanopurine was prepared to aid in the analysis of the purine anion spectrum and to confirm the assignment by theory of the 10.4-G splitting to the 6 position. This compound was chosen since the cyano group has been shown to have a relatively small electron withdrawing effect, ${ }^{\circ}$ i.e., in electron withdrawing power $\mathrm{CN}<\mathrm{COOCH}_{8}<\mathrm{COCH}_{3}$ $<\mathrm{CHO}<\mathrm{NO}_{2}$. It is therefore reasonable to assume for the case of 6-cyanopurine anion that the cyano group will have only a modest effect on the spin density distribution.

The spectrum of 6-cyanopurine was observed from -50 to $+25^{\circ}$. Best resolution occurred at $25^{\circ}$ (Figure 6). Analysis of this spectrum is complicated due to

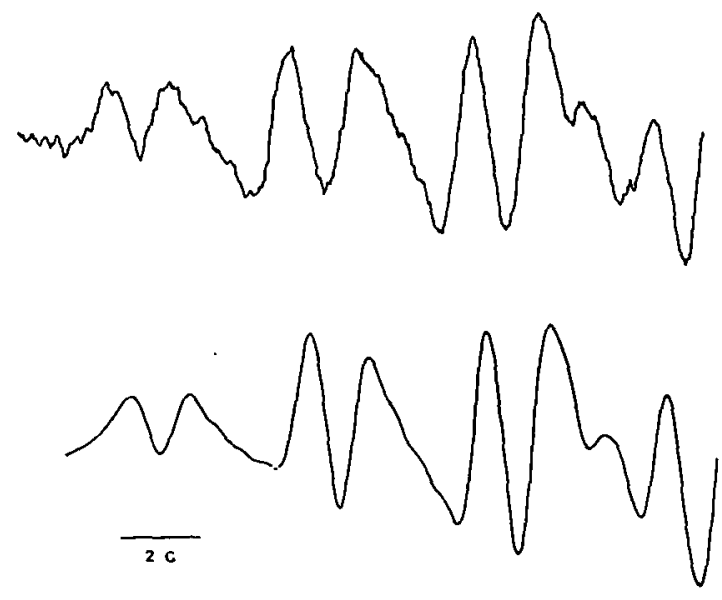

Figure 5. Upper curve, one-half the first derivative esr spectrum of purine anion at $-55^{\circ}$; lower curve, calculated spectrum using 10.4, 4.4, and 1.85-G splittings arising from one hydrogen each as well as 4.4 and $1.25-G$ splittings arising from one nitrogen each $\left(\Delta H_{\mathrm{ms}}=0.9 \mathrm{G}\right)$.

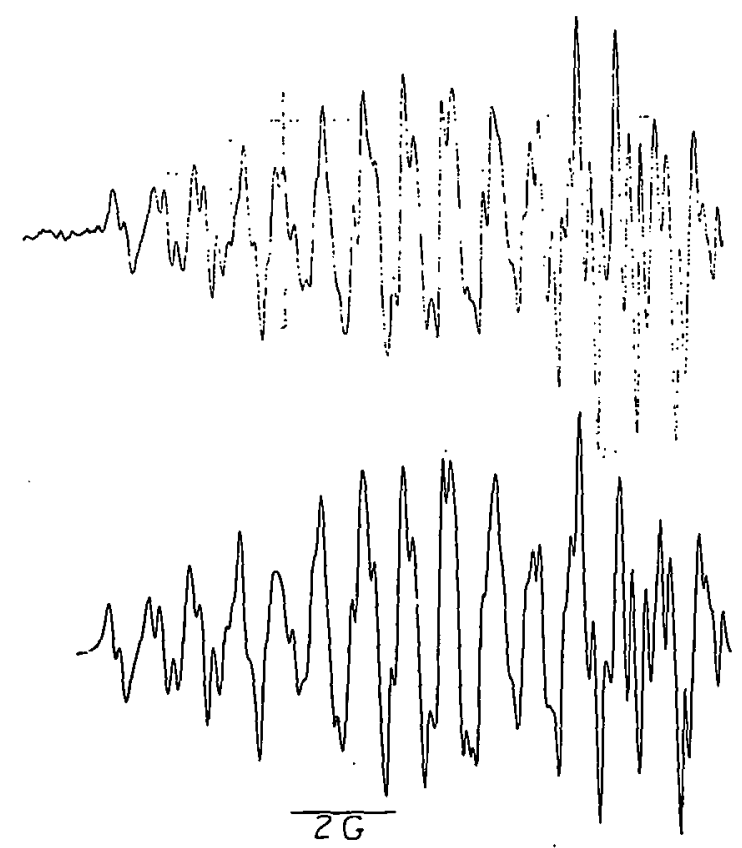

Figure 6. Upper curve; one-half of the experimental esr spectrum of 6 -cyanopurine anion at $25^{\circ} ;$ - lower curve, computer simulated spectrum using hyperfine parameters discussed in text.

the fact that all positions on the molecule are unequivalent. In addition there are both nitrogen and hydrogen splittings, and there are a large number of theoretical

(9) M. Hirayama and T. Isobe, Bull. Chem. Soc. Jap., 41, 1502 (1968).

The Journal of Phyeical Chemietry

$\mathrm{AI}-\mathrm{AEC}-12974$ 
hyperfine lines. Interpretation of the spectrum proceeded by examination of the end portion of the spectrum. This yielded the splittings $0.18,0.74,0.99,1.55$, and $2.43 \mathrm{G}$. The spectrum shows that the Q18-G splitting is obviously a proton splitting. 'The other splittings were all shown to be due to nitrogens by spectrum simulation. The remaining larger splittings were determined to be $4.14 \mathrm{G}$ (proton) and $3.81 \mathrm{G}$ (nitrogen) by an inspection of the central portion of the spectrum and many computer simulations. The reconstruction of the 6-cyanopurine spectrum with the above splittings is shown in Figure 6 and is in excellent agreement with experiment. The hyperfine splittings clearly show that the proton of $10.4-G$ splitting in purine has been replaced by the cyano group in 6-cyanopurine. The remaining proton splitting unaccounted for in the analysis must be less in magnitude than the line width of $0.13 \mathrm{G}$.

As in the case of purine, 6-cyanopurine also has two possible tautomeric forms, $9 \mathrm{H}$ or $7 \mathrm{H}$. The clearly resolved spectrum for the anion shows that the concentration of one form is much greater than the other. Molecular orbital calculations performed for both of these possible species (see helow) are used to assign the hyperfine splittings to positions on the 6-cyanopurine structure where possible (see Table I).

\section{Spin Density Calculations}

McLachlan SCF-MO calculations ${ }^{10}$ have been performed for the radical anions in this study to aid in the assignment of experimental splittings to molecular positions, to compare experimental and theoretically calculated splittings, and possibly to indicate which of the tautomeric forms of the purine anions predominate. The heteroatom coulomb and resonance parameters and hyperconjugation parameters used in these calculations are given in Table II. The parameters for the aromatic nitrogen are considered to be the most critical to the calculation. The value of $h_{\mathrm{N}}$ was therefore varied between 0.4 and 1.0. The results are found to be relatively insensitive to the different values of $h_{\mathrm{N}}$ and no improvement in the overall agreement with experiment over that for $h_{\mathrm{N}}=0.8$ is found. The spin density calculations are reported in Table III. The comparison of theory with experiment is best accomplished by calculation of theoretical values of the hyperfine splittings. This requires relationships which relate spin density and isotopic hyperfine splitting. The relations $A_{\mathrm{H}}=Q_{\mathrm{C}-\mathrm{H}}{ }^{\mathrm{H}} \mathrm{CC}{ }^{*}$ $\left(Q_{\mathrm{HC}^{\mathrm{H}}}=-24.5\right)$ for $\mathrm{C}-\mathrm{H},{ }^{2 \mathrm{~b}} A_{\mathrm{N}}=Q_{\mathrm{N}}{ }^{\mathrm{N}} \rho_{\mathrm{N}}{ }^{*}+Q_{\mathrm{CN}^{N}}$ $\left(\rho \mathrm{C}^{*}+\rho_{\mathrm{C}^{\prime \prime}}\right)\left(Q_{\mathrm{N}}^{\mathrm{N}}=27.3, Q_{\mathrm{CN}^{\mathrm{N}}}=-1.7\right)$ for $\stackrel{\mathrm{C}^{\prime}}{\mathrm{C}}>\mathrm{N},{ }^{2 \mathrm{~b}}$ $A_{\mathrm{N}}=Q_{\mathrm{N}}{ }^{\mathrm{N}} \rho_{\mathrm{N}}{ }^{\mathrm{N}}+Q_{\mathrm{CN}}{ }^{\mathrm{N}} \rho_{\mathrm{C}}{ }^{\mathrm{N}}\left(Q_{\mathrm{N}}{ }^{\mathrm{N}}=23.1, Q_{\mathrm{CN}^{\mathrm{N}}}=-6.8\right)$ for $\mathrm{C}-\mathrm{C} \equiv \mathrm{N}, "$ and $A_{\mathrm{CH}_{1}}=217 \rho_{\mathrm{H}_{1}}{ }^{\prime}$ for $\mathrm{C}-\mathrm{CH}_{3}{ }^{12 \mathrm{a}, \mathrm{b}}$ have been employed with good results in similar mole-
Table II: MO Parameters Used in Calculations

\begin{tabular}{|c|c|c|}
\hline Group & Parameterg & Ref \\
\hline & $\begin{array}{l}h_{\mathrm{N}}=0.8 \\
k_{\mathrm{CN}}=1.08\end{array}$ & $2 b$ \\
\hline & $\begin{array}{l}h_{\mathrm{N}}=1.5 \\
k_{\mathrm{CN}}=1.0\end{array}$ & 18 \\
\hline $\mathrm{C}-\mathrm{C} \equiv \mathrm{N}$ & $\begin{array}{l}h_{\mathrm{N}}=1.0 \\
k_{\mathrm{C}-\mathrm{N}}=2.0 \\
k_{\mathrm{c}-\mathrm{C}}=0.9\end{array}$ & 11 \\
\hline $\mathrm{C}-\mathrm{C} \equiv \mathrm{H}_{\mathbf{a}}{ }^{a}$ & $\begin{array}{l}h_{\mathrm{H}_{1}}=-0.5 \\
h_{\mathrm{C}^{\prime}}=-0.1 \\
h_{\mathrm{C}-\mathrm{H}_{2}}=2.5 \\
h_{\mathrm{C}-\mathrm{C}^{\prime}}=0.93\end{array}$ & \\
\hline
\end{tabular}

a R. Bershon, J. Chem. Phys., 28, 1188 (1958).

cules and are used in the calculation of hyperfine splittings. These results are listed in Table III.

The results found for pyrimidine anion are in reasonable agreement with experiment and have been discussed elsewhere. ${ }^{2 b, 13}$ The calculated splittings for 5-methylpyrimidine are nearly identical with those calculated for pyrimidine discounting the methyl proton splitting. In agreement with theory the experimental results for these two anions show only a small effect of the methyl group. Methyl groups do not usually result in large shifts in spin density but such a small change is unusual. ${ }^{14}$ This can be understood from the form of the Huckel molecular orbital (HMO) occupied by the unpaired electron in pyrimidine. This MO has a node at position 5 where the methyl group is substituted and consequently the methyl group has no effect on the coefficients of this MO, but several of the MO's associated with other energy levels do not have a node at position 5 and thus are affected by the methyl group. Although the HMO spin densities are unaffected by the methyl group, the McLachlan spin densities are altered slightly since they

(10) D. A. McLachlan, Mol. Phys., 3, 233 (1960).

(11) P. H. Rieger and G. K. Fraenkel, J. Chem. Phys., 37, 2795 (1962).

(12) (a) D. Lazdins and M. Karplus, ibid., 44, 1600 (1966); (b) D. H. Levy, Mol. Phys., 10, 233 (1966).

(13) The calculated spin densities for pyrimidine reported here differ froin those reported by Talcott and Myers (ref 2b). The same parameters are employed in each calculation. The difference arises in the computation of the atom-atom polarizabilities. Important to the computation of the polarizabilities is a sum which is taken over the filled and vacant orbitals. The problem arises that for a radical one orbital is half-filled. In this work this orbital is included as part of orbital is halt-filled. In this work this orbital is included as part of the filled set as recommended by McLachlan (ref 10). Talcott and Myers include the half-filled orbital with the vacant set and achieve better agreement with experiment; however, the improvement in results is not found to extend to computations for purine and o-cysnopurine where these methods give similar results.

(14) J. A. Valenzuela and A. J. Bard, J. Phys. Chem., 73, 779 (1969). 
Table III : Theoretical Spin Densities and Hyperfine Splittings

\begin{tabular}{|c|c|c|c|c|c|c|}
\hline Anion & Position & \multicolumn{2}{|c|}{ McLachlan spin density } & \multicolumn{2}{|c|}{ 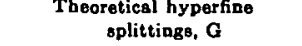 } & $\begin{array}{l}\text { Experinentistings } \mathrm{G} \\
\text { aphne }\end{array}$ \\
\hline \multirow{4}{*}{ Pyrimidine } & 1 & & 0.177 & & 4.23 & 3.34 \\
\hline & 2 & & -0.028 & & 0.69 & 0.72 \\
\hline & 4 & & 0.375 & & 9.20 & 9.54 \\
\hline & 5 & & -0.078 & & 1.91 & 1.24 \\
\hline \multirow[t]{6}{*}{ 5-Methylpyrimidine } & 1 & & 0.177 & & 4.23 & 3.34 \\
\hline & 2 & & -0.027 & & 0.66 & 0.67 \\
\hline & 4 & & 0.377 & & 9.24 & 9.26 \\
\hline & 5 & & -0.073 & & $\ldots$ & $\ldots$ \\
\hline & 7 & & -0.000 & & $\ldots$ & \\
\hline & 8 & & -0.0082 & & 1.78 & 1.56 \\
\hline \multirow{7}{*}{$\begin{array}{l}\text { 5,5'-Dimethyl-2,2'- } \\
\text { bipyrimidine }\end{array}$} & 1 & & 0.082 & & 1.91 & 1.92 \\
\hline & 2 & & 0.210 & & $\ldots$ & $\ldots$ \\
\hline & 4 & & -0.013 & & 0.32 & $<0.10$ \\
\hline & 5 & & 0.137 & & $\ldots$ & $\ldots$ \\
\hline & 7 & & -0.003 & & $\ldots$ & $\ldots$ \\
\hline & 8 & & 0.0180 & & 3.90 & 3.19 \\
\hline & & $9 \mathrm{H}$ & $7 \mathrm{H}$ & $9 \mathrm{H}$ & $7 \mathrm{H}$ & \\
\hline \multirow[t]{12}{*}{ Purine } & 1 & 0.048 & 0.082 & 0.49 & 1.63 & 1.2 \\
\hline & 2 & 0.048 & 0.013 & 1.18 & 0.32 & 1.8 \\
\hline & 3 & 0.162 & 0.156 & 4.22 & 4.06 & 4.4 \\
\hline & 4 & 0.070 & 0.112 & $\ldots$ & $\ldots$ & $\ldots$ \\
\hline & 5 & 0.007 & -0.034 & $\ldots$ & $\ldots$ & $\ldots$ \\
\hline & 6 & 0.436 & 0.391 & 10.68 & 9.59 & 10.4 \\
\hline & 7 & 0.017 & 0.022 & 0.07 & $0.19(\mathrm{~N})$ & $\ldots$ \\
\hline & & & & & $0.55(\mathrm{H})$ & \\
\hline & 8 & 0.220 & 0.274 & 5.38 & 6.72 & 4.4 \\
\hline & 9 & -0.009 & -0.018 & $0.64(\mathrm{~N})$ & & $(1.2)$ \\
\hline & & & & $0.22(\mathrm{H})$ & 1.09 & \\
\hline & & $9 \mathrm{H}$ & $7 \mathrm{H}$ & $9 \mathrm{H}$ & $7 \mathrm{H}$ & \\
\hline \multirow[t]{12}{*}{ 6-Cyanopurine } & 1 & 0.090 & p. 107 & 1.84 & 2.36 & 2.43 \\
\hline & 2 & 0.011 & -0.003 & 0.27 & 0.07 & $0.18(<0.13)$ \\
\hline & 3 & 0.152 & 0.153 & 3.99 & 4.00 & 3.81 \\
\hline & 4 & 0.081 & 0.112 & $\ldots$ & $\ldots$ & $\ldots$ \\
\hline & 5 & 0.030 & -0.005 & $\ldots$ & $\ldots$ & $\ldots$ \\
\hline & 6 & 0.353 & 0.329 & $\ldots$ & $\ldots$ & \\
\hline & 7 & 0.002 & 0.007 & 0.28 & $0.17(\mathrm{~N})$ & $0.74(0.99)(\mathrm{N})^{a}$ \\
\hline & & & & & U.18 (F) & \\
\hline & 8 & 0.172 & 0.217 & 4.22 & 5.31 & 4.14 \\
\hline & 9 & -0.010 & -0.018 & $\begin{array}{l}0.72(\mathrm{~N}) \\
0.25(\mathrm{HI})\end{array}$ & 1.05 & $\begin{array}{l}0.99(0.74)(\mathrm{N}) \\
<0.13(0.18)\end{array}$ \\
\hline & 10 & 0.032 & 0.027 & & & \\
\hline & 11 & 0.0872 & 0.0794 & 1.79 & 1.66 & 1.55 \\
\hline
\end{tabular}

are calculated using atom-atom polarizabilities which depend on the coefficients of all the molecular orbitals.

The steric interaction of the pyrimidine groups of 5,5'-dimethyl-2,2'-bipyrimidine is such that a nonplanar structure would be expected. For biphenyl, a molecule with a similar molecular structure but perhaps more steric interaction from its ortho hydrogens, the dihedral angle between the phenyl groups has been estimated to be approximately $40^{\circ} .16$ For this reason theoretical splittings for this 5-methylpyrimidine "dimer" have been calculated as a function of the angle between the two aromatic planes. The angle of twist has been simulated in the calculation by a reduction in the resonance integral between the carbon atoms joining the two rings. The relation $k^{*}=k \cos \theta$ describes the reduction in the resonance parameter $k$ with the angle of twist $\theta$ and has been both experimentally and theoretically justified. ${ }^{16}$ Results of the calculations showed that the methyl proton splitting is nearly invariant with angle while the nitrogen splitting is more sensitive. Best results are found at $k=0.8, \theta=37^{\circ}$. The results of this calculation are given in Table III. The uncertainty in the value of $\theta$ must be considered large due to the only moderate change in splitting with angle and the uncertainty in the calculation of the

(15) K. Mobius, Z. Naturforsch., 20a, 1117 (1965).

(16) M. D. Sevilla and G. Vincow, J. Phys. Chem., 72, 3647 (1968). 
nitrogen hyperfine splitting constant; however, the results clearly suggest that the anion is nomplanar. It should be noted that the good agreement between the calculated and experimental splittings is further evidence for the structure of this molecule and consequently the dimerization reaction.

The molecular orbital calculations for purine and 6-cyanopurine listed in Table III are especially important since they must be used to assign hyperfine splittings to molecular positions. Further, they may aid in the assignment of the correct tautomeric structure to the anions. ${ }^{17}$

The calculated hyperfine splittings for both the $7 \mathrm{H}$ and $9 \mathrm{H}$ tautomers of purine given in the table predict that positions $3(\mathrm{~N}), 6(\mathrm{H})$, and $8(\mathrm{H})$ are the positions of large splitting with the largest splitting arising from the 6 position. Since substitution of the cyano group at the 6 position of purine showed this position to be the site of the 10.4-G hydrogen splitting, the calculation is in agreement with experiment. The remaining larger splittings of $4.4 \mathrm{G}$ due to a nitrogen and a hydrogen can therefore be assigned to positions 3 and 8 with confidence. Closer examination of the calculated splittings shows that the calculation for the $9 \mathrm{H}$ tautomer is in much better agreement with the individual magnitudes of the larger splittings. The smaller splittings of $1.8 \mathrm{G}(\mathrm{H})$ and $1.2 \mathrm{G}(\mathrm{N})$ are also in better agreement with the calculation for the $9 \mathrm{H}$ tautomer and have been assigned accordingly. The improvement for the $9 \mathrm{H}$ calculation is sufficient to suggest that the $9 \mathrm{H}$. tautomer may be the anion species which predominates in the spectrum of purine anion.

The calculated hyperfine splittings for the 6-cyanopurine $7 \mathrm{H}$ and $9 \mathrm{H}$ tautomers are quite similar; so similar that the same assignment of splittings to positions results for each calculation. In addition, the agreement between the calculated results and experiment is excellent. The largest splitting is in better agreement with the calculation for the $9 \mathrm{H}$ tautomer, but from the overall agreement it is not possible to differentiate between the two calculations. A comparison of the calculated results for purine and 6cyanopurine predicts that the effect of the cyano group on the larger splittings is small. This is confirmed by the experimental results. The theoretical results predict that the splittings at positions 2,3 , and 8 will be lowered while that at position 1 will be raised by the substitution of the cyano group. This is also in agreement with the experimental results.

It is apparent that in this case an indication of which tautomer is the more stable cannot be obtained from the calculation of hyperfine splittings. Another method to obtain such an indication may be the calculation of the total HMO $\pi$-electron energy for the two tautomers. The total energy of such a system cannot be expected to be predicled accurately but simple MO theory often correctly predicts qualitative differences in results ${ }^{18}$ and might be expected to do so in this case. This calculation was performed and shows the $9 \mathrm{H}$ tautomer is favored by $1.6 \mathrm{kcal}$ ( $\beta=50 \mathrm{kcal}$ ) over the $7 \mathrm{H}$ tautomer.

\section{Summary}

Comparison of theory and experiment for purine and 6-cyanopurine shows that McLachlan MO computations of the spin density are in reasonable agreement with experiment. In addition, this comparison suggests that the $9 \mathrm{H}$ tautomer may be favored for the purine anion. Simple HMO calculations of the total electron energy also suggest that the $9 \mathrm{H}$ tautomer may be favored for 6-cyanopurine as well. ${ }^{10}$

The theoretical and experimental results for pyrimidine and 5-methylpyrimidine are also in reasonable agreement. The experimental results for 5-methylpyrimidine and possibly pyrimidine show that dimerization and aromatization can occur through electrolysis. The mechanism of aromatization is unknown; however, it is known that in alkali melal reductions an excess of alkali metal catalyzes the aromatization of the dimer. ${ }^{3}$ In electrolysis, catalysis at the metal electrode surface must certainly be considered.

Acknowledgment. The author wishes to express his thanks to Richard Holroyd for many helpful discussions and to Kay Medeiras for her aid in programming the McLachlan SCF-MO theory.

(17) It should be noted that a rapid conversion between the two tautomeric forms of the purines is not considered likely since an aprotic solvent has been employed.

(18) A. Streitwieser, Jr., "Molecular Orbital Theory for Organic Chemists," John Wiley \& Sons, New York, N. Y., 1961.

(19) It should be noted that in the crystalline state the neutral purine molecule has been shown to be the $7 \mathrm{H}$ tautomer (D. G. Watson, R. M. Sweet, and R. E. Marsh, Acta Cryst., 19, 573 (1965)). The results found here are not considered to be in disagreement with those reported by Watson, et al., since the species observed here is the anion in solution, not the neutral molecule in a crystalline state. 
THIS PAGE

\section{WAS INTENTIONALLY \\ LEFT BLANK}


An Electron Spin Resonance Study of

Acetate Dianion and Acetamide Anion'

by Michael $\mathrm{D}$. Sevilla

Atomics International Division of North American Rockwell Corporation, Canoga Park, California 91304 (Received June 30, 1969)

Reactions of the electron with amino acids and dipeptides are under investigation in this laboratory through use of electron spin resonance (esr) spectroscopy. ${ }^{2}$ To elucidate the structure of the anion radicals formed it was desirable to investigate model compounds for these systems. Acetate ion and acetamide were chosen becanse the acetate dianion should havo a $\pi$-electronic structure similar to anions of amino acids ${ }^{3}$ and the acetamide anion should closely approximate the electronic structure of an anion of the peptide bond. These species were prepared through electron attachment in an alkaline glass. They are found to exhibit interesting properties owing to restricted rotation of their methyl groups which are described in this note.

\section{Experimental Section}

The experimental procedure was essentially that of Ayscough, Collins, and Dainton ${ }^{4}$ as modified by Holroyd and Glass. ${ }^{5}$ In this method a deoxygenated $8 N \mathrm{NaOD}$ . $\left(92 \% \mathrm{D}_{2} \mathrm{O}\right)$ solution containing $5 \mathrm{~m} M \mathrm{~K}_{4} \mathrm{Fe}(\mathrm{CN})_{6}$ and 1-10 mM solute is cooled to $77^{\circ} \mathrm{K}$. The glass formed is photolyzed with $2537-\AA$ uv light at $77^{\circ} \mathrm{K}$ for approximately $1 \mathrm{~min}$. The photolysis produces a dark blue color due to the electron. At this point, an esr spectrum is taken of the sample to ensure that photolysis of the organic solute is minimal. The sample is then photobleached at $77^{\circ} \mathrm{K}$ with light from an infrared lamp for approximately $4 \mathrm{~min}$. The electrons become mobile, attach to the solute, and the esr spectrum of the anion can be then observed.

A Varian V4510 esr spectrometer equipped with a dual cavity and Fieldial magnetic field regulator was employed in this work. Measurements of hyperfine splittings and $g$ values were made vs. potassium peroxylamine disulfonate $\left(A_{\mathrm{N}}=13.0 \mathrm{G}\right.$ and $\left.g=2.0056\right)$.

\section{Results}

Photolysis of the deuterated alkaline glass containing sodium acetate $(10 \mathrm{mM})$ produces mainly the electron. Photobleaching results in a radical whose esr spectrum shows a large doublet splitting (ca. $27 \mathrm{G}$ ) (Figure 1a). A small amount of methyl radical is formed in the

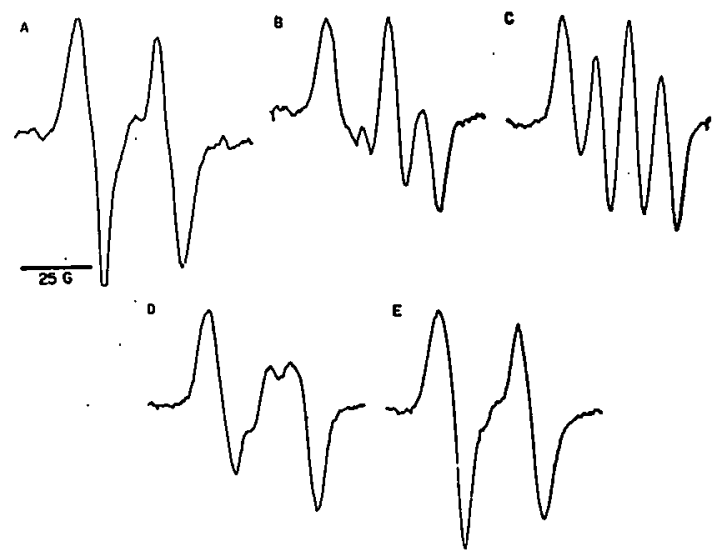

Figure 1. First derivative esr spectra of the acetate dianion in a deuterated alkaline glass at various temperatures: $A$, spectruon taken immediately aster photobleaching, $T=85^{\circ} \mathrm{K}$. (The very weak outer lines are due to the methyl radical); B, spectrum after warming to $150^{\circ} \mathrm{K} ; \mathrm{C}$, spectrum at $180^{\circ} \mathrm{K}$; $\mathrm{D}$, spectrum after cooling to $150^{\circ} \mathrm{K} ; \mathrm{E}$, spectrum at $85^{\circ} \mathrm{K}$. After first warming to $180^{\circ} \mathrm{K}$ repeated cycling results in reproducible spectra.

(1) This work was supported by the Division of Blology and Medicine of the U. S. Atomic Energy Commission.

(2) M. D. Sevilla, Abetracts, The 158th National Meeting of the American Chemical Bociety, New York, N. Y., 1969.

(3) (a) J. W. Sinclair and M. W. Hanna, J. Phys. Chem., 71, 84 (1967); (b) P. B. Ayecough and A. K. Roy, Trañe. Paraday Sac., 64, 582 (1968).

(4) P. B. Ayscough, R. G. Colling, and F. B. Dainton, Nature, 205, 065 (1965).

(5) R. A. Holroyd and J. W. Glass, Int. J. Radiat. Biol., 14, 445 (1988).

Volume 74, Number 8 February 8, 1870

AI-A EC- 12974 
photolysis. $^{6}$ Photobleaching results in no increase in the methyl radical concentration; thus, this species is not produced by a reaction of the electron. Upon warming the sample, the doublet spectrum changes gradually (Figure $1 \mathrm{~b}$ ) until at $180^{\circ} \mathrm{K}$ it appears as a quartet whose lines have approximately the same intensity (Figure 1c). ${ }^{7}$ Cooling the sample after initially warming to $180^{\circ} \mathrm{K}$ does not reproduce the line intensities in the intermediate temperature region (Figure 1d); however, at $85^{\circ} \mathrm{K}$ a doublet splitting, 26.5 $\mathrm{G}$, similar to that initially formed is found (Figure $1 \mathrm{e}$ ). After this first annealing of the sample repeated cycling of the temperature between 85 and $180^{\circ} \mathrm{K}$ results in reproducible spectra at each temperature identical with those found in Figures 1c, d, and e. Increasing the temperature to $190^{\circ} \mathrm{K}$ results in a loss of the esr signal.

The results for acetamide are shown in Figure 2. The results are similar to those found for "annealed" samples of sodium acetate. Photolysis again produces electrons and only a small amount of methyl radical. Photobleaching at $77^{\circ} \mathrm{K}$ results in a radical whose esr spectrum at $85^{\circ} \mathrm{K}$ consists of a large $30.8-\mathrm{G}$ doublel splitting. Warming the sample to $180^{\circ} \mathrm{K}$ produces a 13.5- $\mathrm{G}$ quartet in the intensity ratio $1: 3: 3: 1$. At intermediate temperatures $\left(85^{\circ} \mathrm{K}<T<180^{\circ} \mathrm{K}\right)$ a gradual change from doublet to quartet is observed (Figures 2b, c) which is reversible. Again at temperatures near $190^{\circ} \mathrm{K}$, the esr signal is lost.

At $180^{\circ} \mathrm{K}$ the $g$ values of acetate dianion and acetamide anion are $2.0032 \pm 0.0003$ and $2.0030 \pm 0.0003$, respectively.

Preparation of samples of acetate and acetamide in alkaline $\mathrm{H}_{2} \mathrm{O}$ solutions results in spectra with larger line widths. At lower temperatures both species show resolved doublets with splittings similar to those found in $\mathrm{D}_{2} \mathrm{O}$ solutions. At $180^{\circ} \mathrm{K}$ the spectrum of acetamide anion appears as a singlet, $\Delta H_{\mathrm{m} . \mathrm{s} .} \simeq 35 \mathrm{G}$, while that of acetaite dlanlun is unly par lially resolved:

\section{Discussion}

The results show that reaction with the electrun at $77^{\circ} \mathrm{K}$ produces the acetate dianion and acetamide anion. Further, the doublet spectra at $85^{\circ} \mathrm{K}$ show that the methyl groups of these anions are not free to rotate rapidly at this temperature and can be considered locked in a spatial configuration corresponding to a potential minimum so as to produce one large splitting. The spectra at $180^{\circ} \mathrm{K}$ indicate that the methyl groups are rotating more rapidly. The results are complicated by the change in line intensities noted in the spectra of acetate dianion before and after annealing. This is considered to be due to either a relaxation of the acetate molecular framework to a more stable configuration accompanied by an adjustment in the electronic wave function ${ }^{8}$ or a change in the nature of the alkaline glass immediately about the dianion to accommodate the extra negative charge. The fact that this effect was not

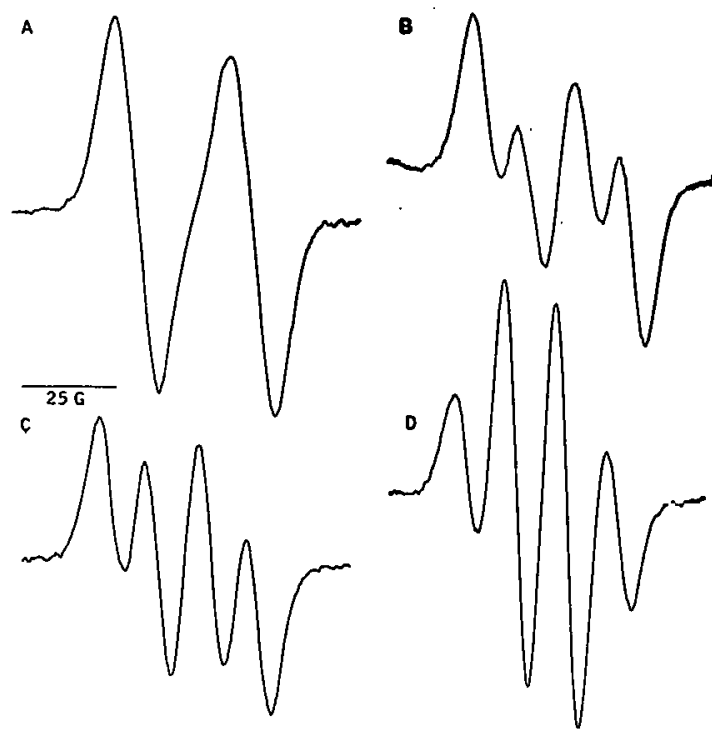

Figure 2. First derivative esr spectra of the acetamide anion. in a deuterated alkaline glass at various temperatures: $A$, $85^{\circ} \mathrm{K}$ (the weak methyl radical signal has been removed by warming); $\mathrm{B}, 133^{\circ} \mathrm{K} ; \mathrm{C}, 146^{\circ} \mathrm{K} ; \mathrm{D}, 180^{\circ} \mathrm{K}$.

found for acetamide anion argues against the latter. Further discussion of the results found for the acetate dianion after annealing and acetamide anion is given below.

The orientation of the methyl group protons in the locked configuration found at $85^{\circ} \mathrm{K}$ can be determined by recourse to relation (1) which describes the $\beta$-proton splitting, $A_{\beta}{ }^{\mathrm{I}}$, as a function of augle ${ }^{8}$

$$
A_{\rho}{ }^{\mathrm{H}}(\theta)=B_{0} \rho^{\pi}+B_{2} \rho^{\pi} \cos ^{2} \theta
$$

where $B_{0}$ and $B_{2}$ are empirical constants with $B_{2} \gg B_{0}$, $\mu^{\top}$ is the opin donoity in tho $p_{2}$ orbital of the $\pi_{-} r a r h n n$ atom, and $\theta$ represents the dihedral angle between the $z$ axis of the $\mathrm{p}_{z}$ orbital and the alkyl $\mathrm{C}-\mathrm{H}$ bond axis. The doublet spectrum obscrved would result only if the three methyl protons were at angles near 0,120 , and $240^{\circ}$. This would produce a large splitting for the proton at $\theta=0^{\circ}$ and two small (apparently unresolved) splittings for the protons at $\theta=120$ and $240^{\circ}$.

As the temperature is increased above $85^{\circ} \mathrm{K}$, the

(6) Since a small amount of dianion was also produced in this step the formation of methyl radicals could be due to uv photolysis of $\mathrm{CH}$ $\mathrm{CO}_{2}^{2}$-.

(7) The signal due to the methyl radical is lost as the sample is warmed. Experiments in which a high concentration of methyl radicals was produced by photolysis of the dianion yielded an esr speotrum of the $\cdot \mathrm{CH}_{2} \mathrm{CO}_{2}-$ radical upon warming to $180^{\circ} \mathrm{K}$. This species proved to be more stable than the dianion and could be observed free from the dianion.

(8) A similur plienomenon found in irradiated crystalline alsaine (ref 38 ) also has been explained in terms of a change in hybridization. (9) See M. D. Sevilla and G. Vincow, J. Phys. Chem., 72, 3647 (1968), and references therein. 
methyl group undergoes increasingly rapid reorientation between potential minima until in the case of acetamide anion at $180^{\circ} \mathrm{K}$, "Iree" rotation occurs (rapid reurientalion in comparison to the hyperfine splitting in cycles per second). In the case of acetate dianion, the methyl group does not rapidly reorient even at $180^{\circ} \mathrm{K}$. Consequently, observed line intensities for acetate at $180^{\circ} \mathrm{K}$ are similar to those for acetamide anion at $146^{\circ} \mathrm{K}$. By comparison to the acetamide anion spestral behavior, the splitting for a freely rotating methyl in the acetate dianion is estimated to be $11.8 \mathrm{G} .^{10}$

The lack of resolution of the two protons at 120 and $240^{\circ}$ in the low-temperature spectrum of both anions can be understood by first solving for values of $B_{0} \rho$ and $B_{2} \rho^{\pi}$ using eq 1 and the experimental splittings for the "locked" and "freely" rotating cases. The assumption is made that there is no significant temperature dependence in $B_{0} \rho^{\pi}$ and $B_{2} \rho^{\pi}$. It is found that $B_{0} \rho^{\pi} \cong-3.2$ and $B_{2} \rho^{*} \cong 29.4$ for acetate dianion, and $B_{0} \rho^{\pi} \cong-3.8$ and $B_{2} \rho^{\pi} \cong 34.6$ for the acetamide anion. The calculated splittings of the protons at 120 and $240^{\circ}$ in the low-temperature case are then $+3.9 \mathrm{G}$ (acetate) and $+4.8 \mathrm{G}$ (acetamide), values which are well within the observed line width of 10 and $13 \mathrm{G}$, respectively.

Since theoretical spin densities are essential to the computation of theoretical values of the methyl proton splittings for comparison to experiment, McLachlan SCF-MO calculations were performed for the acetate and acetamide radical ions (Table $I$ ). ${ }^{11}$ The effect of the methyl group is simulated by the use of typical hyperconjugation parameters and a small inductive effect. The results of this calculation are given in Table I. The coulomb $(h)$ and resonance $(k)$ parameters employed are: $k_{\dot{\mathrm{C}}-\dot{\mathrm{o}}}=\left(k_{\mathrm{C}-\mathrm{o}}+k_{\mathrm{C}=\mathrm{o}}\right) / 2=$ $1.2, k_{\mathrm{C} \doteq \mathrm{O}}=1.6, h_{\mathrm{O}}=1.5, k_{\mathrm{N}}=0.8$, and $h_{\mathrm{N}}=1.5 .^{12}$ Moderate changes in these parameters are not found to affect the spin density distribution significantly. For example, a value of $h_{0}=2.5$ instead of 1.5 raised $\rho_{8}{ }^{\pi}$ by only 0.09 for acetate dianion. Two methods are available to obtain theoretical methyl splittings for comparison with experiment. First the spin density on the carboxyl carbon, $\rho_{3}{ }^{\pi}$ can be used to estimate the methyl group hyperfine splittings for free rotation assuming a relation of the form $A \mathrm{C}_{3}{ }^{B}=Q_{\mathrm{CH}_{3}} \rho_{3}{ }^{\pi}$ where $Q_{\mathrm{CH}_{3}} \cong 20 \mathrm{G}^{13}$ Second, the methyl proton hyperfine splitting can also be calculated from the spin density in the pseudo- $\pi$ orbital composed of a linear combination of methyl hydrogen ls orbitals, by use of the relation $A_{\mathrm{CH}_{2}}{ }^{\mathrm{H}}=217 \rho_{\mathrm{H}}{ }^{2}{ }^{14}$ For acetate dianion it is found that $A_{\mathrm{CH}_{3}}{ }^{\mathrm{B}}=13.9$ and $14 \mathrm{G}$ for the first and second calculation, respectively. The results for acetamide anion are slightly lower, 13.7 and $13.8 \mathrm{G}$. The two types of calculations are in excellent agreement with one another and in reasonable agreement with experiment. Thus the calculated and "experimental" spin density distributions should also be in reasonable agreement.
Table I: McLachlen Spin Density Calculations ${ }^{\circ}$
Position<smiles>C#CC([O-])OC</smiles>

0.0646

$-0.032$

0.693

0.137

0.137
Acetamide anion<smiles>C=CC(=O)[N+](=O)[O-]</smiles>

0.0636

$-0.033$

0.685

0.228

0.057
${ }^{a}$ Hyperconjugation parameters used were: $h_{1}=-0.5, h_{2}=$ $-0.10, h_{3}=-0.10, k_{12}=2.5, k_{23}=0.9$.

The spectra of acetamide anion show no resolution of nitrogen hyperfine splittings whether isotropic or anisotropic. This is explained by the spin density calculations which predict only a small spin density and consequently a small splitting for nitrogen. The deuteriums bonded to nitrogen of course should give rise to negligible hyperfine splittings.

The results found in this work show that anions can be made of small molecules quite easily. Further, they show that by a suitable choice of the molecular species and use of a deuterated alkaline glass, esr spectra can be obtained which are well resolved and easily interpretable.

Radicals structurally related to acetate dianion have been reported as products of the radiolysis of acetic acid $^{15}$ and a number of other carboxyl-containing compounds. ${ }^{16}$ A protonated acetate dianion was reported in the radiolysis study of acetic acid at $77^{\circ} \mathrm{K}$. The results found for this species are in good agreement with those found here but suggest a moderate effect of the protonation (and dimerization) on the methyl proton hyperfine splitting. The acetate dianion has also been reported as a product of the radiolysis of sodium acetate; ${ }^{17}$ however, the species observed has been shown to (10) The spectra in the intermediate temperature range between the
locked and freely rotating cases can be understood in terms of the locked and freely rotating cases can be understood in terms of the effect of hindered rotation on line widths and splittings of methyl groups. See J. H. Freed, $J$. Chem. Phys., 43, 1710 (1965), and refer-
ences therein for quantum mechanical and classical treatments of this phenomenon.

(11) A. D. McLachlan, Mol. Phys., 3, 233 (1960).

(12) (a) A. Streitwieser, "Molecular Orbital Theory for Organic Chemists," John Wiley \& Sons, Inc., New York, N. Y., 1962, p 135. (b) G. Vincow in "Radical 'Cations," E. T. Kaiser and L. Kevan, Ed., Interscience, New York, N. Y., 1968, p 175.

(13) Reference 12b, p 165

(14) (a) D. Lazdins and M. Karplus, J. Chem. Phys., 44, 1600 (1966); (b) D. H. Levy, Mol. Phys., 10, 233 (1966).

(15) I. Miyagawa and W. Gordy, J. Amer. Chem. Soc., 83, 1036 (1961).

(16) J. Sinclair and M. W. Hanna, J. Chem. Phys., S0, 2125 (1969), and references therein.

(17) D. G. Cadena, V. Mendez, and J. R. Rowlands, Mol. Phys., 13, 157 (1967).

Volume 74, Number 3 February 5,1970

AI-AEC- 12974 
be the methyl radical through ${ }^{13} \mathrm{C}$ substitution studies. ${ }^{18,19}$ Up to. the present time neither the acetate dianion nor the acetamide anion have been shown to be products of the radiolysis of sodium acetate and acetamide. Since these anions would be expected to be products of radiolysis, the results reported here should aid in their future identification.

(18) M. T. Rogers and L. D. Kispert, J. Chem. Phys, 46, 221 (1967).

(19) M. T. Rogers and L. D. Kispert in "Radiation Chemistry," Advances in Chemistry Series, No. 82, American Chemical Bociety. Washington, D. C., 1968, p 327.

The Journal of Physical Chemistry 


\title{
Radicals Formed by the Reaction of Electrons with Amino
}

\author{
Acids in an Alkaline Glass ${ }^{1,2}$
}

\author{
by Michael $D$. Sevilla \\ Atomics International Division, North American Rockwell Corporation, Canoga Park, California 91304 \\ (Received November 4, 1969)
}

\begin{abstract}
The reactions of electrons with a number of amino acids in an alkaline $\mathrm{D}_{2} \mathrm{O}$ glass have been investigated by use of electron spin resonance spectroscopy. The electron initiates a series of reactions upon attachment to glycine and alkyl-substituted amino acids. Electron attachment at $77^{\circ} \mathrm{K}$ first produces the dianion which deaminates upon warming to produce a second radical species. Further warming to the sof tening point of the glass results in the appearance of a third radical species. The esr spectra of this species are consistent with the structure, $\mathrm{ND}_{2}-\dot{\mathrm{C}}-\mathrm{CO}_{2}^{-}$, which indicates that the deaminated species is abstracting from the $\alpha$ carbon of the parent !

amino acid. Reactions of electrons with other amino acids depend on the nature of the side group. For example, electron attachinent to methionine produces methyl radicals by clcavage of the $\mathrm{S}-\mathrm{CH}_{3}$ bond, and electron attachment to asparagine produces an anion of the amide group. The radical intermediates identified are found to be in agrecment with those proposed from investigations of the radiolysis of aqueous solutions of amino acids. A comparison of results of this work with those found in esr investigations of irradiated single crystals shows that the subsequent reactions of the deaminated radical species of amino acids with alkyl side groups are different in aqueous media than in erystalline amino acids.
\end{abstract}

\section{Introduction}

Investigations of the radiolysis of the amino acids glycine and L-alanine in dilute aqueous solution have given evidence that the hydrated electron adds to the carboxyl group. ${ }^{3}$ Results of the analysis of products of the radiolysis of these systems are consistent with the interpretation that the amino acid anion formed subsequently deaminates to produce a $\cdot \mathrm{CH}$ (R) $\mathrm{COOH}$ radical and that this species reacts by abstraction from the parent molecule

$$
\begin{aligned}
& \mathrm{NH}_{3}+\mathrm{CH}(\mathrm{R}) \mathrm{COO}-+\cdot \mathrm{CH}(\mathrm{R}) \mathrm{COOH} \rightarrow \\
& \mathrm{NH}_{2} \mathrm{C}(\mathrm{R}) \mathrm{COOH}+\mathrm{CH}_{2}(\mathrm{R}) \mathrm{COOH}
\end{aligned}
$$

Electron spin resonance studies of irradiated solid amino acids (usually single crystals) at $77^{\circ} \mathrm{K}$ have also shown that electrons formed in the radiolysis add to the carboxyl group and that deamination subsequently occurs upon warming. ${ }^{4-13}$ Thesc esr studies show that the abstruction step as in reaction 1 does not occur in solid amino acids with alkyl side groups. $5.11,12$ No abstraction reaction is found to occur in L-alanine. ${ }^{5}$ For valine, deamination is followed by abstraction of a hydrogen atom from the tertiary carbon of the alkyl side group. ${ }^{11,12}$ Results found for irradiated solid leucine and isolcucine also indicate that abstraction occurs from the tertiary carbon of the alkyl group." lesults found for solid glycinc $(R=H)$ may suggest partial abstraction of one of the a protons; 13 however this is uncert;in. $"$

The Journal of J'hynical Chemistry
In this work an esr study of the reactions of photolytically produced electrons with a number of amino acids in an aqueous medium has been performed to further elucidate the role of the electron in the radiolysis of these systems. In the course of this investigation it was found that several reactions occurred after electron attachment to an amino acid and that the free radical intermediates in these reactions could be

(1) This work was supported by the Division of Biology and Medicine of the U.S. Atontic Energy Commission.

(2) The work was presented in part at the 158 th National Meeting of the American Chemical Society, New York, N. Y., Sept 9, 1969.

(3) See D. B. Peterson, J. Holian, and W. M. Garrison, J. Phys. Chem., 73, 1568 (1909), and references therein.

(4) J. Sinclair and .I. W. Hanna, J. Chem. Phys., 50, 2125 (1069).

(5) J. Sinclair and M. W. Hanna, J. Phys. Chem., 71, 84 (1967).

(6) H. C. Box, E. E. Budzinski, und II. G. Freund, J. Chem. Phys., 50, 2880 (1969).

(7) H. C. Box, H. G. Freund, and E. F. Budzinski, J. Amer. Chem. Soc., 88, 658 (1966).

(8) l'. B. Ayscough and A. K. Koy, Trans. Faraday Soc., 64, 582 (1968).

(9) Y. A. ICrugly'ak, MI. L. Pulatova, Y. Y.:Mozdor, Y. N. Sud'hina, V. C. Yrsoyan, and I. P. Kajushin, Biofizika, 13, 401 (1968).

(10) Electron attachinent to carboxyl groups has been found to occur it irradiated carboxytlic acids as well. See J. 1:. J3ennett and L. H. Giale. Trans. Faraday Soc., 64, 1174 (1968).

(11) F. P'atten and W. Gordy, Radial. Res., 14, 573 (1001).

(12) II. C. Box, H. G. Freund, and I. I.. Budzinski, J. Chem. Thya., 46, 4470 (1907).

(13) M. A. Collins and D. H. Whiffen, Mol. Mhys., 10, 317 (1906) (14) The uncertuinty is nut whether a radieal of the form $\mathrm{NH} \mathrm{H}_{2}+$ Cil- $\mathrm{CO}_{2}-$ is present 13 this is indectuttely provelt. It is whether this species arises from alsstraction as in reaction I or is the product of a series of renctions initiated by the positive ion which is formed in the radiulysis see rel s and y for a dischesiun of this cyucstion. 
stabilized and observed by esr spectroacopy. From this study, information confirming the reaction scheme proposed through radiolysis studies in aqueous solution is found. Results are found for alkyl-substituted amino acids which confirm the difference in the abstraction step between aqueous solution and the crystalline state. In addition, results for several amino acids with reactive side groups show these groups to be the site of electron attack.

One previous study of the reaction of radiolytically produced electrons with several amino acids in an alkaline glass has been reported. ${ }^{8}$ The amino acids common to both studies are glycine and alanine. These workers find that a deaminated radical species is the product of electron attachment, as is found here. However, they did not observe the first radical species, the dianion. In this work it is found that the dianions are relatively stable. In addition, a third radical species which was not previously reported is found in this work.

\section{Experimental Section}

The amino acids uscd in this study were obtained from Calbiochem (Grade $\Lambda$ ) and were used without further purification.

The experimental procedure employed was essentially that of Ayscough, Collins, and Dainton ${ }^{15}$ as modified by Holroyd and Glass. ${ }^{16}$ In this method a deoxygenated $8 \mathrm{~N} \mathrm{NaOD}\left(92 \% \mathrm{D}_{2} \mathrm{O}\right)$ solution containing 5 $\mathrm{m} M \mathrm{~K}_{6} \mathrm{Fe}(\mathrm{CN})_{6}$ and 1 to $50 \mathrm{~m} M$ solute (amino acid) is cooled to $77^{\circ} \mathrm{K}$ to form a glass. The concentration of amino acid used is dependent upon its absorbance at 2537 $\AA$. Amino acids such as glycine and those with alkyl side groups do not absorb appreciably at this wavelength and therefore the higher concentrations were used.

The glass formed is photolyzed with $2537-\AA$ uv light at $77^{\circ} \mathrm{K}$ for approximately $1 \mathrm{~min}$. The photolysis produces a dark bluo color due to the electron. At this point, an esr spectrum is taken of the sample to ensure that photolysis of the organic solutc is minimal. The sample is then photobleached at $77^{\circ} \mathrm{K}$ with light from an infrared lamp for approximately $4 \mathrm{~min}$. The electrons become mobile and react with the solute.

A Varian V4510 esr spectrometer equipped with a dual-cavity Fieldial magnetic field regulator and variable temperature accessory was emplojed in this work. Measurements of hyperfine splittings and $g$ values were made vs. potassium peroxylamine disulfonate $\left(A_{\mathrm{N}}=13.0 \mathrm{G}, g=2.0056\right)$.

\section{Results and Discussion}

1. Glycine and Amino Acids with Alkyl Side Groups. At $77^{\circ} \mathrm{K}$ electron attachment to glycine and the amino acids with alkyl side groups, i.e., alanine, leucine, isoleucine, and valine, results in csr spectra at $(g \cong 2.003$ (Figures 1-3) which show good resolution

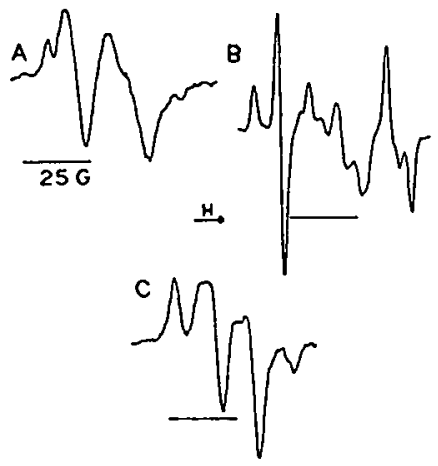

Figure 1. Electron spin resonance (esr) spectra of radical species produced by reaction of electrons with glycine in a deuterated alkaline glass. A, First species the dianion at $90^{\circ} \mathrm{K}$. B, Second species $\mathrm{CH}_{2} \mathrm{CO}_{2}-$ after warming to $180^{\circ} \mathrm{K}$. C, Third species $\cdot \mathrm{CH}\left(\mathrm{ND}_{2}\right) \mathrm{CO}_{2}-$ at $190^{\circ} \mathrm{K}$. The magnetic field increases from left to right for each spectrum in this figure and subsequent figures.

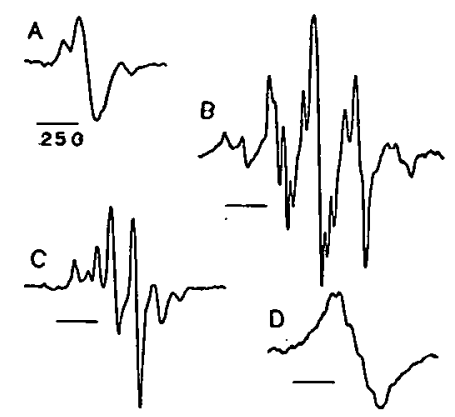

Figure 2. Esr spectra of radical species produced by reaction of electrons with $\mathrm{L}$-alanine in a deuterated alkaline glass. A, First species the dianion at $90^{\circ} \mathrm{K}$. B, Second species - $\mathrm{CH}\left(\mathrm{CH}_{3}\right) \mathrm{CO}_{2}-$ at $180^{\circ} \mathrm{K}$. $\mathrm{C}$, Third species $\mathrm{ND}_{2} \dot{\mathrm{C}}\left(\mathrm{CH}_{3}\right) \mathrm{CO}_{3}-$ at $195^{\circ} \mathrm{K}$. D. Third species $\mathrm{NII}_{2} \mathrm{C}\left(\mathrm{CH}_{3}\right) \mathrm{CO}_{4}^{-}$ at $190^{\circ} \mathrm{K}$ in alkaline $\mathrm{H}_{2} \mathrm{O}$, Nole loss of resolution due to the proton splittings on nitrogen and increased dipole-dipole interactions.

only for glycine (Figure 1a). ${ }^{17}$ The remaining amino acids generally show only broad singlet spectra 10-12 G wide (see Figures $2 a$ and $3 a$ ). These spectra can be associated with the dianion radicals of the amino acids formed through reaction 2 . The dianions are rela-<smiles>[R]C([R])[N+](=O)[O-]</smiles>

(15) P. B. Ayscough, R. G. Collins, and F. S. Dainton, Nature, 205, 965 (1965).

(16) R. A. Holroy and J. W. Glass, Int. J. Radiat. Biol., 14, 445 (1968).

(17) The $\sigma$ values found for the various dianions did not differ significantl $y^{*}$. The $g$ values for the subsequent radical species found in this work were also npproximately 2.003 . Thus it was not pusin this work were also npproximately 2.003 . Thus it was not pus-
sible to distinguisl the vitrieus radical gpecies on the basis of the 0 value.

Volume 74. Number 10 May 14, 1070

$\mathrm{AI}-\mathrm{A} E \mathrm{EC}-12974$ 


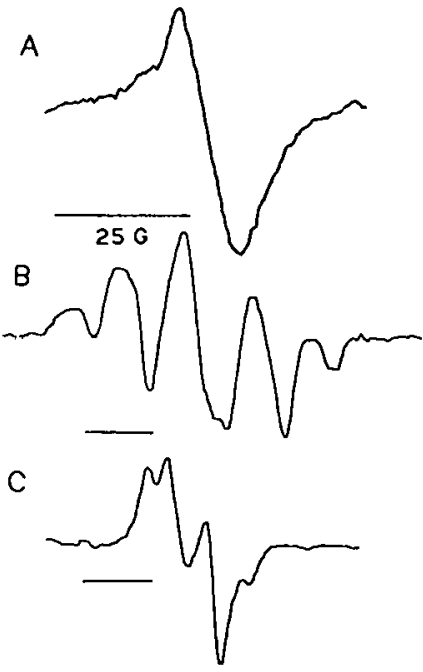

Figure 3. Esr spectra of radical species produced by reaction of electrons with L-leucine. A, First species the dianion at $90^{\circ} \mathrm{K}$. B, Sccond species $\cdot \mathrm{CHRCO}_{2}-$ at $180^{\circ} \mathrm{K}$. Another radical species, possibly unreacted dianion, increases the intensity of the central component. C, Third speries $\mathrm{ND}_{2} \dot{\mathrm{C}}_{2 \mathrm{CO}_{2}-}$ at $195^{\circ} \mathrm{K}$.

tively stable at $77^{\circ} \mathrm{K}$ although for glycine there was evidence for partial deamination even at this temperature.

The glycine dianion spectrum consists of a ca. 23-G doublet (the small cumponents at the ends of the spectrum arise from the deaminated species). ${ }^{18}$ The 23-G splitting can only arise from one of the protons $\beta$ to the carboxyl carbon. Its magnitude can be used to determine the spatial configuration of the $\beta$ protons. The relation between the isotropic $\beta$-proton splitting, $A_{\beta}{ }^{H}$, and spatial configuration is given by

$$
A_{\beta}{ }^{\mathrm{H}}=B_{0} \rho^{*}+B_{2} \rho^{*} \cos ^{2} \theta
$$

This relation has been previously described in detail ${ }^{19}$ and shown applicable to anions in an alkaline glass in work on the acetate dianion. ${ }^{20}$ The acetate dianion should have a $\pi$-electron structure similar to glycine. Work on this species has given values of $B_{0} \rho^{*}=-3.2$ and $B_{2} \rho^{\pi} \cong 30 .{ }^{20}$ Using these values we find that $\theta \cong$ $20^{\circ}$ for the $\beta$ proton of $23-\mathrm{G}$ splitting. The lack of resolution of the second proton indicates that $\theta$ is near $-100^{\circ}$ for this proton.

The dianions of L-alaninc, I-lcucine, $\mathrm{J}$-isoleucine, and I-valine have one $\beta$ proton but their spectra do not show resolution of $n$ proton splitting. ${ }^{21}$ This suggests that the $\beta$ proton is in an orientution $(\theta)$ which produces $a$ small coupling $\left(50 \leq \theta \leq 130^{\circ}\right)$.

When the dimions of glycine and the alkyl amino acids are warmed to $T \leq 180^{\circ} \mathrm{K}$, a second radical species is furmed. The esr spectra for these radicals (which are discussed in detail below) can only be interpreted on the basis that the dianions have undergone reductive deamination (reaction 3 ).

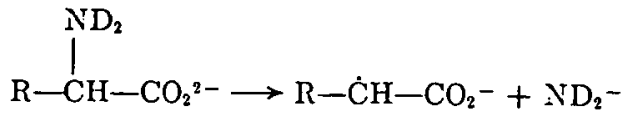

For glycine a polycrystalline anisotropic spectrum (Figure $1 b$ ) due to the $2 \alpha$ protons of the $\cdot \mathrm{CH}_{2} \mathrm{CO}_{2}-$ radical is observed. At high modulation amplitudes in an $\mathrm{H}_{2} \mathrm{O}$ glass the spectrum becomes more nearly a $1: 2: 1$ intensity ratio with a $c a$. 21-G splitting expected from other work on this species. ${ }^{7-9,11}$ The structure of this radical has been verified by the reaction of electrons with $\alpha$ chloroacetic acid. This species is known to react by loss of chlorine to form the $\mathrm{CH}_{2} \mathrm{CO}_{2}-$ radical. ${ }^{15}$ An identical spectrum to that found in Figure 16 is observed. For L-alanine a spectrum (Figure 2b) expected from the $\cdot \mathrm{CH}\left(\mathrm{CH}_{3}\right) \mathrm{CO}_{2}$ - radical is observed. The spectrum arises from three equivalent methyl protons and one anisotropic $\alpha$ proton. The end multiplets of this spectrum clearly show the anisotropy of the $\alpha$ proton. The structure of the radical is further verified due to the fact that an identical spectrum is found by the reaction of electrons with $\alpha$-chloropropionic acid. Previously reported isotropic couplings of $24 \mathrm{G}$ (methyl) and $21.4 \mathrm{G}$ ( $\alpha$ proton) adequately reproduce the spectrum when resolution of the anisotropic structure is lost in $\mathrm{H}_{2} \mathrm{O}$ glass. ${ }^{5.8}$

The spectra found for the second radical species of leucine, isoleucine, and valine can also be interpreted in terms of a deaminated radical, although in each case an interfering radical signal (probably unreacted dianion or electron) is apparent in the central portion of the spectra. ${ }^{22}$ The spectrum for L-leucine (Figure $3 \mathrm{~b}$ ) can be interpreted in terms of a large $48-G$ splitting due to a single proton and a $20 . \mathrm{G}$ splitting due to two approximately equivalent protons. Owing to its magnitude the large $48-G$ splitting must arise from a $\beta$ proton. Thus the $\alpha$ proton and the remaining $\beta$ proton in the lcucine $\alpha$ carbon radical structure have a splitting of approximately $20 \mathrm{G}^{23}$ The intensity ratio expected from this interpretation is $1: 2: \sim 2: 2: 1$. The agreement with the experimental ratio is only fair. Ilowever, the interpretation presented here is considered the most likely since the total spread in the spectrum of 88

(18) Similar $\beta$-proton splittings have been found for glycine anion in single crystals (sce ref 4,8 , and 8 ).

(19) M. D. Sevilla and G. Vincow, J. Phys. Chem., 72, 3047 (1968). (20) M. D. Sevilla, ibid., 74, $669(1970)$.

(21) The t.-alunine dianion does show some resolution (Figure $2 \mathrm{~A}$ ) The line shape is suggestive of an anisotropic nitrogen hyperfine splitting.

(22) The deamination step for these species occurs at slightly higher temperuture and is sloser thin for alanine or glycine. Thus it is dificult to prevent some thixture of the three raclicil ojevies in this step.

(23) Done to the large line width in this radical, ca. $12 \mathrm{G}$, the hyperfine splittings for the a und o protun mity ditfer significantly und stilt Hveruge to $20 \mathrm{G}$.

The Journal of Physical Chemistry

AI-A EC- 12974 
$\mathrm{G}$ must arise from the interaction of $\beta$ protons. The spatial configuration of the $\beta$ protons in the deaminated species necessary to produce the observed splittings can be estimated by use of eq 1 . For radicals of this type $B_{0} \rho^{x}$ and $B_{2} \rho^{*}$ are typically $0-4 \mathrm{G}$ and $45 \mathrm{G}$, respectively ${ }^{19}$ The observed splittings would then arise for $\theta_{1} \sim 0^{\circ}$ and $\theta_{2} \sim 120^{\circ}$. This interpretation is suppurted by the fact that similar splittings are found for the deaminated species of $\alpha$ aminobutyric acid, ${ }^{8}$ a radical whose steric interactions should place the $\beta$ protons in a configuration similar to the protons in leucine.

The esr spectrum of the second radical of $\mathrm{L}$ isoleucine (Figure 4a) shows only a $22-\mathrm{G}$ doublet presumably due to the $\alpha$ proton and no further splitting. Since the radical species expected has a single $\beta$ proton

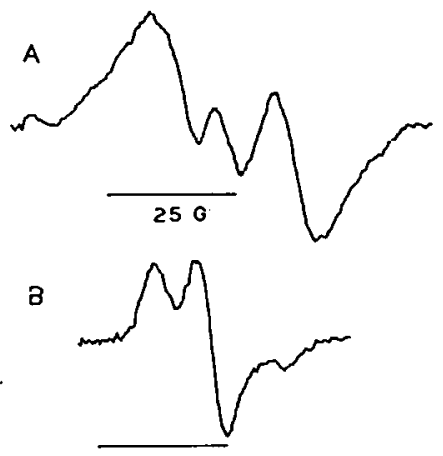

Figure 4. Esr spectra of radical species produced by reaction. of electrons with L-isoleucine. A. Second species $\cdot \mathrm{CHRCO}_{2}-$ at $180^{\circ} \mathrm{K}$. The central component arises from another radical species, most likely the unreacted dianion. B. Third species $\mathrm{ND}_{2} \mathrm{C}, \mathrm{RCO}_{2}-$ at $185^{\circ} \mathrm{K}$. The dianion radical spectrum consists of a $10 \mathrm{G}$ wide singlet.

as well as an $\alpha$ proton, this indicates that the $\beta$ proton is less than the line width in magnitude (10 G). A configuration $\left(75^{\circ}<\theta<105^{\circ}\right)$ which corresponds to a small $\beta$ proton splitting is reasonable from considerations of the steric interactions of the alkyl substituent in the radical.

The valine second species has a structure similar to that of isoleucine, i.e., one $\beta$ proton and one $\alpha$ proton. The observed spectrum show's a $34 \mathrm{G}$ total spread but little resolution. The $34-\mathrm{G}$ spread is $12 \mathrm{G}$ wider than expected for only an $\alpha$ proton. This suggests a $12-G \beta$ proton splitting for the only $\beta$ proton.

Further warming of the alkaline glass containing the second radical species and the parent amino acid to $c a$. $190^{\circ} \mathrm{K}$ causes the glass to soften and results in an early complete conversiun of the second radical species to a third ( $g_{\text {isotropic }} \cong 2.003$ ). Interpretation of the esr spectra of the third species for each amino acid provides strong cvidence for an abstraction reaction (reaction 4 ).

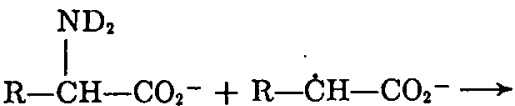

$$
\begin{aligned}
& \mathrm{R}-\mathrm{C}-\mathrm{CO}_{2}-+\mathrm{RCH}_{2} \mathrm{CO}_{2}-
\end{aligned}
$$

The esr spectrum observed for the third species of glycine consists of a 13.5-G doublet with small line components on cither side of the doublet (Figure 1c). This spectrum can be interpreted on the basis of a radical of the structure $\mathrm{ND}_{2} \dot{\mathrm{C}} \mathrm{HCO}_{2}-$. The 13.5-G doublet must then arise from the $\alpha$ proton and the smaller line components from an anisotropio nitrogen with $A_{\|} \cong$ $14.5 \mathrm{G}, A_{\perp}<3.5 \mathrm{G}(1 / 2$ line width $)$ and $g_{\perp} \cong g_{\| 1}$.

By analogy to glycine the spectrum observed for the third species of alanine (Figure 2c) would be expected to urise from the radical $\mathrm{ND}_{2} \dot{\mathrm{C}}\left(\mathrm{CH}_{3}\right) \mathrm{CO}_{3}-$. For this radical a quartet splitting due to the methyl group would be expected which should be approximately equal to the $\alpha$-proton splitting in the third radical species of glycine. In addition, an anisotropic nitrogen splitting with parameters similar to thosc for the glycine radical should be found. Analysis of the spectrum yields a 13$\mathrm{G}$ splitting due to three equivalent protons, an anisotropic nitrogen splitting with the parameters $A_{\|} \cong$ $12 \mathrm{G}$ and $A_{\perp}<2.5 \mathrm{G}$, and $g_{\perp}-g_{\|} \cong 0.0014 .{ }^{24}$ The results therefore provide convincing evidence for the identity of the radical species and consequently for the abstraction reaction, reaction 4 .

The third spectra found for leucine (Figure 3c), isoleucine (Figure $4 \mathrm{~b}$ ) and valine are also interpretable on the basis of a radical of the structure $\mathrm{ND}_{2} \dot{\mathrm{CRCO}}_{2}^{-}$. Leucine shows a 13-G doublet and the anisotropic splittings of the nitrogen, $A_{\|} \cong 12 \mathrm{G}, A_{\perp}<3.5 \mathrm{G}$ with $g_{\perp}-g_{\|} \cong 0.0012$. The doublet must arise from one of the $\beta$ protons. The other $\beta$ proton must have a splitting less than the line width in magnitude. The values $\theta_{1}=45^{\circ}$ and $\theta_{2}=-75^{\circ}$ would produce such proton splittings. ${ }^{25,26}$ Isoleucine and valine show nearly identical third spectra. $\beta$-Proton splittings are not observable; only spectra which are characteristic of an anisotropic nitrogen are observed. ${ }^{27}$ The nitrogen splittings are $A_{\|} \cong 12 \mathrm{G}$ and $A_{\perp}<3 \mathrm{G}$ with $g_{\perp}-$

(24) Owing to the large line widths and the consequent overlapping of components, the differences in values of the molecular $\theta$ values, $\theta \perp$ and $g \|$, must be considered as estimates.

(25) The $\alpha$-carbon splitting for the third species of glycine suggests a spin density of ca. 0.5 . A value of $B_{2} p^{*}$ equal to $25 \mathrm{G}$ was therefore employed in this culculation.

(26) In polyleucine the anilogous radical $(-\mathrm{NHC}(\mathrm{R}) \mathrm{C}(\mathrm{O})-$ ) is la

formed after radiolysis (R. C. Drew and W. Gordy, Radiat. Res. 18,552 (1963)). To explain the hyperfine sulittings found for the $\beta$-protons values of $\theta=40^{\circ}$ and $-80^{\circ}$ werc suggested. These values are in good agrecment with those found here for the thitd ratieal are in good ngrecies of leucine.

(27) N. Edelstein, A. Kwok, and A. II. Maki, J. Chem. I'hys., 41, $170(1904)$.

Volume 74, Number 10 May 14,1070 
$y_{\| 1} \cong 0.0013$ for both rudicals. The lack of observation of a $\beta$-proton splitting suggests a spatial configuration $(\theta)$ for the $\beta$ proton near $90^{\circ}$. This orientation is in excollent agreement with that expected from the steric interactions of the alkyl groups in these radicals.

It should be noted that the other possible site of hydrogen abstraction for lcucine, isolcucine, and valine, i.e., abstraction from the tertiary carbon of the alkyl group, would produce spectra totally inconsistent with those found in this work. ${ }^{11,12}$

The identification of the third radical species of the amino acids with the $\mathrm{ND}_{2}-\dot{\mathrm{C}}(\mathrm{R})-\mathrm{CO}_{2}$ - radical is further confirmed by the work of Taniguchi, et al. ${ }^{28}$ They produced the $\mathrm{NH}_{2}-\dot{\mathrm{C}}(\mathrm{H}) \mathrm{CO}_{2} \mathrm{H}$ radical in an aqueous flow system by the reaction of glycine and "hydroxyl" radicals. They find the $\alpha$-proton splitting to be $12.4 \mathrm{G}$ in good agrecment with that found here $(13.5 \mathrm{G})$ for the third radical species of glycine. In addition, they find an isotropic nitrogen coupling of $0.6 \mathrm{G}$. From this value, the nitrogen spin density of 0.26 found by Taniguchi, ct al., to give good agreement with experiment, and the anisotropic hyperfine tensor for an axially symmetric aromatic nitrogen, ${ }^{29} A_{\|}{ }^{\mathrm{N}}$ and $A_{\perp}{ }^{\mathrm{N}}$ arc calculated to be $14.4 \mathrm{G}$ and $2.7 \mathrm{G}$, respectivcly. These values are in excellent agreement with the experimental results of $14.5 \mathrm{G}$ and $<3.5 \mathrm{G}$ found for glycine. The values of $A_{\|}{ }^{\mathrm{N}}$ and $A_{\perp}{ }^{\mathrm{N}}$ found for alanine, leucine, isolcucine. and valine are also in good agreement with the calculated values. This is expected because an $\alpha$ alkyl group should affect the spin density distribution only slightly.

2. L-A sparagine and $\beta$-Alanine. The amino acids discussed below were not found to conform to a general mecliauism. In most cases they reacted in a unique manner depending on their side group. Thus they are discussed individually.

I.-Asparagine. Reaction of the electron with asparagine at $77^{\circ} \mathrm{K}$ produces a radical whose esr spectrum shows a well resolved $24-\mathrm{G}$ doublet (Figure 5a). Upon warming to $180^{\circ} \mathrm{K}$ the doublet splitting increases slightly to $26 \mathrm{G}$; however deamination does not occur. Upon further warming to $190^{\circ} \mathrm{K}$ the doublet converts directly to a spectrum (Figure 5b) characteristic of a third radical species showing a 13.5-G doublet splitting further split by an anisotropic nitrogen with $A_{\|}{ }^{\mathrm{N}} \cong$ 14.5, $A_{\perp}{ }^{\mathrm{N}}<3.5 \mathrm{G}$, and $g_{\perp} \cong g_{\|}$.

Since doublet splittings were not found for carboxylic dianions with side groups such as alanine, leucine, isoleucine, and valine, and since the amide group of acctamide has been found to be quite reactive to electrons, ${ }^{20}$ the first radical species is most likely the anion of the amide group of asparagine. The magnitude of the doublet splitting is that expected for a $\beta$ proton adjacent to the amide carbon at an angle of approximately $25^{\circ}$ (this calculation assumes that the values of $B_{0} p^{*}$ and $B_{2} \rho^{*}$ for acetamide and the aspatagina: annide group

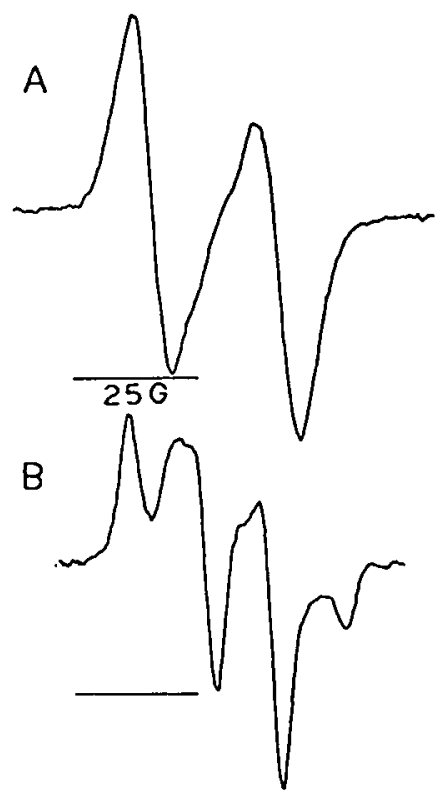

Figure 5. Esr spectra of radical species produced by reaction of electrons with L-asparagine. A, First species, the amide anion, at $175^{\circ} \mathrm{K}$. B, Second radical species at $190^{\circ} \mathrm{K}$. The second species resulted directly from the first. A radical species of the form $\mathrm{HC} \mathrm{CCO}_{2}{ }^{-}$was not observed.

are the same). ${ }^{20}$ The remaining $\beta$ proton which is unresolved must then be at an angle $(\theta)$ near $-95^{\circ}$.

The final species observed upon warming to $190^{\circ} \mathrm{K}$ may be the species associated with abstraction of the $\alpha$ proton. However, the fact that identical hyperfine parameters are found for this species and the glycine third species may point to a unique reaction resulting in $\mathrm{ND}_{2}-\mathrm{C} \mathrm{C}-\mathrm{CO}_{2}-$.

$\beta$-Alanine. Reaction of the electron with $\beta$-alanine at $77^{\circ} \mathrm{K}$ produces the dianion whose esr spectrum consists essentially of a $24-G$ doublet with a further splitting on the up-field line. Upon warming to $180^{\circ} \mathrm{K}$ the spectrum changes to a more nearly symmetric doublet (Figure 6), possibly due to a reorientation of the $\beta$ protons but deamination does not occur. Further warming to $190^{\circ} \mathrm{K}$ results in a loss of signal without observance of a second or third radical species. These results are in agreement with those of product analysis which show $\beta$-alanine does not undergo reductive deamination in aqueous solution. ${ }^{*}$

Reactions of electrons with the amino acids lysine, glutamic acid, phenylalanine, threonine, and serine were also investigated. All formed anion radicals, al-

(28) H. Taniguchi, K. Fukui, S. Ohnishi, II. Hatano, H. Hasegawa, and T. Marusama, J. Phys. Chem., 72, 1920 (1009).

(29) J. N. Ilerack and W'. Cordy, Proc. Nall. Acad. Sci.. 54, 1287 (1965).

(30) R. L. Willin and W. M. Garrison, Radiat. Res., 32, 452 (1967). 


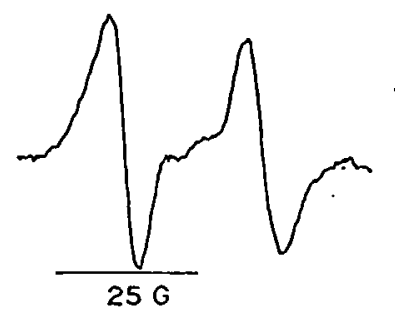

Figure 6. Esr spectrum of the $\beta$-alanine dianion at $180^{\circ} \mathrm{K}$ produced by reaction of electrons with $\beta$-alanine. No further reaction was observed for the dianion.

though threonine and serine produced very litile anion radical, perhaps due to the fact that the parent compound is in the alkoxy! ion form ( $\left.\mathrm{RO}^{-}\right)$befure reaction with the rlectron. Upon warming to $170^{\circ} \mathrm{K}$ lysine and glutamic acid showed evidence of deamination and eventually upon further warming produced spectra characteristic of the third radical species found for the alkyl amino acids. The dianion of phenylulanine did not give evidence of any further reaction.

3. Sulfur-Containing Amino Acids. L-Melhionine. Reaction of the electron with methionine at $77^{\circ} \mathrm{K}$ results in the spectrum in Figure 7 . The sharp 1:3:3:1 quartet of 22.5-G separation is undoubtedly due to the methyl radical. A second singlet species $(g \cong 2.003)$, which is probably the carboxylic dianion, is also present in the spectrum.

The production of methyl radicals must occur by carbon-sulfur bond cleavage<smiles>CCCSCCC(CCCC(C(=O)[O-])[N+](=O)[O-])[N+](=O)[O-]</smiles>

To ensure that the methyl radical did not arise from photolysis, samples were photolyzed in the absence of $\mathrm{K}_{4} \mathrm{Fe}\left(\mathrm{CN}^{-}\right)_{6}$. The results showed no signal due to the methyl radical. Thus it is certain that the methyl radicals are produced by reaction of the electron with methionine.

Upon warming the sample the methyl radical and the carboxylic dianion signals disappear and a new spectrum appears which could and probably does arise from sevcral species formed by renctions of the methyl radicals and the dianion. No assignment is therefore uttempted.

I-Cystine. Cystinc proved to be very reactive toward the electron. Photobleaching a solution of crstine $(1 \mathrm{mI} /)$ and the clectron at $77^{\circ} \mathrm{K}$ produced a bright yellow color associated with the disulfide anion. The esr spectrum shows a single broad (30 G wide) resonance at $g \cong 2.012$. The high $g$ value is indicative

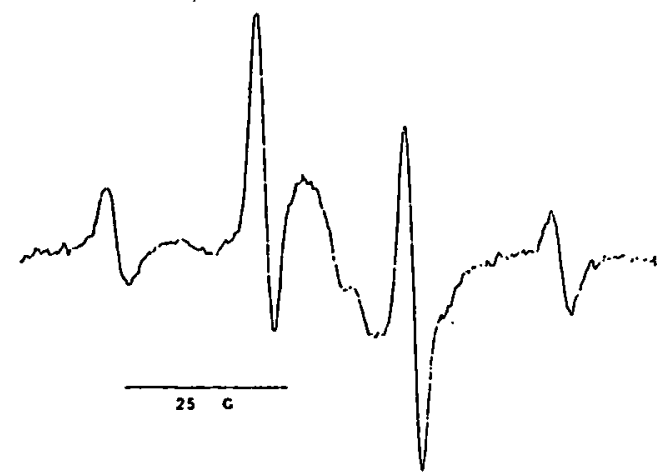

Figure 7. Est spectrum of radical epecies pritincted by reaction of electruns with $\mathrm{L}$-mcthionine at. $77^{\circ} \mathrm{K}$. The sharp four-line spectrum is due to the methyl radical. The broad signal in the central portion of the specturn is most likely the carboxylic dianion.

of a sulfur anion. During warming, the signal decays without the growth of a second species.

\section{Summary and Conclusions}

1. Amino Acids with Reactive Side Groups. The reaction of elcctrons with the amino acids asparagine, methionine, and cystine shows that the reactive side group in these molecules is a point of electron localization or attack. For asparaginc, elcctron attachment to the amide group is indicated. Reactions of electrons with methionine produce methyl radicals by $\mathrm{C}-\mathrm{S}$ bond cleavage. Cystine is found to producc the disulfide anion.

It is felt the results found here for methionine and cystine may be of significance in the interpretation of the results of previous electron spin resontuce studies of irradiated single crystals of methionine ${ }^{31-33}$ and cystine. ${ }^{34.35}$

\&. Glycine and Amino Acids with Alkyl Side Groups. Radical intermediates observed ln this work after oloo. tron attachment. to glycine and L-alanine in an alkaline medium are in agreement with those proposed previously to account for the results of radiolysis cxperiments in aqueous solution at pH 7 ; that is, the electron is found to add to the carboxyl group, the amino acid dianion formed subseçuently deaminates to produce a - $\mathrm{CHRCO}_{2}$ - radical, and this species abstracts from the $\alpha$ carbon of the parent amino acid to form the $\mathrm{ND}_{2-}$ $C(R) \mathrm{CO}_{2}$ - radical. Results found here for the anino acids leucine, isoleucine, and valine are also in agreement with this mechanism.

(31) D. G. Cadena and J. R. Rowlands, J. Chem. Soc., R, 488 (1963).

(32) E. Cipollini and W. Gurdy, J. Chem. Phys., 37, 13 (1962).

(33) J. H. Iladley, Bull. Amer. 1hys. Since, 13, 1695 (1909).

(31) K. Ak:ssak:, S. Ohnishi, 'I'. Suita, and I. Nitti, J. Chrm, Phys.. 40, 3110 (1964).

(35) II. C. Box and H. (i. Freund, ihid., 40, 817 (190(i-1). 
The difference in pH between this work and previous work results in certain differences in the radical specics solely due to protonation. For eximple, the parent compound at $\mathrm{pH} 7$ is the ewitterion, $\mathrm{NH}_{3}+\mathrm{CHRCO}_{2}-$. The anion, deaminated, and final radical specics most likely have the structure $\mathrm{NH}_{3}+\mathrm{CHRCO}_{2} \mathrm{H}^{-}, \cdot \mathrm{CHR}$ $\mathrm{CO}_{2} \mathrm{H}$, and $\mathrm{NH}_{2} \mathrm{C} R \mathrm{CO}_{2} \mathrm{H}$, respectively. The amine group of the third species is not considered to be protonated at $\mathrm{pH} 7$, since esr results in aqueous solution have shown that the amine group of $\mathrm{NH}_{2} \mathrm{CHCO} H$ is unprotonated even at acid $\mathrm{pH} .{ }^{28}$ This differs from results in the solid state which show the amine group is protonated. ${ }^{13}$

As was discussed previously, electron spin resonance investigations of irradiated single crystals of amino acids with alkyl side groups have shown that the clcctron attachment and deamination steps occur but ab- straction from the $\alpha$-carbon position does not occur. Instead, abstraction occurs from the tertiary carbon of the alkyl group. If no tertiary carbon proton is available, as in the case of alanine, abstraction does not occur. The difference in results between the crystalline and aqueous medin is considered significant. It suggests that the environment largely determines the most stable final radical species.

Finally, the fact that the radical intermediates stabilized in an allialine glass correspond to those proposed from studies of the radiolysis of amino acids in aqueous solution (taking into account differences in protonation) suggests the techniques used in this work may be employed in other sy'stems to yield results applicable to the solution chemistry of these systems.

(30) A study of the reactions of electrors and peptides is in progress. 
THIS PAGE

\section{WAS INTENTIONALLY \\ LEFT BLANK}


RADICALS FORMED BY ELECTRON ATTACHMENT TO PEPTIDES ${ }^{1,2}$ by Michael D. Sevilla

Atomics International Division

North American Rockwell Corporation

P. O. Box 309

Canoga Park, California 91304

Journal of Physical Chemistry in press 


\section{ABSTRACT}

The reactions of electrons with a number of peptides, $\mathrm{N}$-acetylamino acids and $\mathrm{N}$-acetylpeptides in an alkaline $\mathrm{D}_{2} \mathrm{O}$ glass have been investigated by use of electron spin resonance (esr) spectroscopy. Results found for dipeptides show that at $77^{\circ} \mathrm{K}$ reaction with the electron forms a dianion. Warming to $180^{\circ} \mathrm{K}$ results in es $\mathrm{r}$ spectra which are consistent with radicals

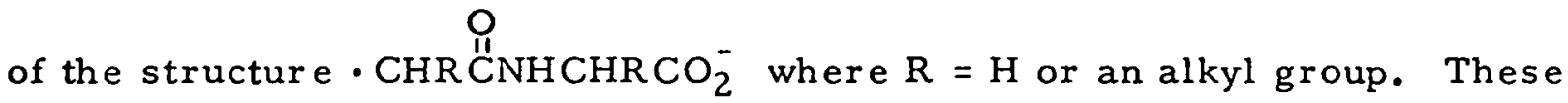
radicals are formed by deamination of the primary or $\mathrm{N}$-terminal amine group. Further warming to the softening point of the glass results in the appearance of a third radical species whose spectra are in most cases consistent with the radical $\mathrm{NH}_{2} \dot{\mathrm{C}} \stackrel{\text { II }}{\mathrm{C}} \mathrm{NHCHRCO}_{2}^{-}$or $\mathrm{NH}_{2} \mathrm{CHR}^{\dddot{O}} \mathrm{NH} \dot{\mathrm{C}} \mathrm{RCO} \mathrm{O}_{2}^{-}$formed by an abstraction reaction between the parent peptide and the deaminated radical. An analogous reaction mechanism to that for dipeptides was founc for the tripeptide L-alanyl-glycylglycine. Electron attachment to N-acely: amino acids results in localization of the electron in the peptide linkage $(-\stackrel{\text { II }}{-} \mathrm{NH}-)$. At $180^{\circ} \mathrm{K}$ the results show that the dianion of the acetylamino acids undergo deamination of the secondary amine group to produce radicals of the structure $\cdot \mathrm{CHRCO}_{2}^{-}$. For $\mathrm{N}$-acetyldipeptides the electron is found to localize predominantly in the N-terminal peptide linkage; however, some localization at the second peptide linkage may also occur. Deamination of a secondary amine group and subsequent abstraction from the parent peptide are found upon warming. The results found here are compared to those found for electron reactions in aqueous solution at $\mathrm{pH} 7$, and radiulysis of the solid state.

$$
\text { AI-A EC- } 12974
$$




\section{INTRODUCTION}

The electron is an important radical intermediate in the radiolysis of water, ${ }^{3}$ and the radiolysis of solids such as amino acids, ${ }^{4-7}$ and peptides. 8 Consequently an investigation of the isolated reactions of electrons with amino acids and peptides should aid the analyses of radiolysis experiments in aqueous media and perhaps in the solid state as well.

The reaction of electrons with amino acids in an aqueous medium (an alkaline glass) have been previously studied by use of electron spin resonance (esr) spectroscopy. ${ }^{4}$ It was found that the electron upon reaction with an amino acid initiated a series of radical producing steps. Radical intermediates were identified which were consistent with the following mechanism:

$$
\begin{aligned}
& \mathrm{NH}_{2} \mathrm{CRHCO}_{2}^{-}+\mathrm{e}^{-} \stackrel{77^{\circ} \mathrm{K}}{\longrightarrow} \mathrm{NH}_{2} \mathrm{CRHCO}_{2}^{\overline{2}} \\
& \mathrm{NH}_{2} \mathrm{CRHCO}_{2}^{-} \leq 180^{\circ} \mathrm{K} \\
& \cdot \mathrm{CRHCO}_{2}^{-}+\mathrm{NH}_{2}^{-} \\
& \cdot \mathrm{CRHCO}_{2}^{-}+\mathrm{NH}_{2} \mathrm{CRHCO}_{2}^{-} \stackrel{>190^{\circ} \mathrm{K}}{\longrightarrow} \mathrm{CH}_{2} \mathrm{RCO}_{2}^{-}+\mathrm{NH}_{2} \dot{\mathrm{CRCO}}_{2}^{-}
\end{aligned}
$$

where $\mathrm{R}=\mathrm{H}$ or an alkyl group.

This mechanism was found to be in agreement with that proposed for the reaction of amino acids and the electron from reaction rate studies and product analysis of the radiolysis of amino acids in aqueous solution. $9 a, b$ The first two steps of the reaction mechanism are also in agreement with those proposed from elcctron spin resonance studies of the radiolysis of solid amino acids. ${ }^{10}$ With these encouraging results it was considered of interest to investigate the reactions of electrons with peptides. 
In previous work Willin and Garrison have found through product analysis and reaction rate studies that in oxygen free aqueous solutions reaction of the electron with glycine dipeptides and tripeptides essentially quantitatively cleaves the $\mathrm{N}-\mathrm{C}$ bond of the primary (terminal) amino group. ${ }^{9 b}$ These workers suggest that electron attachment to the carbonyl linkage next to the terminal amino group precedes deamination.

In this work a study of a number of peptides and acetyl peptides has been performed. This work verifies the conclusion of Willin and Garrison that deamination of primary amine groups occur and further shows that it extends to peptides composed of glycine and amino acids with alkyl side groups. Results are found which confirm the suggestion electron localization occurs at the peptide linkage for dipeptides and predominantly at the $\mathrm{N}$-terminal peptide linkage in tripeptides. In addition, evidence for $a_{2}$ abstraction step analogous to that found in amino acids (reaction 3) is found.

\section{EXPERIMENTAL}

The peptides used in this work were obtained from Cyclo Chemical Company and were the highest grade available.

The experimental procedure employed has been described previously. $4,11,12$ In this procedure a deoxygenated $8 \mathrm{~N} \mathrm{NaOD}\left(95 \% \mathrm{D}_{2} \mathrm{O}\right)$ solution containing $5 \mathrm{mM} \mathrm{K}_{4} \mathrm{Fe}(\mathrm{CN})_{6}$ and ca $50 \mathrm{mM}$ solute (peptide) is cooled to $77^{\circ} \mathrm{K}$ to form a glass. The glass formed is photolyzed with $2537 \AA$ UV light at $77^{\circ} \mathrm{K}$ for approximately one minute. The photolysis produces a dark blue color due 
to the electron by photoionization of the $\mathrm{K}_{4} \mathrm{Fe}(\mathrm{CN})_{6}$. At this point, an esr spectrum is taken of the sample to insure that photolysis of the organic solute is minimal. ${ }^{13}$ The sample is then photobleached at $77^{\circ} \mathrm{K}$ with light from an infrared lamp for approximately four minutes. The electrons become mobile and react with the solute. An esr spectrum is then taken of the sample. The solutions were prepared with $\mathrm{D}_{2} \mathrm{O}$, since this results in improved resolution of the es $\mathrm{r}$ signal.

To prevent hydrolysis of the peptides the solutions were prepared when necessary by addition of the peptide dissolved in a small amount of $\mathrm{D}_{2} \mathrm{O}$ to the cooled $\left(<0^{\circ} \mathrm{C}\right)$ alkaline $\mathrm{NaOD}$ solution. The sample is then quickly $(<20 \mathrm{sec})$ prepared and cooled to $77^{\circ} \mathrm{K}$.

A Varian V4500-10esr spectrometer equipped with a dual cavity, Fieldial magnetic field regulator and variable temperature accessory was employed in this work. Measurements of hyperfine splittings and g values were made vs. potassium peroxylamine disulfonate $\left(A_{N}=13.0\right.$ Gauss, $\left.g=2.0056\right)$.

\section{RESULTS AND DISCUSSION}

1. Electron Reactions with Dipeptides

The reactions of electrons with dipeptides were investigated to determine whether primary or secondary deamination results from electron attachment. For this reason dipeptides of the form $\mathrm{NH}_{2} \mathrm{CHRCNHCHR}^{\prime \prime C O}{ }_{2}^{-}$ where $R \neq R^{\prime}$ were principally investigated. The differing side groups ease the identification of the resulting radical species and consequently the deamination process. 
a. Glycyl-L-Alanine, L-Alanylglycine, and Glycylglycine

At $77^{\circ} \mathrm{K}$ electron attachment to the dipeptides gly-ala, ala-gly and gly-gly results in es $r$ spectra which are associated with the dianion radicals (reaction 4 ).

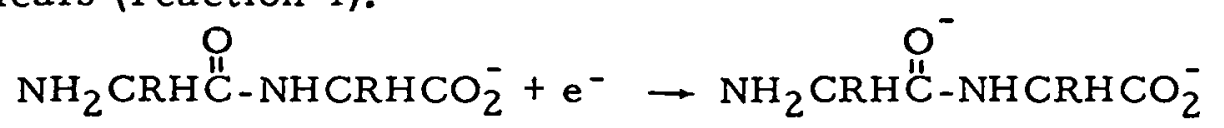

The spectra for gly-ala and ala-gly (Figures IA and 2A) show little resolution of structure. The spectrum of gly-gly shows a $22 \mathrm{G}$ doublet. Warming the samples containing the dianion radicals to $180^{\circ} \mathrm{K}$ results in esr spectra which are indicative of primary deamination reaction 5 .

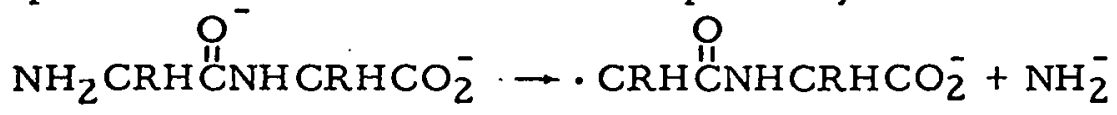

Thus for gly-ala a three line spectrum of $22 \mathrm{G}$ separation in the intensity ratio ca $1: 2: 1$ (Figure $1 \mathrm{~B}$ ) is found which is expected from the $\cdot \mathrm{CH}_{2} \stackrel{\mathrm{O}}{\mathrm{C}} \mathrm{NH} \sim_{\sim}$ radical. 4 In the case of ala-gly a spectrum (Figure $2 B$ ) consisting of five lines separated by $24 \mathrm{G}$ is found as expected for the $\cdot \mathrm{CH}\left(\mathrm{CH}_{3}\right) \stackrel{\text { II }}{\mathrm{C}} \mathrm{H}-$ radical. $4,8,15-17$

The evidence for the $\mathrm{N}$ =lerinimal or prinary deamination step for gly-ala and ala-gly is made stronger by a consideration of the other possible deamination site, that is deamination of the secondary amine group. If this reaction took place a spectrum of the $\cdot \mathrm{CH}_{2} \mathrm{CO}_{2}^{-}$radical would be found for ala-gly and a spectrum of the $\cdot \mathrm{CHCH}_{3} \mathrm{CO}_{2}^{-}$radical would be found for gly-ala. It should be first noted that the spectra in Figures $\mathrm{IB}$ and $2 \mathrm{~B}$ are not in agreement with the structure of these 
radicals. In addition the esr spectra of these radical species were found to show well resolved anisotropic hyperfine components; 4 consequently if they were formed in significant concentrations they would be easily detected. The spectra in Figures $1 \mathrm{~B}$ and $2 \mathrm{~B}$ show no evidence of these radicals; thus very little, if any, secondary deamination occurs.

Results for gly-gly are also in agreement with the primary deamination mechanism. The spectrum found at $180^{\circ} \mathrm{K}$ is nearly identical to that found for gly-ala (Figure IB). If secondary deamination occurred the anisotropic components of the $\cdot \mathrm{CH}_{2} \mathrm{CO}_{2}^{-}$radical would be observed. Since no such components are observed, it is evident that only primary deamination occurs.

Further warming of the sample containing the deaminated radical species and the parent dipeptide to $190^{\circ} \mathrm{K}$ where the glass softens resuits. in a third esr spectrum. This final spectrum consists of a $14 \mathrm{G}$ doublet for gly-ala (Figure 1C), a 13.5G doublet for ala-gly (Figure 2C) and a $14 \mathrm{G}$ doublet for gly-gly. 19 A similar doublet of $13.5 \mathrm{G}$ was found for the third radical species of glycine produced by the abstraction reaction (reaction 3). It is therefore considered likely that an abstraction step like that found for the individual amino acids occurs for the dipeptides as well. This abstraction is shown below (reaction 6)for gly-gly.<smiles>CC(=O)NCC(=O)C[C@H](CC(=O)NCC(=O)NCC(=O)[O-])C(=O)[O-]</smiles> 
A radical of the form $\mathrm{NH}_{2} \dot{\mathrm{C}} \stackrel{\text { Ö }}{\mathrm{C}} \mathrm{NHCH}_{2} \mathrm{CO}_{2}^{-}$would result in a similar spectrum and may be produced as well.

The results for gly-ala and ala-gly are somewhat more complex since $\alpha$ carbon radicals may be produced on either the glycyl or alanyl residues. Since a quartet would be expected for the alanyl $\alpha$-carbon radical, $8,16,17$ the spectra found suggest the predominant radical formed is that on the glycyl residue; however, for ala-gly and gly-ala the small end components may be indicative of some abstraction from the alanyl residue. 20

Further warming of the sample or long standing at $190^{\circ} \mathrm{K}$ results in a loss of the esr signal due to the final radical species. This is most likely a result of radical-radical recombination. b. Glycyl-L-leucine and Glycyl-L-valine

The spectra found for gly-leu and gly-val after electron attachment and warming to $180^{\circ} \mathrm{K}$ are essentially the same as those found for gly-ala. At $90^{\circ} \mathrm{K}$ a partially resolved spectrum due to the dianion is found (Figure $3 \mathrm{~A}$ ). Warming tn $180^{\circ} \mathrm{K}$ results in a $1: 2: 1$ triplet of $22 \mathrm{G}$ separation (Figure $3 \mathrm{~B}$ ) for both molecules. No evidence is found for either leucyl or valyl radicals in this step; ${ }^{4}$ consequently evidence for significant secondary deamination is not found. Thus primary deamination as in reaction 5 occurs for these dipeptides as well.

Warming the gly-leu sample to $190^{\circ} \mathrm{K}$ where the glass softens and then recooling to $180^{\circ} \mathrm{K}$ resulted in a spectrum (Figure $3 C$ ) which consists of 
six resolved components. The total width of the spectrum (120G), the regularity of spacing (24G), and the relatively narrow linewidths of the outcr four lines (7G) suggest a radical with a number of equivalent $\beta$-protons. Such a radical has been observed previously in irradiated solid leucine, 21 as well as hydrogen bombarded solid leucine, 22 and poly-d, 1-leucine. 15 For the amino acids the radical has been assigned the structure $\mathrm{CH}_{3} \cdot \mathrm{C}-\mathrm{CH}_{2}-\mathrm{CH}\left(\mathrm{NH}_{2}\right) \mathrm{CO}_{2} \mathrm{H} \cdot{ }^{21,22}$ At $77^{\circ} \mathrm{K}$ this radical shows an eight line spectrum due to equal coupling with the methyl protons and one of the methylene protons. The intensity ratios are theoretically $1: 7: 21: 35: 35: 21: 7: 1$ and the hyperfine splitting is in the range 23 to $25 \mathrm{G}$. The intensity ratios of the lines with the expected ratio $7: 21$ are in the ratio of ca. $7: 18$. The hyperfine splitting of $24 \mathrm{G}$ is also in good agreement with such a radical. The intensities of the central pair of lines are greater than expected from the above radical species alone. Another species is present which has a doublet splitting. This species is most likely that produced by abstraction of an $\alpha$-carbon hydrogen atom.

Rewarming the glass to its softening point for a few minutes results in a loss of the spectrum of the leucyl alkyl radical. A partially resolved doublet of ca $15 \mathrm{G}$ remains and is increased in intensity. This suggests a further reaction, i.e. abstraction of an $\alpha$-carbon hydrogen atom by the leucyl alkyl radical.

The abstraction of the tertiary hydrogen atom from the alkyl group of the leucyl residue is a somewhat surprising result. This is because 
(1) abstraction from the $\alpha$-carbon not the alkyl side group was found fur: amino acids, 4 and (2) the alkyl radical evidently later abstracts from the $\alpha$-carbon position. A possible explanation for these results is that the tertiary radical is formed by intramolecular abstraction (reaction 7)<smiles>CC(=O)NC(CC(C)(C)C)C(=O)[O-]</smiles>

just as the glass softens but before diffusion through the glass occurs. Rewarming the glass so that appreciable diffusion takes place allows the alkyl radical to abstract from an $\alpha$-carbon position.

It should be noted that in the case of the amino acid leucine, the leucyl $\alpha$-carbon radical produces a $13 G$ doublet es $r$ spectrum due to interaction of one of the $\beta$-protons on the alkyl side group. ${ }^{4}$ In irradiated polyleucine a $21 \mathrm{G}$ doublet is found due to the analogous radical, $\left(-N H-\dot{C} R-\ddot{C}_{-}\right) .^{8}$ The $15 \mathrm{G}$ doublet found in this casc is in the range expected for a $\alpha$-carbon radical on the leucyl residue. It is expected that the spectrum consists of an overlap of both the leucyl and glycyl $\alpha$-carbon radicals. Since the spectra expected for the two radicals are so similar, no estimate cun be made of the relative amounts of each present.

2. Reaction of electrons with a tripeptide: L-Alanylglycylglycine

Electron attachment to ala-gly-gly at $77^{\circ} \mathrm{K}$ results in a broad partially resolved singlet esr spectrum which is attributed to the dianion. Warming to $180^{\circ} \mathrm{K}$ results in a spectrum similar to that found for ala-gly with the 
exception that the central component is more intense than expected. The deamination step is slow and the large intensity of the central peak is probably due to unreacted dianion. Further warming to $190^{\circ} \mathrm{K}$ results in a well resolved doublet of $13 \mathrm{G}$ similar in line shape to that found for ala-gly. These results suggest that the reaction mechanisms found for dipeptides apply to tripeptides as well.

3. Reaction of Electrons with N-Acetylamino acids and N-Acetylpeptides

The reaction of electrons with $\mathrm{N}$-acetylamino acids and peptides were investigated to determine whether electron localization on the peptide occurs. If localization does occur it is of interest to determine on which peptide unit the electron localizes. The acetyl-methyl group at the peptide end should aid in this determination since it should act as a probe to ascertain the unpaired electron density at the terminal peptide linkage. Since the possibility of primary deamination is eliminated for acetyl amino acids and peptides, it is also of interest to determine whether secondary deamination occurs.

\section{a. N-Acetyl amino acids}

Electron attachment to $\mathrm{N}$-acetylglycine, $\mathrm{N}$-acetyl-L-alanine, and $\mathrm{N}$-acetyl-L-valine produce esr spectra which show 30 to $32 \mathrm{G}$ doublets at $90^{\circ} \mathrm{K}$. The spectra are shown in Figures $4 \mathrm{~A}, 5 \mathrm{~A}$ and $6 \mathrm{~A}$. Warming the samples to $170^{\circ} \mathrm{K}$ results in a quartet of ca $13.5 \mathrm{G}$ separation for each of the dianions (Figures 4B, 5B and $6 \mathrm{~B}$ ). This process is reversible, that is, cooling to $90^{\circ} \mathrm{K}$ results in the original doublet. The reversibility shows that no 
chemical reaction has taken place and suggests the change in spectra is due to a change in the configuration of the acetyl-methyl group. A similar phenomenon has been found to occur for the acetamide anion. At $85^{\circ} \mathrm{K}$ the esr spectrum of this species consists of a $30.8 \mathrm{G}$ doublet. Upon warming to $180^{\circ} \mathrm{K}$ the doublet reversibly converts to a $1: 3: 3: 1$ quartet of $13.5 \mathrm{G}$ separation. This phenomenon was interpreted on the basis that the methyl group was freely rotating at $180^{\circ} \mathrm{K}$ and locked in a particular conformation at the lower temperature so as to produce one large hyperfine splitting. Since the structure of acetamide is that of the end portion of the acetyl peptides, the nearly identical hyperfine splittings found for the locked conformation and the more freely rotating case can only be explained if the unpaired electron is localized at the acetylpeptide linkage $\left(\mathrm{CH}_{3}-\mathrm{C}-\mathrm{NH}-\right)$. The spin densities found to agree with the hyperfine splittings in acetamice anion place 0.69 of the unpaired spin at the carbonyl carbon, 0.23 at the oxygen, and 0.06 at the nitrogen. 23 The similarity in hyperfine splittings suggest these densities apply to the acetylamino acid dianions as well. As can be seen in Figures $4 B, 5 B$ and $6 B$ spectra found for the quartet in some cases differ significantly from the $1: 3: 3: 1$ intensity ratio expected for a freely rotating methyl group. This is not unexpected since similar intensity ratios are found for acetamide anion at temperatures below $170^{\circ} \mathrm{K} .23$

Warming the acetyl amino acid anions to $185^{\circ} \mathrm{K}$ results in the spectra shown in Figures 4C, 5C and 6C. These spectra are identical to 
those found for the corresponding deaminated amino acids; that is, the spectra in Figures $5 \mathrm{C}$ and $6 \mathrm{C}$ for acetylalanine and acetylvaline are identical to those found for deaminated alanine and valine. The spectrum (Figure 4C) found for acetylglycine shows some evidence of unreacted dianion; otherwise it is identical to that found for deaminated glycine. These results present convincing evidence that secondary deamination occurs via the reaction:

$$
\mathrm{CH}_{3}-\stackrel{\mathrm{O}^{-}}{\mathrm{C}}-\mathrm{NH}-\mathrm{CHRCO}_{2}^{-} \rightarrow \mathrm{CH}_{3}-\stackrel{\mathrm{O}}{\mathrm{C}}-\mathrm{NH}^{-}+\cdot \mathrm{CHRCO}_{2}^{-}
$$

Further warming to the softening point of the glass resulted in third radical species in the cases of acetylglycine and acetylvaline.

\section{b. N-Acetyl-Dipeptides}

The results for the acetyl amino acids show that electron localization occurs at the peptide bond in preference to a carboxyl group. It is of interest to determine where electron localization occurs when there is a choice of peptide bonds. For this reason two acetyl dipeptides were studied. They are acetylglycyl-L-leucine and acetylglycylglycine. The spectra found after electron attachment to the former is shown in Figure 7. The results expected for localization at the end peptide bond are found. The 27 doublet spectrum at $90^{\circ} \mathrm{K}$ reversibly converts to the quartet of $13 \mathrm{G}$ separation at $165^{\circ} \mathrm{K}$. The intensities of the individual components of the quartet are far from the $1: 3: 3: 1$ expected for a freely rotating methyl group. This suggests considerable hindrance to rotation at $165^{\circ} \mathrm{K}$. It should also 
be noted that due to the poor resolution the possibility of a sigrificant amount of localization at the second peptide bond cannot be eliminated. Warming the sample to $180^{\circ} \mathrm{K}$ results in a spectrum which consists of three major components separated by $22 \mathrm{G}$ in a ca $1: 2: 1$ intensity ratio. This spectrum is good evidence that radical formed in this step is a glycyl-like radical and that secondary deamination of the acetyl peptide unit occurs. The radical formed in this process should be the same as that formed by the primary deamination of gly-leu. The spectra found for the two cases (Figure 7C and Figure 3B) are quite similar but not identical. This is probably a result of the fact that in this case the deamination step was slow to occur and a small amount of the dianion remains. It is also possible that a small amount of secondary deamination at the gly-leu bond occurs; however, the radical produced in this prucess (deaminated leucine radical) has a spectral width of $88 \mathrm{G}$. Therefore if it were formed in significant amounts it would have components outside those of the glycyl radical and it would be easily observable. The spectrum shows no evidence of this species.

Further warming to $190^{\circ} \mathrm{K}$ results in a $13 \mathrm{G}$ doublet (Figure $7 \mathrm{D}$ ) characteristic of abstraction from an $\alpha$-carbon position.

Somewhat different results are found for $\mathrm{N}$-acetyl-gly-gly. At $90^{\circ} \mathrm{K}$ a $26 \mathrm{G}$ doublet is found which converts reversibly to a quartet whose components are separated by $13.4 \mathrm{G}$ at $170^{\circ} \mathrm{K}$. The spectrum found at $170^{\circ} \mathrm{K}$ 
is less rcsolved than that found for the acetyl amino acids and may indicate some localization at the second peptide bond. Warming the sample to $180^{\circ} \mathrm{K}$ gives evidence for only partial deamination. The lineshapes of the deaminated species resemble that of $\cdot \mathrm{CH}_{2} \mathrm{CO}_{2}^{-}$(Figure $4 \mathrm{C}$ ) rather than

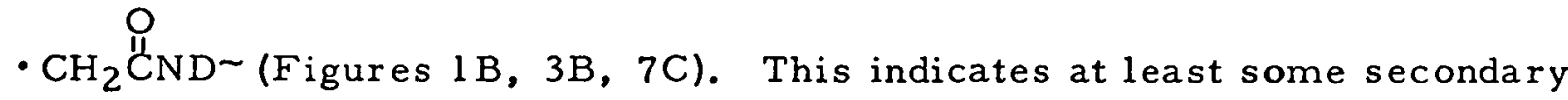
deamination of the C-terminal group. Complete deamination does not occur until temperatures are reached where the glass softens. At these temperatures $\left(190^{\circ} \mathrm{K}\right)$ a $13.2 \mathrm{G}$ doublet with components due to an anisotropic nitrogen is found which is indicative of abstraction of a hydrogen atom from an $\alpha$-carbon.

Although the results for the acetyl dipeptides may suggest some localization at the C-terminal peptide bond, the spectra give good evidence that the predominant localization is at the $\mathrm{N}$-terminal.

\section{c. N-Acetyl glycylglycine methyl ester}

The localization of the free electron at the $\mathrm{N}$-terminal peptide bond can. be explained by either of two hypotheses. First it may be due to simple charge repulsion. This is because in $8 \mathrm{~N} \mathrm{NaOH}$ the carboxyl group is unprotonated and carries a negative charge. Therefore avoidance of the charge on the carboxyl group may result in localization of the electron at the $\mathrm{N}$-terminal peptide linkage. Second, the $\mathrm{N}$-terminal peptide linkage may form a deeper potential energy well than the other linkages and thus preferentially trap the electron. 
To test the first hypothesis acetyl-gly-gly methyl ester was reacted with the electron. Esterification of the carboxyl group removes the charge on the group without greatly changing the electronic structure of the peptide. The spectra found after electron attachment are shown in Figure 8 . The conversion from the $27 \mathrm{G}$ doublet in Figure $8 \mathrm{~A}$ to the quartet of $13.5 \mathrm{G}$ separation in Figure $8 \mathrm{~B}$ is reversible. These results demonstrate electron localization at the $\mathrm{N}$-terminal bond is not a result of charge repulsion. This suggests an inherent property of the electronic structure of the peptide causes localization at the $\mathrm{N}$-terminal peptide bond.

The results found on warming the anion to $185^{\circ} \mathrm{K}$ are somewhat unexpected (see Figure $8 \mathrm{C}$ ). The spectrum found consists of a triplet in the intensity ratio $1: 2: 1$ with a $15 \mathrm{G}$ separation.

The $15 \mathrm{G}$ splitting and the narrow central component are not consistent with radicals of structure $\cdot \mathrm{CH}_{2} \stackrel{\mathrm{R}}{\mathrm{C}} \stackrel{\mathrm{R}}{\mathrm{NHCHCOCH}_{3}}$ or $\cdot \mathrm{CH}_{2} \stackrel{\mathrm{R}}{\mathrm{COCH}_{3}} \cdot$ Results found for the reaction of electrons... with glycine methyl ester suggest that the radical formed has the structure $-\stackrel{\stackrel{\mathrm{O}}{\mathrm{COCH}}}{\mathrm{OCH}_{2}} \cdot 24$ The formation of this species could be a result of intra- or inter-molecular abstraction after deamination.

Further warming of the sample results in a spectrum (Figure 8D) associated with abstraction from an $\alpha$-carbon position in the parent peptide. 
This may indicate that the abstraction reaction which produced the II $-\stackrel{\mathrm{C}}{\mathrm{O}} \mathrm{CH}_{2} \cdot$ radical was intramolecular in nature. Comparison to Other Work and Conclusions

In previous work it has been found by Willin and Garrison through product analysis and reaction rate studies that electron attachment to gly-gly and gly-gly-gly in dilute aqueous solutions at $\mathrm{pH} 7$ results in deamination of the primary amine group. ${ }^{9 b}$ These workers suggest that electron attachment to the peptide linkage adjacent to the primary amine group precedes the deamination. The results found here confirm those of the previous work and show that primary deamination extends to other peptides composed of glycine and amino acids with alkyl side groups. The suggestion of electron attachment \pm 0 the $\mathrm{N}$-terminal peptide linkage is in good agreement with results found for the $\mathrm{N}$-acetylamino acids; although the acetylpeptides may suggest some localization of the electron at the second peptide bond.

The localization of the electrons at the $\mathrm{N}$-terminal peptide linkage is most likely due to a deeper potential well for the end linkage. However, the potential energy difference between peptide linkages cannot be very large. One should therefore expect the effects of electron migration between the various peptide units at higher temperatures. Thus the preferential deamination of the one amino group over another may be more due to the competitive rates of deamination rather than simply localization 
itself. This is clearly indicated by the fact that the primary amine group deaminates in dipeptides even though the electron is localized at the peptide linkage. This extends to the acetyldipeptides where the "weakest" bond would be expected to rupture even though the electron is "localized" at the $\mathrm{N}$-terminal linkage.

Rodgers, Sokol, and Garrison have studied the reactions of electrons produced by radiolysis with $\mathrm{N}$-acetylpeptides in $\mathrm{H}_{2} \mathrm{O}$ solution at $\mathrm{pH} 7{ }_{7}{ }^{25}$ In dilute solutions reaction of the electron with $\mathrm{N}$-acetylalanine is shown to lead to liberation of the free amino acid alanine. This is not in accord with the mechanism found here in $8 \mathrm{~N} \mathrm{NaOH}$ (reaction 7). An explanation may be that in this case the mechanism for product formation is $\mathrm{pH}$ dependent.

There are a number of studies of the radiolysis of peptides in the solid state. $8,16,17,26-29$ Several of these studies give evidence that radicals of the type $\cdot \mathrm{CHR}^{\mathrm{I}} \mathrm{NH}^{\sim}$ are formed by cleavage of primary or secondary amine linkages and that these species further react probably by abstraction to form the usual $\alpha$-carbon radical. 8,16 It is interesting to note that the first species could be a result of primary or secondary deamination caused by the electrons produced during radiolysis. However, the reactions of positive ions, ${ }^{8}$ excited molecules, ${ }^{30}$ and hydrogen atoms $15,31,32$ must be considered as well. 
The author wo uld like to thank R. A. Holroyd of Brookhaven National Laboratory, as well as, L. S. Myers and J. Ward at the Laboratory of Nuclear Medicine and Radiation Biology, UCLA, for helpful discussions. The author would also like to thank the Division of Biology and Medicine of the U.S. Atomic Energy Commission for support of this work. 


\section{REFERENCES}

1. This work was supported by the Division of Biology and Medicine of the U. S. Atomic Energy Commission.

2. This work was presented in part at the 158th Meeting of the American Chemical Society, New York, September 9, 1969.

3. E. Hayon, in Radiation Chemistry of Aqueous Systems, Stein, Gabriel editors, New York, John Wiley and Sons, Inc., 1968, pp 157-209.

4. M. D. Sevilla, J. Phys. Chem.,74,2096 (1970).

5. J. Sinclair and M. W. Hanna, J. Phys. Chem., 71, 84 (1967).

6a. H. C. Box, E. E. Budzinski and H. G. Freund, J. Chem. Phys.,50, 2880 (1969).

b. H. C. Box, H. G. Freund, K. T. Lilga, E. E. Budzinski, J. Phys. Chem., 74, 40 (1970).

7. P. B. Ayscough and A. K. Roy, Trans. Faraday Soc., 64, 582 (1968)。

8. R. C. Drew and W. Gordy, Radiat. Res., 18, 552 (1963).

9a. D. B. Peterson; J. Holian, and W. M. Garrison, J. Phys. Chem., 73, 1181 (1969).

b. R. L. Willin and W. M. Garrison, Radiat. Res., 32, 452 (1967).

10. An abstraction step is also found in solid amino acids; however, it differs from abstraction in aqueous media (see ref 4 for a discussion).

11. P. B. Ayscough, R. G. Collins and F.S. Dainton, Nature, 205, 965 (1965).

12. R. A. Holroyd and J. W. Glass, Int. J. Rad. Biol., 14, 445 (1968).

13. Photolysis of solid peptides has been found to produce radicals (see A. Meybeck and J. J. Windle, Photochem. Photobiol, 10, 1 (1969)). The short photolysis time, the relatively low concentration of the peptide, and the absorbance of the $\mathrm{K}_{4} \mathrm{Fe}(\mathrm{CN})_{6}$ in the $\mathrm{UV}$ prevented any significant photolysis in this work. 
14. The splitting for gly-gly presumably arises from the interaction of the unpaired electron localized in the peptide linkage (see section 3 ) with a proton at the $\mathrm{N}$ terminal $\alpha$-carbon position. The lack of structure in the spectra found for gly-ala and ala-gly is most likely due to the orientation of the protons to produce only a small $\beta$-proton hyperfine splitting.

15. F. G. Liming, Radiat. Res., 39, 252 (1969).

16. A. Meybeck and J. Windle, Radiat. Res., 40, 263 (1969).

17. H. C. Box, H. G. Freund and K. Lilga, in Free Radicals in Biological Systems, M. S. Blois, Ed., Academic Press, New York, 1961, pp 239-248.

18. The lack of resolution of anisotropic components in the . CHRC $-\mathrm{NH} \sim$ radicals may be due to broadening of hyperfine components due to unresolved nitrogen splittings.

19. These results compare favorably with the radiolysis of glycine peptides in their solid state. For the se peptides 16-17G doublet spectra are found which are attributed to $\alpha$-carbon radicals (See Ref. 8, 16, 17 and R. S. Mangiaracina, Radiat. Res., 32, 27 (1967)).

20. It should be noted that these components may also arise from anisotropic nitrogen hyperfine couplings. Such components are observed from the amino acid $\alpha$-carbon radicals (Ref. 4), but have not been previously observed in polycrystalline peptides.

21. F. Patten and W. Gordy, Radiat. Res., 14, 573 (1961).

22. W. Snipes and J. Schmidt, Radiat. Res., 29, 194 (1966).

23. M. D. Sevilla, J. Phys. Chem., 74, 669 (1970). 
24. The reaction of electrons with glycine methyl ester results in deamination at $\leq 170^{\circ} \mathrm{K}$ to produce a radical of structure $\cdot \mathrm{CH}_{2} \mathrm{C}(\mathrm{O}) \mathrm{OCH}_{3}$. This species yields a spectrum showing distinct anisotropic components very similar to that found for $\mathrm{CH}_{2} \mathrm{CO}_{2}^{-}$. However, warming to $185^{\circ} \mathrm{K}$ results in a new spectrum virtually identical to that found in Figure $8 \mathrm{C}$. Since cooling does not result in the original spectrum and since the isotropic and anisotropic hyperfine splittings are so different for the two spectra, it is concluded that a new radical has been produced. The methoxy methyl group is the only possible site of abstraction which would produce a spectrum due to two equivalent protons. It is therefore considered likely that this new radical has the structure $\cdot \mathrm{CH}_{2} \mathrm{OC}(\mathrm{O}) \sim$ (the complete structure depends on whether the abstraction is intraor intermolecular). This interpretation is supported by the fact that a reduced hyperfine splitting would be expected for a radical of the above structure. For example a $17.4 \mathrm{G}$ splitting is found for the $\cdot \mathrm{CH}_{2} \mathrm{OH}$ radical ( $R$. Livingston and $\mathrm{H}$. Zeldes, J. Chem. Phys., 44, 1245 (1966)).

25. M. A. J. Rodgers, H. A. Sokol, W. M. Garrison, J. Am. Chem. Soc., 90, 4720 (1968).

26. W. C. Lin and C. A. McDowell, Mol. Phys., 4, 333 (1961).

27. M. Katayamaand, W. Gordy, J. Chem. Phys., 35, 117 (1961).

28. R. S. Mangiaracina, Radiat. Res., 32, 27 (1967).

2.9. A. F. Isatyi, V. I. Panin, M. A, Ponomareva-Stepnaya, and L. A. Molodov, Khim. Vys. Energ. 2, 444 (1968).

30. M. A. J. Rodgers and W. M. Garrison, J. Phys. Chem. 72, 758 (1968); Int. J. Radiat. Phys. Chem., I, 541, (1969).

31. R. Braams, Nature,200, 152 (1966).

32. R. A. Holroyd, J. W. Glass, P. Riesz, Radiat. Res., in press. 
FIGURE LEGENDS

Figures 1-3 Electron spin resonance spectra of radical species produced by reaction of electrons with glycyl-L-alanine (Figure 1), Lalanylglycine (Figure 2), and glycyl-L-leucine (Figure 3 ) in a deuterated alkaline glass. A. The dianion species formed by electron attachment at $77^{\circ} \mathrm{K}$. B. The second radical species,

- $\mathrm{CHR} \stackrel{\text { IINHCHRCO }}{-}$, produce by deamination of the primary amine group upon warming to $180^{\circ} \mathrm{K}$. C. The third radical species at $190^{\circ} \mathrm{K}$ produced by hydrogen abstraction from an $\alpha$-carbon. The third spectrum of glycyl-L-leucine shows evidence of abstraction from the leucine side group as well (see text for a discussion). The magnetic field increases from left to right for each spectrum in these figures and subsequent figures.

Figures 4-6 Esr spectra of radical species produced by reaction of electrons with $\mathrm{N}$-acetylglycine ( $F$ igure 4$), \mathrm{N}$-acetyl-L-alanine (Figure 5), and $\mathrm{N}$-acetyl-L-valine (Figure 6). A. The dianion species at $90^{\circ} \mathrm{K}$ produced by electron attachmient to the peptide linkage. The doublet spectra arise from interaction of one of the acetylmethyl group protons. B. Same radical species as in A at $170^{\circ} \mathrm{K}$. These spectra show evidence of a more freely rotating: methyl group. The conversion from $A$ to $B$ is reversible. C. The radical species, $\cdot \mathrm{CHRCO}_{2}^{-}$produced by deamination of the secondary amine group at ca $180^{\circ} \mathrm{K}$.

Figures 7-8 Esr spectra of radical species produced by reaction of electrons with $\mathrm{N}$-acetylglycyl-L-leucine (Figure 7) and $\mathrm{N}$-acetylglycylglycine methyl ester (Figure 8). A. The dianions at $90^{\circ} \mathrm{K}$. B. Same species at $170^{\circ} \mathrm{K}$. The conversion from the doublets in Figures $A$ to the quartet in Figures $B$ is reversible. This shows that the electron is predominantly localized in $\mathrm{N}$-terminal peptide linkage. C. Radicals produced by further warming. Figure $7 \mathrm{C}\left(180^{\circ} \mathrm{K}\right)$ indicates $\mathrm{N}$-terminal deamination and Figure $8 \mathrm{C}$ $\left(185^{\circ} \mathrm{K}\right)$ suggests a radical of structure $\cdot \mathrm{CH}_{2} \mathrm{OC}(\mathrm{O})^{-}$is produced. D. Third radical species at $190^{\circ} \mathrm{K}$. These spectra are indicative of abstraction from an $\alpha$-carbon position. 


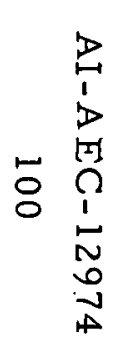
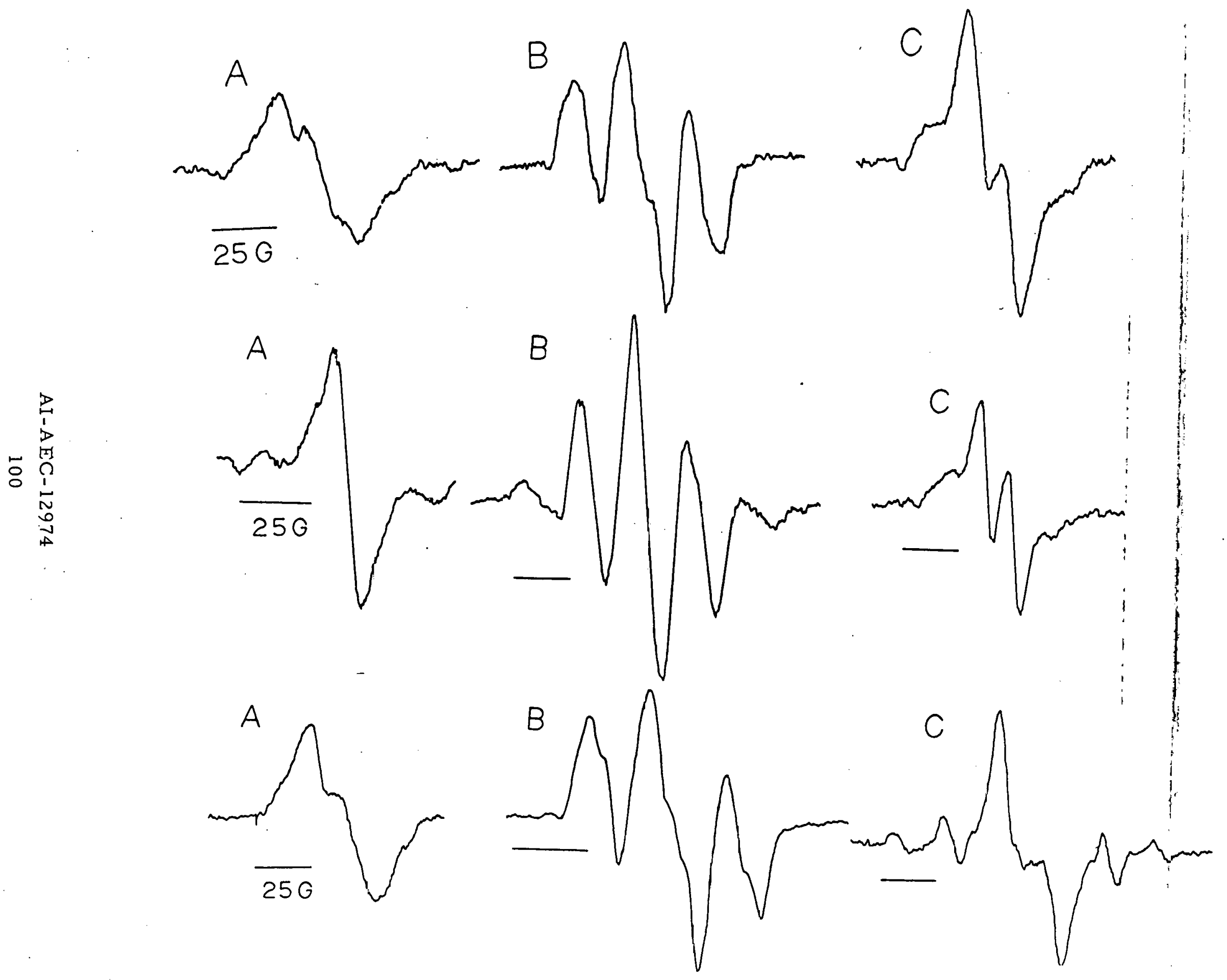


$$
\begin{aligned}
& \text { - vimridur } \\
& \text { Ahrimp-iffr } \\
& \text { offrilf is }
\end{aligned}
$$




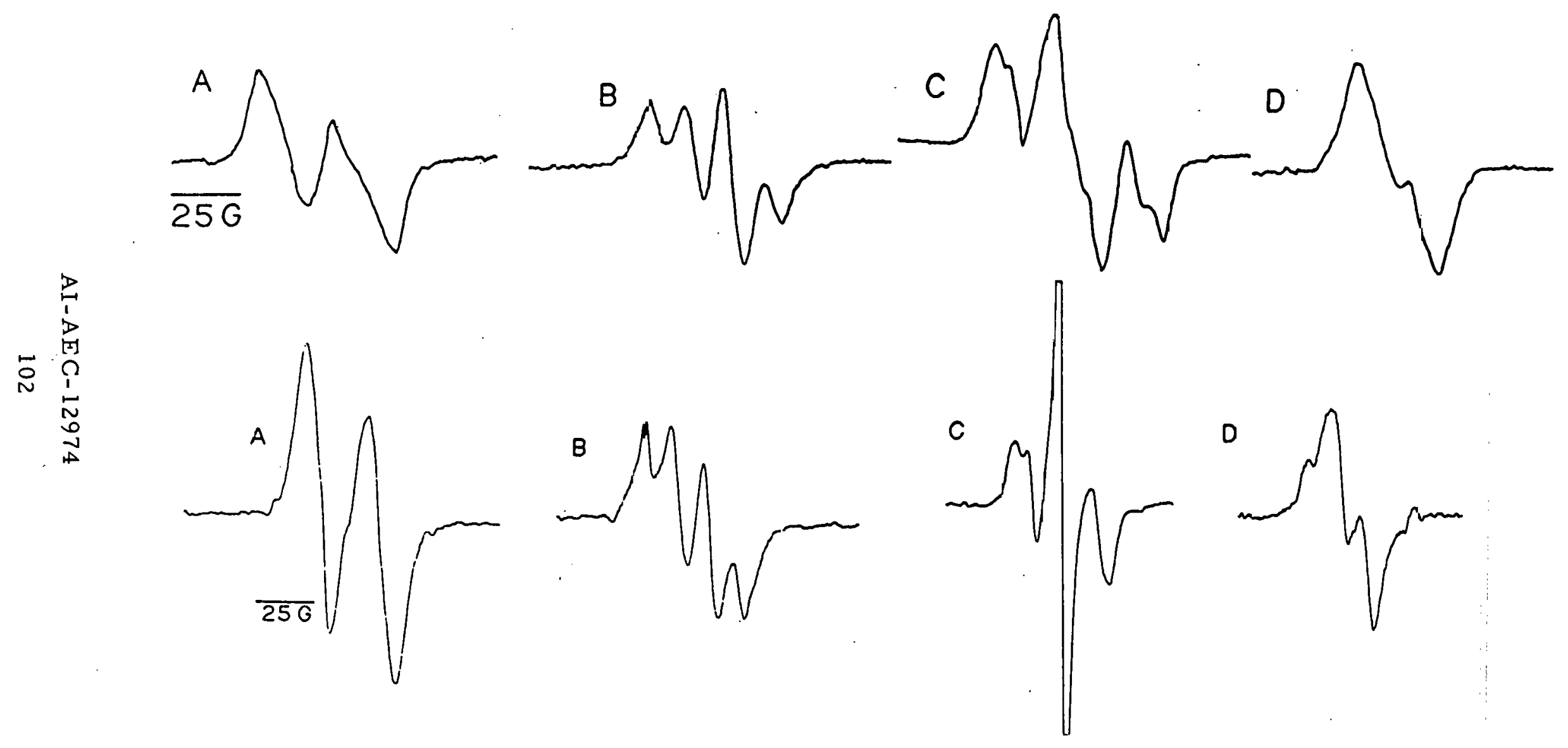


RADICALS FORMED IN PROTEINS BY REACTION WITH HYDROGEN ATOMS

\author{
Richard Holroyd ${ }^{2}$ and Joseph Glass \\ Atomics International, North American Rockwell Corporation \\ Canoga Park, California 91304
}

Peter Riesz

National Cancer Institute

National Institutes of Health, Bethesda, Maryland 20014

Radiation Research in press 


\section{ABSTRACT}

Radical formation in the reactions of hydrogen atoms with some cystine-free proteins and polyalanine was investigated by both ESR and tritium labeling techniques. The results show that hydrogen atoms can cause chain cleavage as well as lead to the formation of carbon radicals. In the case of histone a large proportion $(67 \%)$ of the carbon radicals is on lysine residues. The distribution of radicals observed for hydrogen atom bombardment was similar to that observed in gamma radiolysis for samples of histone, nagarse and poly-D, L-alanine. Reasons for this similarity are discussed. Exposure to hydrogen atoms produces $\alpha$-carbon radicals in poly-D, $L$-alanine and chain cleavage in poly-L-alanine, demonstrating that conformation affects the secondary radical distribution. 


\section{INTRODUCTION}

Several recent studies (1-3) have dealt with the reaction of hydrogen atoms with proteins and some progress has been made in identifying the sites of reaction. It has been shown that exposure of dry ribonuclease to atomic hydrogen inactivates the enzyme (3). Studies in solution $(1,2)$ indicate that liydiogen dlums effectively deactivate enzymes such as trypsin and ribonuclease by reaction with aromatic and divalent-sulfur containing amino acids. Studies of polyamino acids in the dry state have shown that hydrogen atoms can react in a variety of ways. In poly-tyrosine, poly-phenylalanine and poly-tryptophane, hydrogen atoms add to the aromatic rings (4). In a recent ESR study of poly-amino acids with alkyl side groups three types of reaction have been suggested (5): addition to the NH group of the peptide bond causing chain scission, abstraction of a hydrogen atom from a $-\mathrm{CH}_{n}-$ group, and abstraction of an alkyl side chain. With the exception of the latter, the corresponding reactions have also been observed for reactions of hydrogen atoms with the individual amino acids (6).

The present investigation was undertaken to elucidate the reactions of hydrogen atoms with cystine-free proteins, particularly histones which are constituents of mammalian chromosomes; and to evaluate the role of hydrogen atoms in radiation damage to such proteins. Solid samples of calf thymus histone, nagarse and polyalanine were exposed to hydrogen 
atoms and to gamma radiolysis at $25^{\circ} \mathrm{C}$. ESR spectra were obtained to determine the structure of radicals formed, and tritium labeling of radical sites was employed to determine the extent of attack on each amino acid.

\section{MATERIALS AND METHODS}

In order to expose the samples to hydrogen atoms, approximately $10 \mathrm{mg}$ of the protein or polypeptide sample was supported by means of quartz wool inside of a quartz tube passing through an ESR cavity $\left(\mathrm{TE}_{102}\right.$ mode). The tube was evacuated, then filled with flowing hydrogen gas. Hydrogen was supplied by heating in vacuo a sample of uranium hydride. Atoms were produced in the hydrogen stream by a microwave discharge. The pressure in the discharge region was 0.1 to 0.2 torr. Ions were screened out magnetically. To prevent direct photolysis of the samples a "T-joint" was used between the sample and discharge as a light trap (7), and the sample was shielded from vacuum U-V light by a layer of quartz wool. Samples were exposed to hydrogen atoms at room temperature for 5 to 10 minutes; this generally produced about $3 \times 10^{16}$ radicals, as determined by the intensity of the ESR signal. Growth of the signal was monitored as the reaction progressed. The ESR spectrometer was a Varian model 4500-10A. For irradiations a lyophilized sample was exposed in a ${ }^{60} \mathrm{Co}$ facility to a dose of approximately 6 megarads.

To tritium label the radical sites in samples of protein which had been ir radiated or exposed to hydrogen atom bombardment, the samples were 
exposed to ${ }^{3} \mathrm{H}_{2} \mathrm{~S}$ (New England Nuclear Corp., specific activity $\sim 225 \mathrm{mc} / \mathrm{mmole}$ ). The labeled sample was then dissolved in water and lyophilized twice to remove exchangeable tritium. The activity in each amino acid was determined with a Phoenix amino acid analyzer by the procedure already described (8). Samples of calf-thymus histone (Calbiochem), nagarse (Nagarse Co., Ltd., Enzyme Development Co.), and polyalanine (Calbiochem and Miles Labs.) were used as received. The polyalanine from both sources was of high molecular weight. Treatment of data.

The distribution of tritium in proteins is presented in terms of a normalized specific activity (NSA), NSA is defined as

$$
\frac{S_{i} \times 100}{\sum S_{i}}
$$

where $S_{i}$ is the specific activity of a given amino acid in counts per $\mu$ mole and $\Sigma S_{i}$ is the sum of specific activities of all of the amino acids under consideration.

\section{RESULTS}

The ESR spectra of radicals formed in a histone sample on exposure to hydrogen atoms is shown in Fig. 1. There are two main lines separated by approximately 19 gauss and weaker lines on either side which are separated by about 100 gauss. Very similar spectra have been obtained for other proteins and for samples of high histone content such as nucleo- 
histone (9). Nagarse, a cystine-free enzyme, also leads to a similar -spectrum- $(-F i g-2) \div=$ The weak=side=lines =observable:in=both $\cdot$ Figures 1 and 2 can reasonably be associated. with substituted_cyclohexadienyl radicals which are formed when hydrogen atoms add to phenyl rings in the proteins (4). The species responsible for the central doublet is considered in the discussion.

The reaction of hydrogen atoms with poly-D, L-alanine leads to a spectrum (Figure 3) with four main lines separated by 18 gauss and the line intensities are in the ratio 1.4:7:7:1, based on peak height. A similar spectrum is obtained in the radiolysis of poly-D, L-alanine (10). Abstraction of the $\alpha$-hydrogen in this polypeptide is expected to produce a radical of Type I.

(I)<smiles>CNC(C)=O</smiles><smiles>CCC(C)=O</smiles>

For this radical an es $r$ spectrum of four lines of relative intensities $1: 3: 3: 1$ is expected. Many of the radicals formed are of this type but other species must be present to account for the strength of the central two lines. Use of a computer technique (9) showed that the observed spectrum could be simulated by assuming that $60 \%$ of the radicals were Type I, $15 \%$ were Type II and $25 \%$ were a species which gave a 16 gauss doublet.

The reaction of hydrogen atoms with poly-L-alanine leads to an entirely different ESR spectrum consisting of eight lines. A similar result for 
this polypeptide was obtained in an earlier study (5) and this spectrum has been assigned to a radical of structure II, formed by cleavage of carbonnitrogen bonds. In this case the computer analysis showed that the spectrum could be simulated by assuming $80 \%$ of the radicals were Type II and $20 \%$ were Type I. The asymmetry in the spectrum arises from the slightly different g-values of these radicals.

After hydrogen atom bombardment the samples were reacted with ${ }^{3} \mathrm{H}_{2} \mathrm{~S}$ to convert the radicals to tritium labeled sites, reaction 1.

$$
\mathrm{R} \cdot+{ }^{3} \mathrm{H}_{2} \mathrm{~S} \rightarrow{ }^{3} \mathrm{HR}+\mathrm{HS} \cdot
$$

ESR spectra were obtained continuously during the reaction. The intensity of the signal remaining after 45 minutes indicated that $95 \%$ of the radicals had reacted in this time. To the extent that the radicals $\left(R^{\circ}\right)$ are those in which a hydrogen atom has been removed from a carbon atom, tritium labeled amino acids are found when the protein is hydrolyzed.

The tritium labeling results for nagarse and histone are shown in Table 1. The distribution of tritium activity is quite different for these two proteins. For nagarse a large percentage of the activity is on methionine. In histone $67 \%^{3}$ of the tritium activity is in lysine and the next most active amino acid is glycine with $8 \%$. Exposure of poly-D, Lalanine to hydrogen atoms and subsequent titration with ${ }^{3} \mathrm{H}_{2} \mathrm{~S}$ followed by hydrolysis yielded at least $75 \%$ of the activity in alanine.

For both proteins the distribution of activity obtained in gamma radiolysis is quite similar to that obtained in hydrogen atom bombardment. However, 
there are several differences. For nagarse hydrogen atom exposure leads to more labeling of phenylalanine and much less labeling of ulinine and arginine than is observed in gamma radiolysis. For histone hydrogen atom exposure leads to more activity in the glycine and aspartic acid and less in the glutamic acid and methionine.

\section{DISCUSSION}

When proteins are exposed to gamma radiation of hydrogen atom bombardment, a doublet ESR spectrum, similar to that in Figs. 1 and 2, is frequently observed $(11,12)$. A doublet spectrum with a splitting of this magnitude indicates a large coupling to one hydrogen but provides no other information. Two suggestions as to the nature of this radical have been made. In a study of radicals formed in polyamino acids by gamma radiolysis, Drew and Gordy (10) attributed the doublet to radicals

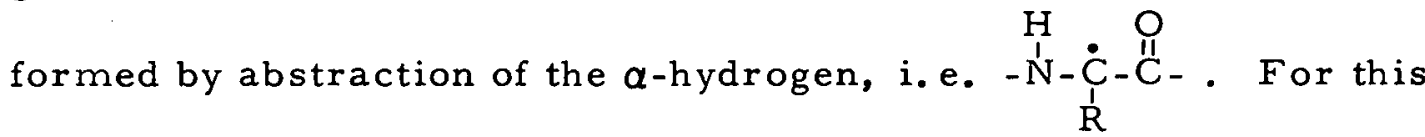
radical there are two $\beta$-hydrogens in most amino acids which can interact with the unpaired spin. They deduced from the spectrum of the radical formed in polyleucine that one of the $\mathrm{C}-\mathrm{H}$ bonds was orlented $40^{\circ}$ from the p-orbital and the other was at $80^{\circ}$. Thus one hydrogen is near the node of the p-orbital and is constrained in such a position by the bulky side chain which is forced out of the plane.

In a recent study of the reaction of hydrogen atoms with polyamino acids, Limming (5) also observed doublet ESR spectra. He attributes the 
doublets to radicals formed by loss of the entire side group, that is "glycyl" radicals: ( $-\stackrel{1}{N}-\underset{\dot{1}}{\dot{C}}-\stackrel{O}{\mathrm{C}}-)$. Our results are inconsistent with this interpretation. If the doublet spectrum which we observe for histone and nagarse were to be associated with glycyl radicals then the ${ }^{3} \mathrm{H}_{2} \mathrm{~S}$ titration would lead to labeled glycine and we find only $8 \%$ of the activity on glycine. Most of the radicals detected are on lysine residues and probably have the structure suggested by Drew and Gordy.

Two different radicals are observed for polyalanine depending on the conformation. In poly-L-alanine the stable radical formed is - $\mathrm{CH}-\mathrm{CO}-(\mathrm{T} y p e \mathrm{II})$. The same radical is formed when hydrogen atoms $\mathrm{CH}_{3}$ react with poly-L-alanine at $77^{\circ} \mathrm{K}(5)$. In the case of hydrogen atom exposure it has been suggested (5) that this radical is formed as a result of hydrogen atom addition to the $-\mathrm{NH}-$ group. In poly-D, L-alanine the stable radical formed is $-\mathrm{NH}-\underset{\mathrm{C}}{\dot{\mathrm{C}}}-\mathrm{CO}-$, (Type I). Hydrogen atoms must $\mathrm{CH}_{3}$ react initially to form the same radical in both polymers. Presumably the initial radical is II which is stable in poly-L-alanine but in poly-D, L-alanine this species abstracts an $\alpha$-hydrogen to form $I$. The difference in behavior must be attributed to the conformation of these polymers in the solid state. The $\alpha$-helix and poly-L-alanine provides a rigid structure which may prevent a radical formed in the chain from reorienting thus precluding the abstraction reaction. There are fewer restraints in the random coil structure of poly-D, L-alanine and a radical formed in the chain would be more free to reorient and form a secondary species. 
In radiolysis it has been concluded that the radicals titrated by ${ }^{3} \mathrm{H}_{2} \mathrm{~S}$

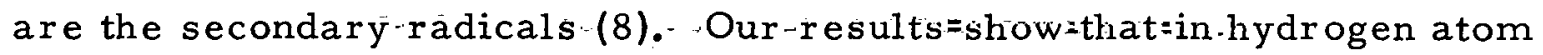
exposure the distribution of radicals is similar to that found for gamma radiolysis (except for minor differences noted earlier). Thus the radicals formed initially by hydrogen atom attack may react to form the secondary radical distribution observed or hydrogen atoms may react like initial radicals to produce the same secondary radical distribution.

It has been pointed out by Garrison et al. (13) that secondary radicals in gamma irradiated proteins are not formed to a large extent by the abstraction reactions of hydrogen atoms, i. e., reaction 2 , since the

$$
\mathrm{H} \cdot+\mathrm{RH} \longrightarrow \mathrm{H}_{2}+\mathrm{R} \cdot
$$

yields of $\mathrm{H}_{2}$ for highly dispersed fibrils of polyalanine and nylon are only 0.45 and 0.85 molecules $/ 100$ ev. respectively (13). However, for proteins containing the "built-in" hydrogen atom scavengers, phenylalanine and tyrosine residues, addition of hydrogen atoms to aromatic rings would be expected if any hydrogen atoms are produced. Such cyclohexadienyl-type radicals may migrate by successive hydrogen atom abstractions to produce the "secondary" radicals. Thus the possibility that a substantial fraction of the "secondary" radicals in both gamma radiolysis and hydrogen atom exposure of proteins are formed in the same way cannot be ruled out.

Of significance to the mechanism of radiation damage in cells and chromosomes in particular is the high percentage of radicals found on 
lysine. Lysine is one of the two basic amino acids in histones. It is these basic amino acids which characterize histones and allow them to intimately associate with DNA molecules and possibly provide structural support in the complex chromosomes of higher organisms. Thus the specific destruction of lysine residues by gamma rays and by hydrogen atoms may inhibit the functional capabilities of the histone. 
TABLE 1

TRITIUM DISTRIBUTIONS IN NAGAKSE AIND HISTOINE

\begin{tabular}{|c|c|c|c|c|}
\hline \multirow[b]{3}{*}{$\begin{array}{l}\text { Amino } \\
\text { Acid }\end{array}$} & \multicolumn{4}{|c|}{ Normalized Specific Activity $(\%)$} \\
\hline & \multicolumn{2}{|c|}{ Nagaise } & \multicolumn{2}{|c|}{ Histone } \\
\hline & $\begin{array}{c}\text { Gamma } \\
\text { Radiolysis }\end{array}$ & $\begin{array}{l}\text { H-Atom } \\
\text { Exposure }\end{array}$ & $\begin{array}{l}\text { Gamma } \\
\text { Radiolysis }\end{array}$ & $\begin{array}{l}\text { H-Atom } \\
\text { Exposure }\end{array}$ \\
\hline ASP & 0.87 & 0.99 & 0.52 & 1.23 \\
\hline THR & 6.20 & 7.07 & 4.12 & 4.81 \\
\hline SER & 6.17 & 5.60 & 3.07 & 3.74 \\
\hline GLU & 1.54 & 1.99 & 4.94 & 0.52 \\
\hline PRO & 13.09 & 11.49 & 8.45 & 5.26 \\
\hline GLY & 5.12 & 5.34 & 2.19 & 6.82 \\
\hline ALA & 6.41 & 1.73 & 1.26 & .83 \\
\hline $\mathrm{CYS} / 2^{\mathrm{a}}$ & - & - & 6.72 & 9.45 \\
\hline VAL & 1.42 & 1.81 & .44 & .32 \\
\hline MET & 26.98 & 27.0 & 13.9 & 5.86 \\
\hline ILE & 1.35 & 2.33 & .35 & .04 \\
\hline LEU & 5.71 & 6.25 & 1.53 & 1.09 \\
\hline TYR & 5.88 & 7.57 & 2.84 & 2.41 \\
\hline PHE & 3.91 & 9.45 & 1.23 & 1.14 \\
\hline LYS & 2.61 & 3.74 & 26.8 & 36.5 \\
\hline HIS & 4.51 & 5.24 & 24.4 & 18.5 \\
\hline $\mathrm{ARG}$ & 8.23 & 2.28 & 1.66 & 1.16 \\
\hline
\end{tabular}

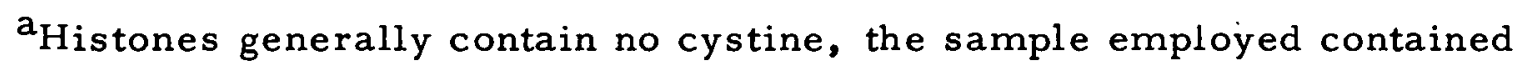
$.2 \% \mathrm{CYS} / 2$ 


\section{FOOTNOTES}

${ }^{1}$ This work was supported in part by the Division of Biology and Medicine of the U. S. Atomic Energy Commission.

${ }^{2}$ Present address: Department of Chemistry, Brookhaven National Laboratory, Upton, N. Y., 11973.

${ }^{3}$ These figures refer to the percent of activity in these amino acids whereas the values in the Table are normalized specific activity (NSA). 
Fig. 1 ESR spectrum of radicals formed by reaction of hydrogen atoms with a calf thymus histone sample, 3 gauss modulation.

Fig. 2 ESR spectrum of radicals formed by reaction of hydrogen atoms with nagarse, 3 gauss modulation.

Fig. 3 ESR spectrum of radicals formed by hydrogen atom reaction with poly-D, L-alanine, 1 gauss modulation.

Fig. 4 ESR spectrum of radicals formed by hydrogen atom reaction with poly-L-alanine; l gauss modulation, hyperfine splittings: ${ }^{a} \frac{\mathrm{H}}{\alpha}=13 \mathrm{G}, \mathrm{a}{ }_{\beta} \mathrm{CH}_{3}=22 \mathrm{G}$. 
1. G. Stein, The inactivation of some enzymes in aqueous solution by atomic hydrogen. In Energetics and Mechanisms in Radiation Biology, pp. 467-477, (G. O. Phillips, ed.), Academic Press, New York, 1968.

2. R. Shapira and G. Stein, Reactions of aromatic and sulfur amino acids with hydrogen atoms in water solution. Science 162, 1489-1491 (1968).

3. H. Jung and K. Kürzinger, Inactivation of bacteriophage, DNA and ribonuclease by thermal hydrogen atoms. Radiation Res. 36 , $369-383$ (1968).

4. F. G. Liming, Jr., and W. Gordy, Hydrogen-addition radicals formed in the aromatic rings of amino acids, polyamino acids and proteins. Proc. Natl, Acad. Sci. U.S. 60, 794-801 (1968).

5. F. G. Liming, Jr., Free radicals formed in aliphatic polyamino acids by exposure to hydrogen atoms. Radiation Res. 39, 252 276 (1969).

6. W. Snipes and J. Schmidt, Free radical formation in amino acids exposed to thermal hydrogen atoms. Radiation Res. 29, 194$202(1966)$.

7. H. Jensen and T. Henriksen, Production of free radicals in organic solids by thermal hydrogen atoms. Acta Chemica Scandinavica 22, 2263-2276 (1968). 
8. P. Riesz and F. H. White, Jr., Tritiated free radical scavengers in the study of the irradiated protein molecule. In Advances in Chemistry Series, No. 81, Radiation Chemistry, Vol. I (Am. Chem. Soc.) pp. 496-520 (1968).

9. R. A. Holroyd and J. W. Glass, The reaction of hydrogen atoms with DNA. Radiation Res. 39, 758-769 (1969).

10. R. C. Drew and W. Gordy, Electron spin resonance studies of radiation effects on polyamino acids. Radiation Res. 18, $552-479(1963)$

11. P. Riesz, F. H. White, Jr., and H. Kon, Free-radical distributions in the $\gamma$-radiolysis of $d r y$ ribonuclease. J. Am. Chem. Soc. $88,872-877(1966)$

12. F. H. White, Jr., P. Riesz and H. Kon, Free-radical distributions in several gamma-irradiated dry proteins as determined by the free-radical interceptor: technique.. Radiation Res. 32, 774759 (1967).

13. W. M. Garrison, Radiation chemistry of organo-nitrogen compounds. In Current Topics in Radiation Research IV, pp. 45-91, (M. Ebert and A. Howard, eds.), John Wiley \& Sons, Inc., New York, 1968. 


\section{H + HISTONE}

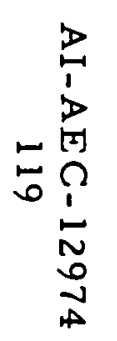

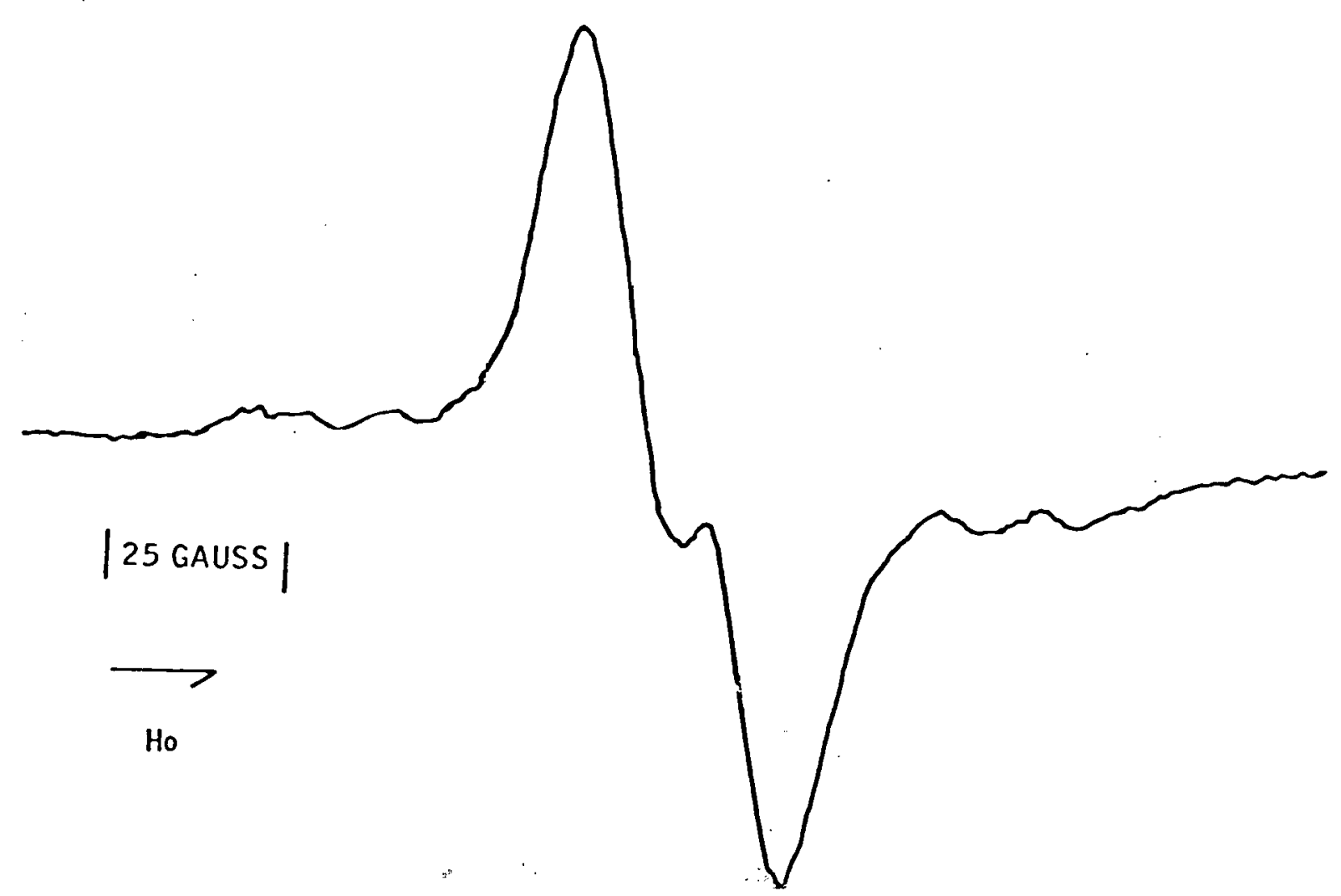


点

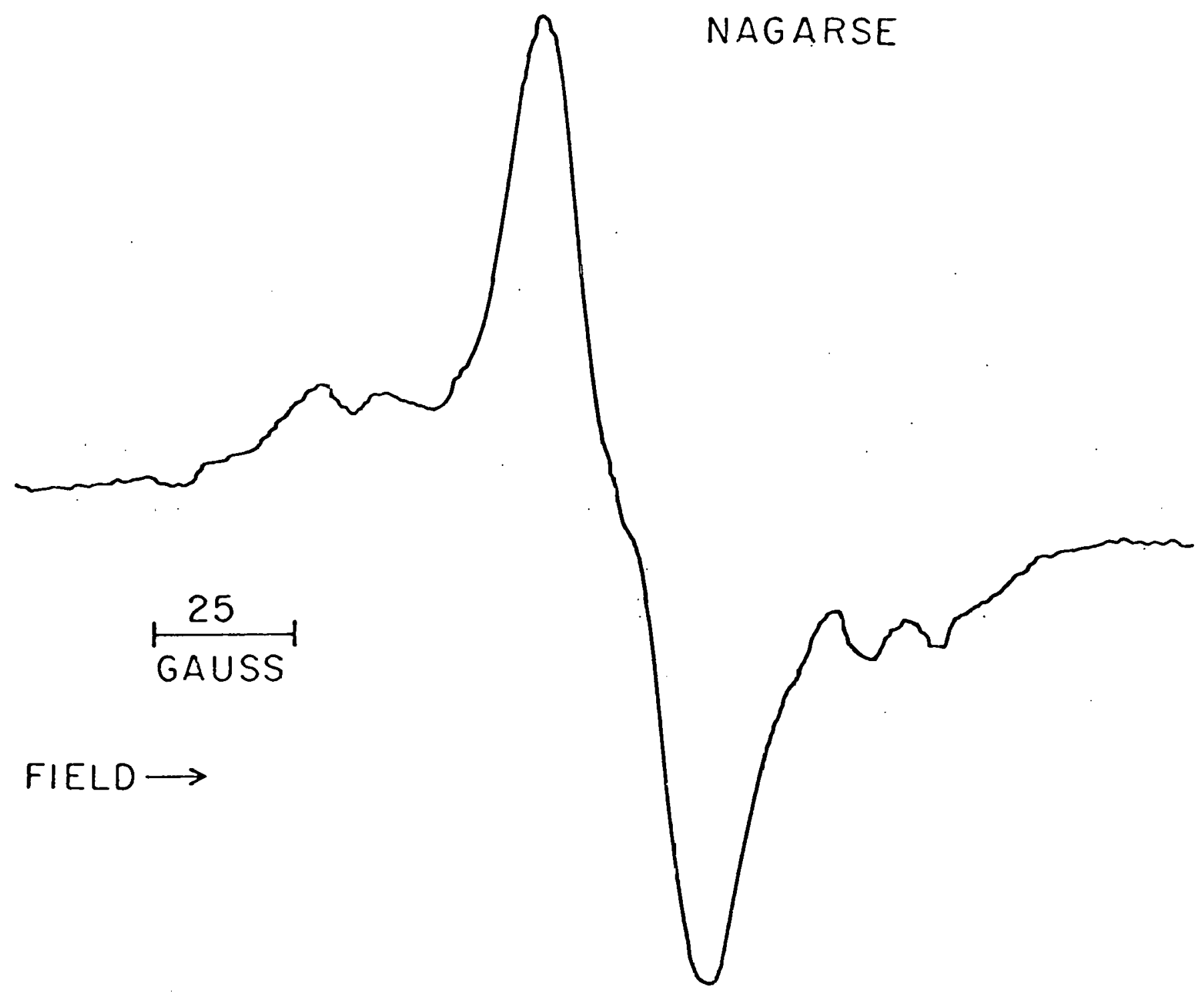



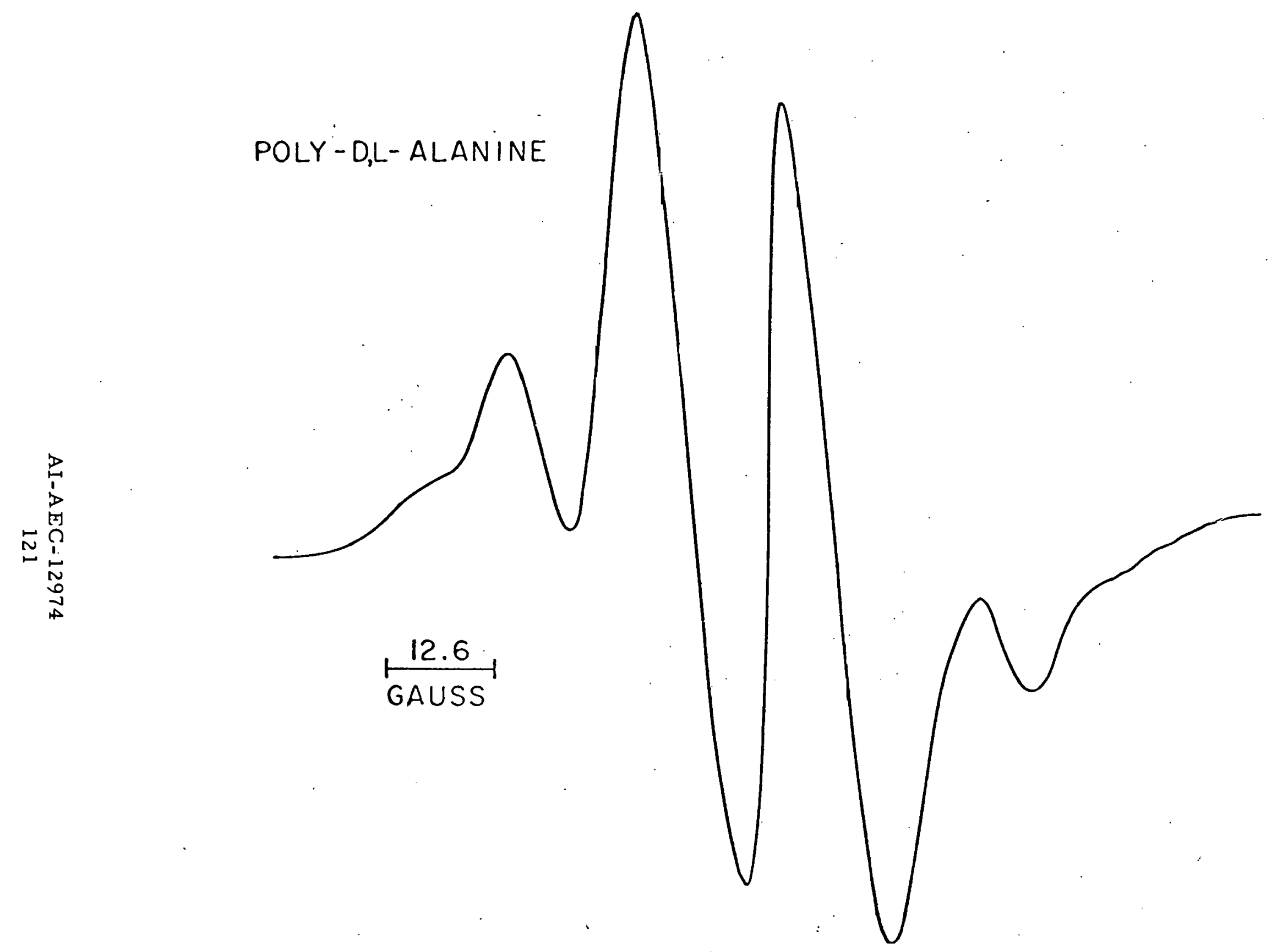


$$
\text { POLY-L-ALANINE }
$$

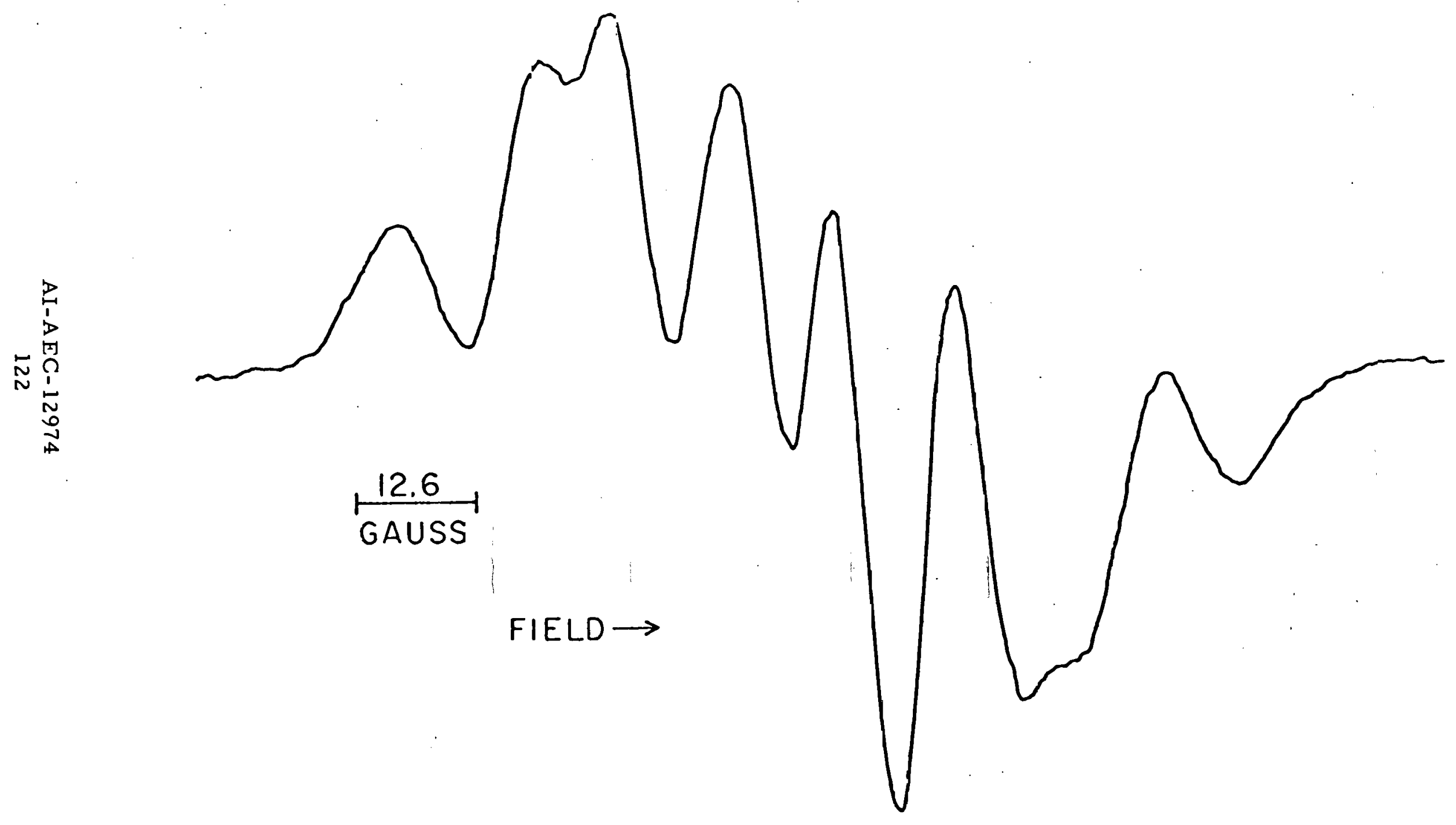

